Illinois State University

ISU ReD: Research and eData

Theses and Dissertations

3-2-2014

\title{
Learning to Practice Leadership for Social Justice: An Autoethnography
}

David S. Martin

Illinois State University, davidsmartin2@hotmail.com

Follow this and additional works at: https://ir.library.illinoisstate.edu/etd

Part of the Educational Administration and Supervision Commons, Liberal Studies Commons, and the Other Education Commons

\section{Recommended Citation}

Martin, David S., "Learning to Practice Leadership for Social Justice: An Autoethnography" (2014). Theses and Dissertations. 170.

https://ir.library.illinoisstate.edu/etd/170

This Dissertation is brought to you for free and open access by ISU ReD: Research and eData. It has been accepted for inclusion in Theses and Dissertations by an authorized administrator of ISU ReD: Research and eData. For more information, please contact ISUReD@ilstu.edu. 


\section{LEARNING TO PRACTICE LEADERSHIP FOR SOCIAL JUSTICE:}

\section{AN AUTOETHNOGRAPHY}

\section{David Martin}

269 Total Pages

August 2014

Some students in schools are served well, whereas others are not. Students traditionally marginalized in schools are students of color, students whose native language is not English, students who receive free and reduced-price lunches, and students with an individualized education program. On nearly all measures in all schools, there exists a persistent achievement gap. The role of leadership in schools can be an important piece in addressing the achievement gap. Traditional leadership has focused on managerial skills such as efficiency, charisma, heroism, decisiveness, and confidence. Another form of leadership exists that can serve to lessen or eliminate the achievement gap: leadership for social justice. Scholars describe the theoretical "calling" for leadership for social justice, however, practical examples of how to enact social justice in schools are rare. Thus, because of the urgency to eliminate the achievement gap in schools, this autoethnographic study set out to answer the question of how learning to practice leadership for social justice manifests in practice. Through the use of short narrative vignettes, I present data depicting my learning process in trying to practice leadership for social justice. Much analysis of my vignettes occurred to try and find meaning. Vignettes were analyzed and categorized into six adjectival categories of 
euphoric, emotional, contentious, inconsistent, uncertain, and tentative. Each vignette was also analyzed through a Freirean lens, and Freirean concepts were applied to each vignette for deeper meaning. A conclusion emerged in a meaningful story at the end. The adjectives, the Freirean concepts, and the literature converge at the end, revealing that I "can't shake it;" that I am leading in two worlds: that of traditional leadership and that of leadership for social justice. 
LEARNING TO PRACTICE LEADERSHIP FOR SOCIAL JUSTICE:

AN AUTOETHNOGRAPHY

DAVID MARTIN

\author{
A Dissertation Submitted in Partial \\ Fulfillment of the Requirements \\ for the Degree of \\ Doctor of Philosophy \\ Department of Educational Administration and Foundations \\ ILLINOIS STATE UNIVERSITY
}


C 2014 David Martin 
LEARNING TO PRACTICE LEADERSHIP FOR SOCIAL JUSTICE:

AN AUTOETHNOGRAPHY

DAVID MARTIN

COMMITTEE MEMBERS:

Amee Adkins, Chair

Patricia Klass

Neil Sappington

Wendy Troxel 


\section{ACKNOWLEDGMENTS}

I would like to thank Dr. Amee Adkins for her undying support and commitment to this project, and for her commitment to me. The ups and downs and fits and starts I put her though during this entire project have not been easy, but Amee never wavered in her belief of what this project can contribute to the field of educational administration. Amee demanded clarity and commitment to this project. Even when I thought I could not write yet another revision, Amee pushed me along and never abandoned my work. Thank you, Amee, for never giving up on the promise of leadership for social justice in schools. Thank you for not giving up on me. I would also like to thank my dissertation committee for all the technical expertise, input, suggestions, and help in assisting me with a successful completion. Thank you Dr. Neil Sappington for staying with me from the proposal through the defense. I remember your words of encouragement to complete this project. Thank you Dr. Patricia Klass for all that you have done from the very beginning of my coursework through the defense. You told all of us at the outset that you "never give up on students" and you stayed true to those words. Thank you, Dr. Wendy Troxel for helping me at a very crucial time during this project. You guided me in the right direction when everything was looking hopeless.

Thanks to my children, Matthew and Dolores, for smiling and keeping me sane while writing my dissertation. You are two of the best children a father could even want. I will be there for you when it is your turn to write your dissertations. Mostly, I would 
like to thank my wife, Nuvia, for the undying love and insistence on my completing my degree at Illinois State University. Thank you for believing I could finish successfully. Even when it would have been easier to quit, you kept the entire family organized, focused, and committed to complete my degree.

Finally, thank you God for helping me learn how to trust you. I'm still learning to let go. I'm getting there.

D.M. 


\section{CONTENTS}

Page

ACKNOWLEDGMENTS

$\begin{array}{lll}\text { CONTENTS } & \text { iii }\end{array}$

TABLES vii

\section{CHAPTER}

$\begin{array}{ll}\text { I. INTRODUCTION } & 1\end{array}$

The Role of Leadership in School 2

An Inkling Early On 5

Feeling the Commitment 6

Wanting to Enact Social Justice in My School 7

How Should I Enact Social Justice? $\quad 10$

Trying to At Least Not Go Backward 13

The Person (and Leader) Being Studied 17

Statement of the Problem 19

Research Question $\quad 20$

Overview of Dissertation 20

II. WHAT HAS INFORMED ME ALONG THE WAY 22

Traditional Leadership in Education $\quad 24$

The Hero 25

Different Theories and Models of Traditional Leadership 26

The Business-School (Dis)Connection 30

Social Justice $\quad 31$

Leadership for Social Justice $\quad 35$

Professional Risk in Leadership for Social Justice $\quad 38$

The Achievement Gap $\quad 39$

Emerging Leadership to Address the Achievement Gap 45

Leadership for Social Justice Addressing the Achievement Gap 47

Examples Needed of How Social-Justice Leadership Manifests in Practice 
Literature on Ethical and Moral Leadership 54

The Theoretical Beginnings of Leadership for Social Justice 55

University Training Programs $\quad 55$

Leadership for Social Justice Internationally $\quad 58$

Autoethnographic Examples Informing this Study $\quad 60$

$\begin{array}{ll}\text { III. RESEARCH DESIGN } & 65\end{array}$

Why I Chose Autoethnography 66

Research Paradigms $\quad 68$

Autoethnography Background $\quad 69$

Definition of Autoethnography $\quad 70$

The Use of Autoethnography for this Study 71

$\begin{array}{ll}\text { Position and Privilege } & 72\end{array}$

My Positionality and Autoethnography 73

Administrative Background and Experience $\quad 75$

Natural Connection of Autoethnography and Social-Justice 80

The Intimacy of Autoethnography $\quad 81$

Two Questions about Autoethnography $\quad 82$

Questioning the Status Quo in Education 83

The Risk of Reflexivity $\quad 84$

Data Collection $\quad 84$

Methodology $\quad 85$

Initial Data $\quad 86$

Toward a Method of Data Analysis for Autoethnographic Data $\quad 88$

Believability and Painful Authenticity 88

Moving Toward Settling on the 17 Vignettes 90

Why Vignettes Were Included; How Recurring Themes and Painful
Authenticity/Believability are Related

My Positionality and the Initial Data Analysis $\quad 92$

Why Vignettes Were Excluded 93

Reading Autoethnographic Writing-Repeatedly 97

Implications for Self-Analysis Through Repeated Readings 97

IV. THEORETICAL FRAMEWORK OF A FREIREAN LENS ON THE
DATA

Introducing Freirean Concepts 101

The Organic Beginnings of My Data Analysis 106

Data Analysis Through the Theoretical Framework of a Freirean Lens 106

Analyzing and Organizing Data 108

Six Adjectives to Describe the Learning Process 115

Reading the Vignettes 117 
Reading the Vignettes with the Freirean Commentary, Criticism, and Limitations

V. VIGNETTES

The Hero-A Lance Armstrong Analogy to Leadership for Social Justice. Emotional/Euphoric

My First Real Attempt at a Team Meeting.

Emotional/Contentious/Tentative

My First Data Road Show. Euphoric

I Don't Know What I'm Doing. Sarcasm Doesn't Work.

Emotional/Contentious

Sarcasm Is Not Effective. People Want Me to Make a Decision.

Emotional/Contentious

Stanford Testing, Race, and the Importance of Teachers' Agency.

Emotional/Euphoric/Contentious

Data Dave is Born. Euphoric/Tentative

What Do You Want Us to Do Dave? Euphoric/Contentious/Tentative 148

The Tracking Debate Goes On. Contentious

It's Frustrating That Dave Doesn't Answer Your Question.

Inconsistent

The Manager Is in the Principal's Office. Uncertain 164

I Question Myself. Uncertain

The Reporter Gets Dave Centered Again on What's Important in School. Uncertain/Tentative

Still Struggling With the Who, How, and Why of Leadership for Social Justice. Uncertain/Tentative

Intelligence Testing, Race and Tracking. Tentative

Teacher Swap, Teacher Agency, and the Teacher as Hero Notion.

Tentative

Dinner Conversation. Tentative

The Vignettes as My Ongoing Story of Learning

VI. MODIFYING THE LEARNING PROCESS

An Emotional and Euphoric Response 201

A Contentious and Inconsistent Response 202

An Uncertain and Tentative Response 204

Difference Between Uncertain and Tentative 205

Paternalistic Behavior and Another Retreat from Leadership for

Social Justice

A Deeper Look into Teaching, Administration and Inner-city and Suburban Schools

The "Eroding" Issue: Trying to Avoid the Retreat From Leadership for Social Justice 
Continual Learning 213

Researched Question Addressed 213

The Adjectives Used and Moving Toward a Meaningful Story 216

Tentative 216

Uncertain 218

Emotional 219

Euphoric 220

Contentious 221

Inconsistent 222

Retreating from Leadership for Social Justice 223

$\begin{array}{lll}\text { VII. A MEANINGFUL STORY } & 227\end{array}$

Beyond the Adjectives 229

Having Two Leadership Belief Systems 230

"I Can't Shake It" 230

Two Sides of Being Impatient 232

Why Be Fearful? 234

Leading for Social Justice in Difficult Times 235

Can't Operate Exclusively Out of Fear 237

What do We Want to Look Like? 238

Toward a Delicate Balance 240

The Constant Pull and the Constant Tension 242

You Have to Ask Yourself "Why?" 245

Don't Retreat from Leadership for Social Justice 246

The Window 249

Autoethnographic Work 251

Some Limitations and Promises 254

$\begin{array}{ll}\text { REFERENCES } & 256\end{array}$ 


\section{TABLES}

Table

Page

1. Matrix of Freirean Concepts Occurring in the Data 109

2. Summary of Data-Analysis Process 110

3. Vignette and Corresponding Adjective Category/Theme 116 


\section{CHAPTER I}

\section{INTRODUCTION}

Arguably, education has the potential to change the social arrangement (Freire, 1970). The world truly would change if all children everywhere received an equitable, fair, and decent education (Kozol, 1991). Hard-fought battles in the United States by civil rights leaders like M. L. King and many, many others have given hope to the dream of a more equitable, just, and fair society. Although perspectives and opinions vary, it would be difficult to find many people today who do not favor a more just society. To take that one step further, it would be difficult to find many people working in the field of education who do not favor more equitable and just schools. Working in the field of education brings with it the prerequisite of believing all children deserve the very best education. The reason educators believe so passionately in their profession is, as Freire (1970) believed, that education can be a form of liberation and freedom, thereby potentially changing the social arrangement of inequality, oppression, and injustice.

The struggle to improve schools and eliminate injustices, segregation, and inequality has existed in U.S. public schools since their inception. Since the beginning of public education, some students have been served well and others have not. This has not happened by chance, but rather through institutionalized discrimination and segregation. The Supreme Court ruling in 1896 of Plessy v. Ferguson attempted to maintain the status quo of injustice and inequality by legally mandating separate schools for children of color 
that were far inferior than schools for White students. Although the struggle continues today as schools are still segregated by class, race, and native language, educators still believe and desire the very best education for their students. Therefore, educators put forth worthwhile effort to create a more just, fair, and equitable society in the meaningful work they do in schools and classrooms. If those of us working in education are interested in changing the status quo, in trying to bring about more just learning spaces for all children, then the focus shifts to how this can be best accomplished in schools. Understandably, improving education for all children is not a new concept. Although educators want better, fairer, more equitable schools for all students, they may not fully understand or be able to articulate what it would take to realize this. I believe that the change needed to bring about more equitable schools for all students can be realized through leadership for social justice in schools.

\section{The Role of Leadership in School}

This study is concerned with the role of school leadership. School leaders help set the context of what is valued and the direction in which teachers and staff are moving. The role school leaders play each day can reinforce the hope and possibility of equitable learning outcomes and equal opportunity for all students. The assumption is that although equality is primary in education, and meeting the learning needs of all students is best accomplished in classrooms by the teacher, school leaders can and should try to create schools that are equitable and socially just for all students. Administrative leaders must create equitable and socially just schools, which equates to success in the broadest sense for all students. 
In this study, I use vignettes to tell a story about my school leadership experiences. My story of trying to learn how to practice leadership for social justice is ongoing and incomplete. Through my vignettes, I can neither sum how to practice leadership for social justice in a few paragraphs nor offer a list of the most effective practices. Through the learning process, I have asked many questions. My questions are ones many school leaders ask: What is school leadership? How do you do it? What's it for? We take dozens of courses on school leadership throughout our administrationpreparation programs. We learn about school finances, policy, curriculum, facility management, building relationships, collaboration, and parent and community involvement. When we finally arrive at the school-leadership position, we find ourselves overwhelmed with the hundreds of tasks we need to perform. We find that we are in an immediate managerial situation; we can get caught up in the managerial aspects of the administration and lose sight of the bigger picture of purposeful leadership. Many times the things we need to accomplish conflict with leadership for social justice.

I believe one needs a leadership orientation to lead a school. This orientation is lacking today as many school administrators neither know why we are leading a school nor for what purpose or end. Furman (2003a) asked this important question: "What is leadership for?" (p. 1)

The following is Furman's (2003a) early call for school leaders to examine why we do what we do:

My first claim is that educational leadership is focusing more and more on what leadership is for. What do I mean by this, and why do I make this claim? What I am saying is that the paradigm is shifting; we are experiencing a sort of sea 
change in the major themes out there, absorbing our attention as scholars. More and more, our scholarship seems to be focusing on the purposes of leadership in schools. (p. 1)

The purpose Furman (2003) referenced goes against what has traditionally been done in schools. To maintain the status quo in education requires school management to go on apace. To overthrow the status quo in education requires school leaders to ask ourselves what leadership is for. If we ask ourselves this important question, we must be prepared for a certain level of risk. It can be risky to practice a leadership orientation that goes against the status quo in education. A school leader striving to lead against inequities and injustices can be unpopular and create feelings of hostility. I argue, in this study, that great intentions to do meaningful work can often be met with frustration, shortcomings, and a sense of incompleteness on the part of the school administrator.

In the subsequent paragraphs, I will briefly show what the process has looked like for me and how I arrived at the point of learning to practice leadership for social justice. I will show how my initial feeling of commitment to social justice included not just ignorance, but raw emotion. This feeling led me to want to enact social justice in my school, even though I did not know what to expect when I would try to enact leadership for social justice. When I became an administrator, I lacked a practical guide for how leadership for social justice would manifest. When I tried to practice leadership for social justice, there were some immediate conflicts. I was not prepared for such conflicts as a new administrator, but I soon began to figure out that what I was trying to practice-a new leadership orientation that conflicted with the status quo in education-was not consistent with the expectation of traditional leadership. I am not certain that traditional 
leadership in schools goes hand-in-hand with my socialization as a White male of privilege. I suspect there is some connection: White kids like me grow up and replicate what we experienced in school, which probably looks fairly traditional and retards social justice. This question may be beyond the scope of this study; however, being aware (or unaware) of social justice is pertinent and what I shall discuss next.

\section{An Inkling Early On}

The term social justice was first used in 1840 by the Sicilian priest, d'Azeglio (Novak, 2000). The term social justice was widely used in the 1960s and beyond by Civil Rights activists. Even though the term social justice has been used for over a hundred years, as a White male of privilege, I did not hear the words social justice very often growing up: not in grade school, high school, college, or even in the Peace Corps. Although I knew all along that injustices existed in society, partly because I was told I should be grateful for having so much, I was unaware and oblivious to the marginalization of certain groups of people. I lacked the knowledge and interest to understand who exactly has been and continues to be marginalized in society. Although I lacked the words to describe my ignorance, I knew that society was unjust. I did not realize schools could be unjust as well.

Early on in my career as a teacher, I wanted to fight against injustices and inequalities in schools. I lacked the knowledge, wherewithal, and words to articulate how to accomplish this. Still, I knew and believed that education in the classroom could be better, could be more just and fair and equitable. As a teacher, I knew that some students in schools were served well and others were not. I knew this to be true in my own classroom as well. Particularly, I knew that students with an individualized education 
program (IEP) were not achieving at the same rate academically as their counterparts without an IEP. Early, questioning why there existed a discrepancy in achievement between students with and without an IEP went against conventional thinking. Many of my fellow teachers at the time would point out to me that this was why these particular students did not achieve commensurate with their peers; because they have an IEP. I could neither understand the discrepancy nor the reasoning behind the achievement gap.

As a special-education teacher, I was not familiar with the idea of social justice. I was unable to articulate that some level of injustice and marginalization existed based on ability/disability. I was ignorant and unaware of the impact of certain historical facts regarding how society systematically discriminated against people with disabilities. I was likely perpetrating what I now struggle against, but still acquiesce to: the "hero man" portrayal. Therefore, I felt an early commitment to social justice as a teacher of special education; however, in retrospect I naïvely believed I alone could reverse injustices in my classroom. In a position of influence, whether teaching or as a school administrator, avoiding the pitfalls of trying to be the hero can be challenging.

\section{Feeling the Commitment}

Before settling on the topic of this study, I was initially interested in finding schools that were doing a good job of lessening or altogether eliminating the achievement gap that exists between students with an IEP and students without. I was frustrated that I could not locate schools that had been successful in this area. In my inquiry, I began to read more literature on leadership for social justice (Brown, 2004; Capper, Theoharis, \& Sebastian, 2006; Furman, 2004; Karpinski \& Lugg, 2006; Larson \& Murtadha, 2002; Marshall \& Gerstl-Pepin, 2005; Shields, 2004). I began to understand that such 
achievement gaps do not simply exist between students with and without an IEP, but many between other groups as well. Because of the persistent achievement gap, many scholars advocated passionately for more equitable education in schools (Larson \& Murtadha, 2002; Skrla \& Scheurich, 2004).

As a teacher, I felt committed to social justice. I was unaware how to articulate that commitment. During my teaching years I may have named this commitment one of various terms including, "Doing the good work," "Doing the right thing," "Helping poor kids," "Doing my part in society," "Fighting the good fight." Lacking the language to articulate the meaning of social justice, these were my typical thoughts and beliefs. Also, I was essentially unaware of my own privilege, that of a White male who grew up in an affluent suburb, and I was fairly naïve about what is really happening in U.S. public schools on fairness, equality, and social justice. At present, I am still not sure why I wanted to become an administrator. As a teacher, I can remember times when I thought I simply could "do it better" if I were put in the position of an administrator or school principal, not because I had an overwhelming sense to make schools more socially just, but rather because I thought I could add value in doing "good work" or doing the "right work." Thus, I became an administrator confident I could make a difference.

\section{Wanting to Enact Social Justice in My School}

When I became an administrator, the intent to enact social justice in my school seemed so real and genuine to me. As is often the case in administration, we continually need to analyze student data, test scores, and achievement levels. Schools and school districts are more closely scrutinized now than ever before, and this scrutiny can almost exclusively center on standardized-testing results. Because of the explosion of 
technologies that can quickly disaggregate test scores, and even more rapidly compare schools and school districts in public spaces, there is a keen interest for school administrators to know and understand student performance data. Like wanting to "do the right thing" with "poor students" when I was a teacher, as an administrator I discovered inequities between subgroups of students in the data. Not because I was trying to uncover social injustices, but because under No Child Left Behind (NCLB), schools were held accountable to show that subgroups of students (students with an IEP, students receiving free and reduced-price lunches, students not speaking English as their native language, students of color) were scoring "proficient" or better on state-mandated tests.

Trying to answer to mandates from NCLB and edicts from the state department of education did not spark my feeling of commitment to social justice. What began as not the best of intentions to achieve social-justice work slowly grew into something much clearer, as I was able to understand and better articulate what social justice meant in schools. I was initially motivated by reading the literature on leadership for social justice. Authors inspired me to try to practice leadership for social justice (Larson \& Murtadha, 2002; Skrla \& Scheurich, 2004). Analyzing student achievement data and seeing disparities persist between various groups of students was only the beginning. Seeing achievement gaps in the data only partially told the story of inequity in education. The authors illustrated and contextualized social injustices in schools. My readings assisted in my awareness, because I naïvely did not understand the historical context behind the persistent achievement gap that falls along lines of race, class, ability/disability, and native language. 
I can vividly remember the enthusiasm, euphoria, charisma, and zeal that overcame me when I finally felt that I had an orientation, a purpose to what I was doing in education. My commitment to social justice made perfect logical sense: As educators, we heard and read about the persistent achievement gap in education split down lines of race, class, ability, and native language. Addressing the achievement gap directly in education would mean addressing issues of injustices, discrimination, prejudices, and inequalities. School leaders wield power and influence in their schools. I discovered the best way to eliminate the achievement gap would be to lead for social justice in education. Leadership for social justice made perfect sense to me.

I wrote passionately about these euphoric emotions of feeling committed to social justice in the vignette "The Hero-A Lance Armstrong Analogy to Leadership for Social Justice." After being initially inspired by the theoretical literature on leadership for social justice, I could not wait to put it into practice. I was absolutely sure I could make a difference, eliminate the achievement gap, fight injustices in school at every turn, and save the world. Some of those early writings are painful to reread, however, they do paint an honest picture of what I was doing and thinking at the time.

I wanted to enact social justice in my school. Fairness and equity for all students should be something everyone in education works to create. When I was a teacher in the Chicago Public Schools, it was clear that poverty, racism, and inequalities were more apparent there than in the affluent suburb where I am currently an administrator. Nonetheless, because social injustices occur in all schools everywhere, there is reason for educators and administrators to try to enact social justice in schools. The theoretical literature on leadership for social justice seemed so compelling that I thought educators 
and administrators would join the fight to try to enact social justice and assist in creating fairer learning spaces for all students. Trying to enact social justice in schools is long, difficult, dogged, tiring, and incomplete work. However, it is also important and very meaningful work that has to happen in schools everywhere.

\section{How Should I Enact Social Justice?}

After the initial energizing moments, I wanted to try out this "new orientation" of leadership for social justice. Because the literature was rich with a theoretical calling for leadership for social justice, I thought I would naturally find many practical examples of what it looked like in practice. Although the literature is growing, practical examples of leadership for social justice do not exist much in the literature. As I read the theoretical literature on leadership for social justice and became energized to practice it as an administrator, there was no step-by-step handbook guiding me on how to practice leadership for social justice. When I became an administrator, first an assistant principal of a middle school then principal of an elementary school, I wanted to enact social justice but did not know how to do it. I tried a few things to enact social justice in my school.

Because there was no guidebook to tell me how to be a leader for social justice in my school, I tried motivating staff with comments like, "We need to address that achievement gap because some students are being served well and others are not." Judging by the many blank stares I received from saying this comment, it did not seem like a particularly effective strategy to use. Some staff did not understand what I was talking about because I never took the time to dialogue with them about what the achievement gaps means: that there are groups of students who have been traditionally marginalized in education and in society. Although I was extremely motivated and 
energized to begin the meaningful work of social justice in school, it did not appear I had many people joining me.

Since then, I have tried other strategies in attempting to lead for social justice; some intentional, some not. Presenting data or hard numbers, showing that the achievement gap really does exist in schools everywhere, can be compelling for anyone to see. When conversations occurred on student-achievement data, the dialogue among professionals can go in many different directions. Emotions can run high when discussing differences in student achievement, especially when data are disaggregated by race, class, students with an IEP, native language, and students receiving free and reduced-price lunches. As a leader trying to enact social justice in my school, when conversations occurred in which I tried to achieve a collective understanding and address areas of inequality in classrooms, I encountered resistance to the very existence of such inequalities. If not resistant to the fact that there are inequalities, apathy or indifference may result, such that staff feels nothing can be done. Similarly, placing immediate blame on someone for how and why inequalities have occurred in school also becomes a point of resistance. I have reacted to resistance to social justice in many different ways.

Making sarcastic remarks neither served to better enact social justice nor get more staff to consider arguments regarding how to better serve all students in school. I was most sarcastic when I was most frustrated with the status quo. Sarcasm seemed to manifest acutely in conversations regarding reasons students were not performing well. When I participated in conversations for possible underlying reasons why students underperform, the topic can shift abruptly to poor parenting and I would make a sarcastic remark. Two vignettes address how I respond to resistance to enacting social justice: "I 
Don't Know What I'm Doing. Sarcasm Doesn't Work.” and “Sarcasm Is Not Effective. People Want Me to Make a Decision." Talking about and trying to do things to address social justice in school can bring about much conflict and strife.

Sometimes when conflict and strife became so intense, due largely to not discerning any progress in leading for social justice, I would begin to question and doubt myself and what I was trying to do. Sometimes I would even question my commitment to leadership for social justice. I would doubt that I could say something when something needed to be said, when a particular injustice would be occurring and I failed to say or do anything. Sometimes I would be silent. In trying to learn to practice leadership for social justice, I faced the gamut of emotional difficulty: self-doubt, defeatism, insecurity, and tentativeness. I even became physically ill on occasion.

I now expect contentious conversations when the subject is social justice in school. There is no consensus on how to best serve all students, and everyone in education has an opinion about what is best for students. When questions are asked and problems posed regarding tracking students by ability, standardized-testing results, and teacher agency, opinions can get personal. Because personal belief systems can be called into question, that is, questioning the influence a particular teacher has in a classroom in changing the status quo and improving the life chances of all the students, interactions among staff can create feelings of defensiveness. However, as I will show in this study, for school administrators interested in learning to practice leadership for social justice, these kinds of questions must be asked to move toward more equitable, fair, and just learning outcomes for all students. 


\section{Trying to At Least Not Go Backward}

Even though I experienced the dramatic changes in emotions, I thought because I had identified a new leadership orientation, although full of ebbs and flows, fits and starts, ups and downs, I would never actually retreat backward. I found myself being drawn away from leadership for social justice to what seemed to be a more traditional form of leadership. Because leadership for social justice questions the status quo in education and directly addresses issues of equality in the classroom, it is not surprising that we do not immediately accept this leadership orientation in education. On one hand, leadership for social justice is bold and democratic. On the other hand, this work is extremely messy, complicated, and contentious. In many ways, it directly conflicts with the more traditional ways of leading in school. In many ways, traditional forms of leadership in schools directly oppose leadership for social justice because the two styles directly conflict. Traditional leadership, although important in some ways, focuses on managing schools to run efficiently and smoothly. Managing my school to ensure important functions run smoothly, particularly in scheduling, can necessarily take precedence over any other aspect, curricular and noncurricular. The list of what is expected traditionally in schools is long. Following are a few characteristics or traits that immediately come to mind when comparing traditional leadership with leadership for social justice.

One aspect of traditional leadership is the focus on the school leader as the hero. Being drawn toward a hero is nothing new. For me, being drawn toward enacting heroism and not for social justice in my school can mean taking a step backward, away from leadership for social justice. The long-lived concept of heroic leadership is alive in 
schools. Many portrayals of heroic leadership in schools were made famous in Hollywood by such movies as Dangerous Minds (Bruckheimer, Simpson, \& Smith, 1995), Stand and Deliver (Musca \& Menéndez, 1988), and Lean on Me (Twain \& Avildsen, 1989). What happened in these movies is typical of what we want from our school administrator in traditional leadership: a hero who always comes through, who can "do it himself" and "get the job done." We want someone who is charismatic, inspirational, passionate, driven, and decisive. Decisive leaders "clean things up" and "turn around schools." Hero leaders in schools solve problems, act quickly and definitively, exude confidence, and are energetic. Being the hero is, in many regards, what is expected in traditionally managed schools. Sometimes it is not only what school staff and community members have come to expect, but what they want and demand.

Leadership for social justice is antiheroic. Leadership in school should not rely on one person for everything. Because leadership for social justice is concerned with changing the status quo in education from a place where some groups of students are served well and others are not to a place where all students experience success, important conversations on how to do that need to take place. Practicing leadership for social justice involves having these important and honest—but extremely difficult—discussions about race, class, ability/disability, and native language with teachers.

The expectation with traditional leadership in schools is not only reliance on one person, the hero as the leader, to make all the important decisions and manage the school efficiently and smoothly. Bells need to ring on time, schedules need to be created down to the minute, and everyone needs a place to be at any given moment. What is expected from traditional leaders is not all bad. These are important aspects in any school to 
prevent chaos. Children deserve the best possible learning environment the professionals in charge can offer. Schools and classrooms must be safe, secure, and free of distractions for children to learn and thrive. However, I show in this study how difficult it is to avoid practicing traditional leadership to the point of excluding the practice of leadership for social justice.

Even with all the motivation, inspiration, and best intentions to try to practice leadership for social justice, sometimes one just acquiesces to traditional leadership. School leaders sometimes take giant steps backward. School leaders become obsessed with getting things done, finishing tasks, and checking off items on "to do" lists. There may be many reasons one does this. In this study I tell stories through short vignettes about the learning process for leadership for social justice. In the shortest vignette, only two paragraphs, The Manager is in the Principal's Office, I describe my frustration with acquiescing to traditional leadership. Chasing the illusive goal of perfect school management, although futile and meaningless, seems to be what I was doing, and doing it rather unhappily. In this vignette, trying to run a smooth and efficient school was neverending. Yet another managerial task was before me to perform, another crisis to manage, more paperwork to complete, or a new schedule to create.

I considered my struggle between the two worlds of leadership for social justice and traditional leadership to perhaps be a question of balance. I considered whether I simply needed to do a little of both: be a manager and be a leader for social justice. Without oversimplifying this complex issue, trying to do both seemed to be a plausible solution to my dilemma. However, trying to strike a perfect balance between two very different ways of leading a school can never be the solution. There are certain 
expectations in leadership for social justice and traditional leadership that cannot and should not be reconciled.

Leadership for social justice is messy work and my natural instinct was to avoid the conflict that is inherent in messy work. Although educators want more equitable and socially just schools, it is difficult to comprehend the enormous sacrifice and hard work that would go into realizing this goal for all students in all schools. Small, incremental gains and improvements are what most of us probably can handle. Thus, I believe our vision for more equitable schools recedes as our desire to maintain the status quo intensifies. With the constant pull of "what people really want"-traditional leadership with well-managed, efficiently run schools_-even small successes toward social justice can be overwhelmed, go unnoticed, and eventually fade away.

For all of the endless managerial tasks that are required, expected, and demanded of traditional leaders, the meaningful alternative of leadership for social justice is still more difficult, complex, and elusive. To sustain movement in the direction of more equitable, fair, and just learning spaces for all students in schools can be far more complicated than the managerial tasks of building master schedules, conducting efficient fire drills, and using the proper forms for teacher evaluations. Asking difficult questions about the level of influence leaders have in classrooms, and critically examining whether leaders can do something different to better meet the learning needs of students who have typically not been successful, is how leadership for social justice differs from traditional leadership. But that is not what staff members want in schools. 


\section{The Person (and Leader) Being Studied}

In this study I am learning how to practice leadership for social justice. Leadership for social justice is a meaningful leadership orientation for school administrators to practice. Some school leaders may not consider this goal acceptable. This study is an autoethnography of my efforts to learn to practice leadership for social justice in a mostly White, upper middle class, public school district. I cannot be an expert, however, my professional background, experience in urban education and bilingual students, and advanced leadership coursework have assisted in preparing me to become a leader for social justice in my school. As a White male of privilege, I realize I do not have first-hand experience with being oppressed, faced with injustices, segregation, or a victim of racism. In this study I am studying myself while also trying to improve my leadership capacity.

By trying to practice leadership for social justice, I learn and grow as a leader, working to influence others to practice social justice in education. I am researching a person belonging to three dominant groups—White, middle class, and male—signaling my seemingly privileged background. This privilege places me in a precarious position as I, and the three groups to which I belong, are somewhat coconspirators in the creation and maintaining conditions of social injustice. Thus, this study is unique in questioning conventional thinking on the role of the school leader and social justice. Conventional thinking on this subject typically points to what school leaders do where students have been traditionally underserved. School leaders in underserved areas are typically people of color. 
The masses of students are not underserved in affluent suburbs; however, students are still marginalized to some degree. Serving all students well must always be the goal to which all schools strive. For school leaders, moving closer to understanding how to best serve all students can be elusive and difficult. I believe White male administrators can come to a better understanding of how to effect social justice through an ongoing, careful self-assessment and reflection of what we do as school leaders. Writing an autoethnography has assisted me in becoming more aware of what I should and of what I should not do as a school leader.

There is a benefit and drawback to autoethnography. With autoethnography, studying oneself can be, at times, self-absorbing and lead to narcissistic tendencies. This is something I constantly guard against. In this study, sometimes it would appear I am successful at being more objective about myself and my practice as a school leader. Other times, I experienced more difficulty and can have narrow focus, only viewing school leadership through what I do as a principal. However, the use of autoethnography is a very genuine and authentic method to study a social phenomenon, in this case the social phenomenon of leadership for social justice (Denzin \& Lincoln, 2000; Ellis \& Bochner, 2000; Reed-Danahay, 1997).

In this study, I attempted to clarify leadership for social justice as essential in all schools to bring about more equitable learning environments for all students. On the surface, it seems simple: school leaders need to lead for social justice so all students can fully participate in the educational process to improve their overall success in school and life chances. It would appear, I thought, that all school leaders would need to use their positions of authority, power, and influence to make their schools more equitable. I 
studied myself partly because I thought, as a school leader, I could easily bring about a more equitable and just learning environment for all students.

Simply stated, leadership for social justice is meaningful. It is difficult to argue that school leaders should not work to provide educational equity for all students. In this study I attempted to examine how to practice leadership for social justice. I believe leadership for social justice is a meaningful practice. My desire to practice leadership for social justice each day as a school administrator is, regrettably, sometimes only evident in word. Sometimes it would appear that I am successful at practicing leadership for social justice. At other times, it seems blatantly obvious that I am failing to practice leadership for social justice.

\section{Statement of the Problem}

There is a persistent achievement gap in schools that continues to occur based on race, class, native language, and ability/disability. Many scholars have called for a change in the status quo in education. Although changing the status quo in education and creating more equitable, fair, and just learning spaces for all students is best accomplished in the classroom, school leaders can play a significant role in assisting to bring about such needed change. Even though demands are placed on school leaders to run smooth and effective schools, improving the education and life chances for all students involves leading schools in bold new ways that opposes many aspects of the traditional ways schools have always functioned. The literature does not contain many concrete examples of how leadership for social justice manifests in practice. This study addresses the problem of how the theoretical construct, leadership for social justice, manifests in 
practice. It will investigate me, a White male administrator in a public school district learning to practice leadership for social justice.

\section{Research Question}

By realizing my efforts in working to become a better leader for social justice, the main research question guiding this work is the following: How does the ongoing learning process to practice leadership for social justice manifest in school?

\section{Overview of Dissertation}

The following is an overview of this dissertation. In Chapter 2, I discuss how the professional literature on leadership for social justice informs my autoethnographic study. It will include what traditionally has been the status quo in educational leadership and give a brief overview of social justice in general; then leadership for social justice in specific. Chapter 2 will also include a definition of leadership for social justice. Next is a brief discussion on the primacy of democracy in leadership for social justice, followed by the centrality of the classroom teacher and social justice. Finally, some attention will be paid to recent literature on leadership for social justice in education.

Chapter 3 is the design of this study. In this chapter, I give a rationale for how and why I arrived at the method of autoethnography, briefly compare and contrast the two research paradigms of positivism and interpretivism, then delve more deeply into the meaning of autoethnography including history, definition, and application in my study. Then, I discuss my position and privilege, briefly describing my administrative background experiences. The rest of Chapter 3 addresses methodological issues of data collection and analysis, how and why certain vignettes were included or excluded, how vignettes were read and analyzed, and connections between how autoethnography and 
leadership for social justice are interwoven. The chapter concludes with a theoretical framework and some direction on how to read the vignettes and the meaningfulness of the Freirean lens through which the reader may view the vignettes.

Chapter 4 contains all 17 vignettes. They are arranged by category and include a Freirean commentary at the end of each vignette. The purpose and function of the vignettes is to depict my leadership in school; to actually show what I was doing in attempting to learn to practice leadership for social justice. Individually they are different and diverse, portraying distinct areas of my leadership experiences over a period of time. Collectively, they portray what the high and low feelings, ebbs and flows, fits and starts of trying to learn to practice leadership for social justice.

Following the vignettes is Chapter 5, I discuss what it looks like to learn to practice leadership for social justice. Here I elaborate on certain adjectives that depict my learning process for leadership for social justice. I then offer a deep and honest discussion of the story emerging from experiences of learning to practice leadership for social justice. 


\section{CHAPTER II}

\section{WHAT HAS INFORMED ME ALONG THE WAY}

As I continue to learn as a school leader, much of what I have read along the way has helped inform my thinking and practices. When I began working in education, I lacked the words to describe the twinge I felt to try to help students who I knew were traditionally underserved. I wanted to help students because I recognized they were struggling. I was aware of the unjust academic and social arrangements in my classroom. It is probably naïve to think that all I needed to do was be good in the classroom. At the time, essentially I was a novice to the meaning of social justice and what enacting social justice looked like in schools. When I transitioned from the classroom to administration, advanced leadership studies exposed me to a greater understanding of leadership for social justice. Because in the classroom I was not initially involved in reading research or theoretical literature that specifically addressed students who were marginalized, I later became energized when I began to read the literature on leadership for social justice. Reading this literature in my advanced leadership studies helped me understand that I could make a difference beyond the classroom, beyond simply "doing good by others." I came to understand, while concluding my transition from the classroom to the administration, that the role leadership could have in schools could foster systemic change: change favoring more equitable academic and social outcomes for all students. 
In this chapter, I use the literature that has shaped my understanding of key concepts, such as the contrast between traditional leadership theories/models and leadership for social justice; the fascination and draw to the "great man" or hero in schools, businesses, and society throughout history; and ideas and practices surrounding ethical and moral leadership that include democratic practices. Scientific management, behavioral science, the Theory X model, and transactional leadership have all had an impact throughout history, as well as presently, on school administrators. I present literature on leadership for social justice as another meaningful path that school administrators can use in their schools. I begin with a general background on social justice, including a brief historical account and definition. I then present a working definition of leadership for social justice, and also include a discussion on the professional risks involved in trying to enact social justice in schools. However, despite the professional risks involved, I attempt to present, supported by literature, that the sense of urgency to address the achievement gap in schools remains imperative.

The theoretical literature on leadership for social justice began decades ago and included a call for more ethical leadership, moral dialogue, courage, and school administrators speaking up and leading. At the end of this chapter, I present what has been occurring currently with leadership for social justice, including the push to address issues of inequality in schools, in university preparation programs, and in leadership for social justice internationally. Finally, due to the lack of examples of how leadership for social justice manifests in practice, I present research studies that dealt specifically with school leaders trying to enact social justice in their schools. 
Traditional leadership and leadership for social justice clearly contrast. In traditional leadership, the "great man" or hero assumes the role of change agent in schools. Being the hero in school can be enticing to those working in schools in a position of authority and influence. The historical impact one senses today for traditional leadership stretches to the days of F. W. Taylor and scientific management (1911/1947). Ever-present business models of traditional leadership continue to pressure schools and school administrators everywhere. In contrast, schools would look different should social justice be the purpose for which school administrators lead our buildings. I learned about the many tasks I needed to do in traditional leadership in my administrative-preparation courses. This study, however, revealed how I attempted to break from traditional leadership (sometimes successfully, sometimes not) to enact social justice in school. Continuing in this chapter, I present a general background on social justice, then move to leadership for social justice, whereby I offer an accessible definition, as well as describing the professional risks involved in trying to practice social-justice leadership in schools. Finally, I present the compelling reason school administrators should enact social justice: the achievement gap. The last discussion in this chapter involves finding examples in the literature on social justice in education that helped inform me.

\section{Traditional Leadership in Education}

At present, educational administration is at an interesting crossroads. The last 100 years of leadership in schools revealed traditional models of leadership in public education that have dictated exactly how school leaders should lead. Many leadership models in schools are models of management borrowed from the business world. Most models of management have, as their goal, an economic outcome such as high 
productivity and efficiency (Blackmore, 1999; Ryan, 1988, 1991). It is this focus on efficiency and productivity and not access, equality, and a shared understanding of fairness that may contribute to the inequities perpetuated in schools. Because of the myriad of business models of leadership that have made their way into public schools, school administrators have perpetuated the status quo of leadership that has served to maintain existing, unjust structures in education. Some scholars in educational administration and leadership have concluded that leadership in schools is narrowing to focus more on the daily managerial aspects of job performance for principals (Shields, 2006). This focus on traditional, efficiency-oriented models of leadership may have contributed greatly to the inequities present in public schools across the nation.

\section{The Hero}

Part of what makes traditional models of leadership so enticing to practice is the theory that "great men" are those who have provided the best leadership and thus should be emulated. The awe that great men have drawn as leaders dates back to Plato's Republic (380bc/1993), in which Plato detailed the fascination with those figures who have set themselves apart from the masses. Centuries later, in 1840, Carlyle expressed a similar fascination with the great-man theory of leadership (1993):

The history of what man has accomplished in this world is at bottom the history of the great men who have worked here ... we cannot look, however imperfectly, upon a great man, without gaining something by him. He is the living lightfountain, which is good and pleasant to be near ... the light which enlightens, which has enlightened the darkness of the world. (p. 3) 
Weber's (1947) concept of charismatic leadership asserted that through the charismatic efforts of one, prophetic leader, followers could be successfully led. Attempts to understand the great man as heroic leader led to research aimed at revealing particular traits of successful leaders (Burns, 1978; Peters \& Waterman, 1982). Such leadership traits included intelligence, problem solving, creativity, energy, confidence, integrity, and flexibility. Whether leadership is viewed as great men leading the masses, or possessing charisma or particular traits, the notion of a singular male leader heroically leading is a powerful phenomenon that, for many reasons, persists today in society and in schools. This way of leading would appear to be undemocratic and in contrast with leadership for social justice. In this project, I contrast traditional leadership with leadership for social justice.

\section{Different Theories and Models of Traditional Leadership}

At the beginning of the 20th century, business and industrial models of leadership in schools began to be used widely as an acceptable form of leadership for school administrators. This was due in large part to the industrial nature of U.S. economic life. Two influential thinkers left a lasting mark on public education. Weber (1947) and F. W. Taylor (1911/1947) are attributed with the formation and implementation of scientific management in industries across the world. School boards and university preparation programs saw scientific management as a viable and useful way for school administrators to manage and lead their schools and thereby endorsed the widespread use of running schools on the principles of scientific management. Nearly 5 decades ago, Callahan (1962) offered a critique of the influence of scientific management or Taylorism. In the book Education and the Cult of Efficiency, Callahan wrote about the extent to which 
school administrators would go to prepare a workforce for businesses between 1910 and 1930. A central focus 100 years ago was how to best operate and manage schools, and to some degree remains the focus today. School leaders are trapped into managerial tasks that are focused on efficiency. Scheduling classes, providing contractual, negotiated planning time to staff members, making sure all students get their pictures taken on Picture Day are managerial task that need to be carefully performed. Because these tasks are so very important in schools today, we still see the "cult of efficiency" present in schools everywhere.

In the 1930s, the organization of school leadership began to change. Although scientific management was not easily dismissed, scholars and researchers at the time began to develop alternate theories of school leadership. Thus began the human-relations approach to school administration (Lewin, 1939, 1951). The human-relations approach to leadership was an era marked by school administrators giving more credence to constituents' thoughts, feelings, ideas, and belief systems (Lewin, 1939, 1951). Another stage of school leadership occurred roughly in the 1960s with the onset of behavioral science. This period was marked by an emphasis on simplifying human interactions in school by attempting to predict certain outcomes, based on punishments and rewards (Skinner, 1953). The various eras in school leadership have impacted school administration today.

One way to holistically view the spectrum of school leadership is through transactional and transformational leadership. As in the eras of school leadership as scientific management, human relations, and behavioral science, transactional leadership focuses on the give-and-take, or transaction, between school administrators and their 
subordinates (Burns, 1978). Transactional leadership, at its most extreme, is similar to the Theory X and Theory Y models developed by McGregor (1990a, 1990b). Theory X assumes subordinates, or teachers and staff, generally do not like work, are dispassionate about it, and need to be controlled and managed to achieve overall organizational goals (McGregor, 1990a, 1990b). Similarly, administrators using transactional leadership seek to satisfy personal needs with little or no regard for higher moral callings, ethical concerns, fairness, and justice that are typical in transformational leaders (Burns, 1978). A closer look at the difference between transactional and transformational leadership is needed and will be discussed next.

Over the last several decades, there has been much research and literature on transformational leadership theory. The transformational leadership theory was originally developed by Burns $(1978)$ and later enhanced by Bass $(1985,1990)$ and Bass and Avolio (1994). According to Bass (1990), transactional leadership involves some sort of exchange between the manager and the subordinate. That is, "they explain what is required of them and what compensation they will receive if they fulfill these requirements" (p. 19-20). Bass (1990) describes the four characteristics of transactional leadership as follows: 1. Contingent Reward: Managers exchange rewards for effort, promise rewards for good performance, and recognize accomplishments of subordinates. 2. Management by exception (active): Managers watch and search for deviations from rules and standards, then take corrective action. Management by exception (passive): Managers intervene only if standards are not met. 4. Laissez-Faire: Managers abdicate their responsibilities and avoid making decisions (p. 22). The transactional leadership 
model looks more traditional and oriented towards maintaining the status quo of efficiency and productivity.

Conversely, according to Bass (1990) transformational leadership occurs when leaders are able to "broaden and elevate the interests of their employees, when they generate awareness and acceptance of the purposes and mission of the group, and stir their employees to look beyond their own self-interest for the good of the group" (p. 21). Like transactional leadership, Bass (1990) has characterized transformational leadership into four components. They are as follows: 1. Charisma: Leaders are successful in providing followers with a vision and sense of mission, instill pride, and gain respect and trust. 2. Inspiration: Leaders communicate high expectations, use symbols to focus the follows' efforts, and are able to express important purposes in simple ways. 3. Intellectual stimulation: Leaders can successfully promote intelligence, rationality, and careful problem solving among employees. 4. Individual consideration: Leaders can give personal, individualized attention to employees. It would appear that these four characteristics of transformational leadership are more closely aligned to what is involved in leadership for social justice in schools. Significant psychological and emotional buy in by teachers and staff in the form of an ethical and moral commitment to social justice needs to be firmly in place if schools have any chance of changing the status quo, eliminating the achievement gap, and transforming the learning spaces for all students so their academic needs are met.

Scientific management, behavioral science, the Theory X model, and transactional leadership have been influential and formative in how school administrators run schools today. They are the traditional models of leadership used in the business world, as well as 
in schools. Traditional models are concerned with management, and work to maintain a status quo of "the way things are run" in schools. Efficiency is at a premium. The scientific management Taylor developed in the early 20th century meant work efficiency translated into economic prosperity for businesses (F. W. Taylor, 1911/1947). Traditional leadership does not appear to be concerned with bringing about changes in the role schools play in addressing inequities. In other words, educational equality is not the expressed or primary focus of traditional leadership. Although equity and fairness may be addressed by traditional-leadership-minded administrators, achieving any level of social justice could be an unintended outcome rather than the result of a concerted focus on social justice.

\section{The Business-School (Dis)Connection}

Business models of leadership do not appear to serve schools well. Public schools are neither in the business of making a financial profit nor competing in economic markets. As Lunenburg (2003) stated, "Education is a social institution" (p. 3). Schools are social arenas where intense human relationships are formed and maintained to maximize academic excellence; schools should nurture and care for all students. In many respects, the world of educational leadership continues to "look out the window" rather than "look in the mirror" for meaningful paths to lead. Marshall (1995) poignantly exposed the educational leadership-big business connection (p. 489):

Theory seems to be derived from studies carried out in bureaucracies and businesses, as if these were the logical forms of organization; researchers do not question the applicability of these models for schools. They often and uncritically start with studies of business management as if production lines for widgets had 
parallels for helping children learn, so leadership and management and the structures for organization should be the same. Also, they seem to assume that teaching professionals need someone to direct, monitor, inspire and make meaning for them.

The legacy of the influence of business in educational leadership is not easily shaken. Murphy (2004) has confirmed the need to "reculture the profession" of educational administration but noted there has been "a fairly strong case over the past 70 years that the profession has drawn energy almost exclusively from the taproot of management and the ideology of corporate America" (p. 181).

In many schools, traditional leadership looks like a business-model approach. Many administrators tend to lead to maintain and run the organization smoothly. There is another path for school leadership, grounded in an alternative and promising way in which schools could be led. The premise offered in this study is that because social injustices exist and persist in public schools, changing the way leaders lead in schools could promise revolutionary and a more equitable education for all students. Thus, in this study, I set out to understand how the theoretical concept of leadership for social justice manifests in the school setting; and what practices aligned with social-justice leadership look like when attempted by a new administrator. The following is a brief history of social justice. Subsequently, I present an overview of leadership for social justice in schools.

\section{Social Justice}

The term social justice is not easily defined. Like many complex ideas in social science, social justice means different things to different people. A good general 
definition and one that will serve as a reference point for this study is that social justice is "an ideal condition in which all members of a society have the same basic rights, protections, opportunities, obligations, and social benefits." (Barker, 1999, p. 451).

Over the centuries, political philosophers from Plato to Rawls have been engaged in a debate arguing the perennial question, What makes a society just? (as cited in Jackson, 2005). The actual term, social justice, is relatively new, especially in political language. First used in 1840 by the Sicilian priest, d'Azeglio, social justice was made more prominent by the work of Mill in Utilitarianism, Liberty and Representative Government (as cited in Novak, 2000). In practical terms, Christian theology throughout the ages has called for more charitable giving in the name of social justice, scrutinized as the connection between individual acts of charity that may or may not embody the holistic ideal of social justice.

As remnants of the French Revolution lingered into the 19th century, socialjustice terminology could be found in various treatises from Rousseau to Kant. The 1948 Universal Declaration of Human Rights contained a modern version of basic principles of social justice. These 30 articles proclaim such rights as the right to life, liberty, and security of person; the right to recognition everywhere as a person before the law; and the right to equality before the law without discrimination (United Nations, 2007). More recently, the work of Rawls (1971) has been influential in a growing body of literature on social justice. Rawls' A Theory of Justice is most notable for the delineation of distributive justice, access to resources, focus on ethics and individuality, and the most disadvantaged in society taking precedence. Rawls's construct of social justice is political, economic, and social. The ideal of a just society is when all citizens are equally 
receiving their fair share of resources. The ideal distribution of resources would be the following (Rawls, 1971; Rawls \& Kelly, 2001):

a) All citizens are free and equal, reasonable and rational, and normal and fully cooperating members of a pluralist society, b) The 'basic structure' of the government is primarily responsible for creating a just society, and c) Cooperation and reciprocity among citizens and institutions are critical for the stability of this just society. (p. 42)

Distributive justice results when the government, its citizens, and institutions fulfill their respective duties and obligations.

Recent scholarship and literature on social justice is diverse. In what seems to be persistent world crises such as genocide, environmental destruction, income and economic disparities, political corruption, and racism, the call for social justice can be heard globally. Adequately providing essential medical services to all people is becoming a top priority for governments and policy makers. Some healthcare providers see themselves as social justice interventionist and not passive or market driven in their work to provide basic healthcare needs to all (Gostin \& Powers, 2006). Moreover, social injustices are often traced to a corrupt social structure (Dwyer, 2005, p. 465):

The real problem is that governments and privileged groups do not care enough to create systems of entitlements to supplement the food supplies that marginalized groups have. Although the particular cause of a particular illness may be a vitamin deficiency, the root cause is often embedded in the social structure.

Governments have played a role in the maintaining social injustices. One of the most devastating consequences of racial and economic segregation has been the 
concentration of poverty in schools. The high concentration of poverty in schools has led to poor academic performance, high dropout rates, more remediation, and less enrichment (Orfield, 2009; Rothstein, 2008). Governments have sponsored such segregation and concentrations of poverty. Through various policies and initiatives dating back decades, governments have accounted for present-day social inequalities. Moreover, real estate policies were designed and carried out with the sole intent of racial and economic segregation (Rubinowitz \& Perry, 2002). Even laws prohibiting discrimination in Federal Housing Administration-insured housing were overturned in the 1950s, and not reviewed by the U.S. Supreme Court (Q. Taylor, 1994). Because of these state-sponsored injustices occurring decades ago, schools located in racially and economically segregated areas continue to suffer today.

Social justice as a concept is far-reaching and broad. The ideal of social justice in all fields or disciplines is that of equality (i.e., access to community resources, employment, basic health care, education, etc.). The following paragraphs narrow the definition of social justice as it applies to public education.

The work of social justice concerns the work of more equality in society. Social structures in society are unjust: they exist to privilege some while oppressing others. Public schools have a long history of inequality and injustice that involves discrimination and oppression of whole classes of people. Non-Whites and people with disabilities were often denied public education altogether. Later, non-White students had to attend separate and often inferior and underfunded, schools (Williamson, Rhodes, \& Dunson, 2007).

One ideal of social justice is recognizing and appreciating difference, a "flattening of racial, ethnic, linguistic hierarchy" in which "social justice is not realized in an 
undifferentiated American populous but in an America that truly allows racial and ethnic minorities the ability to prosper without having to forfeit their cultural and linguistic identities" (Williamson et al., 2007, p. 211). Given the ideal that a socially just society recognizes and appreciates difference, students with disabilities could be understood as possessing special talents and abilities rather than damaged and faulty.

The legacy of social injustice persists today, and many public schools remain unjust and oppressive institutions. Schools could be more democratic: public schools could openly dedicate themselves to eradicating inequalities and injustices; working against the forced assimilation of all students into the the dominant, middle-class White culture. "Social justice is an integral feature of democratic life, as democratic societies are, at least in the ideal, just societies" (Hytten, 2006, p. 221). Although the definition of social justice is still emerging, this study follows a definition set forth by Bell (1997, as cited in Hytten, 2006):

The central goal of social justice in education is full and equal participation of all groups in a society that is mutually shaped to meet their needs...to have a sense of their own agency as well as a sense of social responsibility toward and with others and the society as a whole (p. 233).

\section{Leadership for Social Justice}

Kozol (1991) called education the great equalizer. Larson and Murtadha (2002, p. 150) stated, "The overall objective of social justice in public education should be improving the education and life chances of poor and minority children." Recognizing the power public education has to transform society, school leaders have the opportunity 
to use their position of power to work toward equality for all students in schools. School leaders can use their positions of power to change the existing status quo.

Rapp's (2002) definition of leadership for social justice provides an accessible, hands-on understanding of what leaders need to do in schools: "Leaders for social justice ... resist, dissent, rebel, subvert, possess oppositional imaginations, and are committed to transforming oppressive and exploitative social relations in and out of schools" (p. 226). Rapp's definition of leadership for social justice accomplishes an important goal. It provides a fairly accessible and concrete understanding for those school administrators interested in fairness, equality, and enacting social justice in schools. The definition also serves as a rallying point for the broader educational community in that it explicitly calls for action.

Aspects of leadership for social justice in U.S. public education can be traced back to Dewey's work in Democracy in Education (1916). Dewey's ideas regarding the use of democratic principles and social-justice practices in the classroom were progressive in the early part of the 20th century. Similarly, some accounts in the history of education detail truly bold examples of leadership for social justice (Counts, 1932/1978; Picott, 1947, 1960). There will always be risk involved in trying to enact social justice in schools. Some recent literature on leadership for social justice attempts to incorporate communication techniques to reduce the combativeness inherent in such highly personal dialogical interactions with school staff members.

Leadership for social justice is difficult, contentious, and combative. Trying to enact social justice in schools is not easily understood or accepted by teachers, staff, administrators, parents or the broader community. For a variety of reasons, just the term 
"social justice" can immediately provoke opinionated reactions. In the absence of the term social justice, the democratic principals of fairness, equality and access still need to be cultivated by school leaders in order to work towards high academic achievement for all students. According to Deal and Peterson (2009), research suggests that a strong, positive culture serves several beneficial functions, including the following: fostering effort and productivity, improving collegial and collaborative activities that in turn promote better communication and problem solving; supporting successful change and improvement efforts; amplifying energy and motivation of staff members and students; and, focusing attention and daily behavior on what is important and valued. Because of the confrontational nature that can occur in schools when discussing issues of social justice, there has been some literature on the ways in which dialogue can occur more civilly regarding race, class, native language, ability/disability and the achievement gap. There is some renewed interest by educational theorists and scholars to utilize invitational rhetoric of the communication paradigm (Foss \& Foss, 2013) to address issues involving social justice in schools. In schools where dialogical interactions take place regarding instructional practices and meeting the academic needs of all students, invitational rhetoric may be utilized as a tool for mediating challenging interactions regarding social justice; those in which a teacher's classroom instruction may be closely examined and discussed. Due to the highly personalize nature that may occur when dialoguing about why some students are served well in schools while others are not, basic tenets of invitational rhetoric must be established. The three most commonly cited tenets of invitational rhetoric are value, safety, and freedom (Foss \& Foss, 2013). Moreover, there are several other key areas that all participants must understand and respect when 
utilizing invitational rhetoric. These key areas include understanding the purpose of communication in invitational rhetoric; participants listen with openness; the speaker and audience are viewed as equals; invitational rhetoric involves power-with instead of power-over; participants change only when they choose to change; participants enter willing to be changed; and, creating a world of appreciation for differences (Foss \& Foss, 2013). Entering into dialogue explicitly dealing with social justice involves professional risk for any school administrator.

\section{Professional Risk in Leadership for Social Justice}

Contemporary accounts of school leaders practicing leadership for social justice, and highlighting such leaders and their practices, remain elusive today. The reason may be that practicing leadership for social justice is not without professional risk (Karpinski \& Lugg, 2006; Lugg \& Shoho, 2006). Some leaders in education have taken the ultimate risk—getting fired—in the name of equality for all students. Lugg and Shoho (2006) detailed the life of Counts (1978) and his infamous speech, Dare the School Build a New Social Order? in which Counts is repeatedly attacked by political opponents. Counts was not deterred but rather galvanized the call for educators everywhere to become more politically involved and lead the push for justice and equality in schools (as cited in Lugg \& Shoho, 2006). Similarly, another prominent educator, Picott (1947), an African American teacher and principal, risked much to work toward equality in schools. Picott clearly viewed the importance of social justice and equality in schools as outweighing personal and professional job security (as cited in Lugg \& Shoho, 2006). Presently, social justice advocates continue to call for educators and administrators everywhere to take 
risks in the name of social justice; a meaningful call that may involve compromising job security (Karpinski \& Lugg, 2006; Lugg \& Shoho, 2006).

This study is concerned with what school leaders might do to assist in bringing about more just learning environments for all students; an alternative to the way in which schools have operated and currently operate. School leaders possessing oppositional imaginations to traditional, managerial-based leadership models can impact the attainment of social justice in their schools. By moving away from traditional ways of leading in schools, school-based leaders can embark on a leadership practice that places issues of social justice at the fore. This is meaningful work in schools. The hope is that by enacting social justice in schools the achievement gap will be eliminated completely.

\section{The Achievement Gap}

Recent scholarship on the achievement gap in schools indicates that while achievement disparities decreased through the 1970s and 1980s, particularly because the gap decreased between Black and Latino students and their White counterparts, some gaps began to widen again in the late 1990s (Lee, 2002). Boykin \& Noguera (2011) cite NEAP data that indicate a disturbing pattern of relative stagnation from the late 1990s to 2007. Arguments regarding the origin—and persistent maintenance—of the achievement gap in schools have varied greatly among researchers, scholars and social scientists for decades. Some state the achievement gap is a result of culture and history (Berlak, 2001), while others blame poor classroom instruction (Ferguson, 2003), the role of race in the classroom and low teacher expectations (Delpit, 2006), the economic disparity that tends to exist between races (Jencks \& Phillips, 1998), deficit thinking (Valencia, 1997;

Valencia, Valenzuela, Sloan \& Foley, 2001), forced assimilation (Valenzuela, 1999), and 
teacher qualifications (Darling-Hammond, 2005). This is only a brief glimpse, not an exhaustive discussion, on the diverse and complicated myriad of literature regarding causes and reasons for why some students are served well in schools while others are not. Whatever the reason, the fact remains that not all students are being educated equally, and thus there continues to be an achievement gap in US schools.

Based on data from the National Assessment of Educational Progress (NAEP), often referred to as the Nation's Report Card, the achievement gap still persists today in schools across the country. While the definition of the achievement may be evident in its name, NAEP defines the achievement gap as the following: "Achievement gaps occur when one group of students outperforms another group and the difference in average scores for the two groups is statistically significant (that is, larger than the margin of error)" (Retrieved from the National Center for Educational Statistics website http://nces.ed.gov/nationsreportcard/studies/gaps/). At first glance, understanding the achievement gap seems straightforward (Murphy, 2009): “The differences in scores between group A (low-income students) and group B (middle- to high-income students) needs to decline, with the goal of arriving at the point where scores between the two groups are equivalent" (p. 8). Murphy (2009) goes on to state that the achievement gap is much more complex in terms of measurement, interpretations of scores, difficult variables in differentiating differences within subgroups, what gets measured, and differences in interpretation between relative and absolute improvement.

Because of the urgency to try and eliminate the achievement gap, it is important to simplify the definition to try and ensure all those working with students in schools can have an accessible understanding of what disparities of achievement look like. 
Specifically, all school staff should have a basic understanding that students of color, students with an IEP, students receiving free and reduced-price lunches, and non-native English speakers may not achieve academically commensurate with their White, middle class counterparts. For this study, enacting social justice in school means to work to improve learning outcomes for all students, not only those that have been traditionally marginalized.

According to many researchers and scholars (Valencia, 1997; Valencia, 2010; Valencia, Valenzuela, Sloan \& Foley, 2001), deficit thinking has been the predominate model of thinking in education to explain the pervasive and persistent achievement gap. These researchers, particularly Richard Valencia (1997, 2010), have conducted extensive research over many years on how and why the deficit thinking model accounts for the achievement gap in schools. Valencia (2010) has outlined six characteristics that summarize deficit thinking in the context of schools. The six characteristics are as follows: 1) blaming the victim, 2) oppression, 3) pseudoscience, 4) temporal changes, 5) educability, and 6) heterodoxy. Because of the relevance of the achievement gap to deficit thinking, each characteristic of deficit thinking will be briefly discussed.

William Ryan's (1971) groundbreaking work on why victims are blamed for the deficiencies in achievement explained much about how schools operate. For staff members working in schools, the concept of blaming the victim to explain differences in achievement is often used rather than examining the structures that exist in schools that may prevent marginalized students from experiencing academic success. Valencia (1997) advances this notion by stating that the law or parsimony in social arrangements—such as the case in schools - is because it is easily understood, accessible to all, and replicable. 
Deficit thinking is easy. For example, in its simplest form, the deficit thinking model-in terms of native language — would blame the student for speaking a language other than English and assume his academic deficits come from not being English proficient.

Valencia (2010) notes that oppression in schools follows Ryan's (1971) concept of blaming the victim for not achieving. For decades school systems everywhere have systematically used unjust policies to keep certain groups of students from fully accessing an appropriate education. Valencia (2010) gives two examples of oppression that have contributed to the legacy of the achievement gap in schools. The first is compulsory ignorance laws which made it illegal for African slaves to actually learn to read and write in the United States. The fear was that if slaves became literate they may seek liberation through revolt. Next, Valencia (2010) notes that school segregation dates back to the inception of public schools and has always attempted to separate certain groups of students (student of color, non-native English speakers) from White students. While these two characteristics of deficit thinking are centered on past events, policies and laws, oppression in schools still exists in subtle ways today.

Deficit thinking and pseudoscience are closely linked. Pseudoscience is defined by Blum (1978) as a "process of false persuasion by scientific pretenses" (p. 12). Valencia $(1997,2010)$ states that the misuse of the scientific method continues to happen today by social scientists, researchers and scholars. Often times with pseudoscientific methods, important variables are not controlled for, alternate hyphothesis are not considered, and weak psychometric instruments are used to explain phenomena that are biased against those traditionally marginalized in schools. Valencia (2010) further delineates the deficit thinking characteristic of pseudoscience into neohereditarianism, 
which he describes as using pseudoscience to explain differences in intelligence testing, an area frequently misunderstood and misused in schools.

Interestingly, Valencia (2010) points out that while deficit thinking is dynamic and would seemingly dictate the mindset regardless of the times, it appears that temporal changes can provide fertile ground for deficit thinking. For example, depending on the political or social climate, deficit thinking can be incorporated into policy and institutions in order to explain why marginalized populations need interventions and assistance.

A balanced perspective on the achievement gap and deficit thinking comes from an African-American author and administrator in a large urban school district in Illinois. Teresa Hill (2011) provides an insight from the African American community on the origins and perpetuation of the achievement gap. Hill (2011) questions both the conservative worldview that African American students do not achieve because they do not have either the capability or the drive to do what is necessary to succeed, and the liberal worldview that the students are merely the victims of uncontrollable outside forces. Hill's (2011) insights are well grounded and helpful to all those working in schools and attempting to address the achievement gap head on.

While it may seem difficult to comprehend that teachers and administrators are unaware of particular achievement gaps occurring in their schools, they often do not know that inequality in programming, and inequality among teachers, are persistent and ongoing. Some scholars in the field of leadership for social justice call for the use of equity audits to create more equitable learning environments for all students, and argue that in order for the achievement gap to be eliminated there must be both programmatic equity and teacher equity to address achievement equity (Skrla, McKenzie \& Scheurich, 
2009). In terms of ensuring the programmatic service delivery models in schools are inclusionary for culturally and linguistically diverse students, school leaders cannot assume all professionals maintain the same knowledge base for reaching this goal. Thus, a cultivation of language proficiency, access to high-quality teaching and learning, and the promotion of socio-cultural integration of all students is vital in lessening the achievement gap (Scanlan \& López, 2012).

Additionally, in programmatic equity, difficult but important questions must be asked such as whether or not some population groups under-represented in advanced placement classes or honors classes? Are some groups over-represented in special education classes? Are some groups disciplined more often and more severely than other groups? In regards to teacher quality equity, close examination must occur in terms of whether or not the most experienced teachers are teaching the students with the greatest needs or are most of the new teachers teaching the students with the greatest needs (Skrla, McKenzie \& Scheurich, 2009). Moreover, in close dialogue and collaboration in and among teachers and administrations, such equity traps must be avoided. Equity traps fall under the deficit thinking paradigm and include rationalizing bad behavior and unsuccessful practices, erasing the race and culture of particular groups, and norming the negative or perpetuating the culture of negative thinking and outcomes by only seeing deficits in students (Skrla, McKenzie \& Scheurich, 2009). Conversely, equity skills should be practiced to address the achievement gap in schools. Equity skills include seeing assets in all students, creating transparency, seeing and respecting race and culture, and deeply reflecting on behavior and practices as school practitioners. 


\section{Emerging Leadership to Address the Achievement Gap}

Although leadership for social justice is not entirely new, it is still considered emerging. Leadership for social justice has its roots in moral leadership (Bates, 2006; Furman, 2003a; Greenfield, 2004; Murphy, 2002, 2004; Sergiovanni, 1992, 2000;). Today, moral leadership seems to be rising to the fore with greater intensity. Because of the changing face of public education in the United States, leadership for social justice appears to be a good fit for the changing times.

More and more schools and districts across the nation are becoming ethnically and economically diverse. A long-standing, persistent achievement gap plagues public schools everywhere. Although this broad, sweeping statement describes the state of schools today, it nonetheless cannot be understated. Some groups of students consistently outperform other groups of students in standardized-test scores, grades, graduation rates, and admission into accelerated and advanced placement classes. Students most at risk of not succeeding academically are students of color, economically disadvantaged, Englishlanguage learners (ELLs) and students with an IEP (Vanneman, Hamilton, Anderson, \& Rahman, 2009). These gaps have led to significant federal and state legislation intended to eliminate achievement disparities between these groups and their more privileged and affluent peers. One result has been a greater emphasis placed on leadership for social justice in university preparation programs for educational administration. This is evidenced by leadership for social justice now occupying space in the Interstate School Leaders Licensure Consortium Standards (Furman, 2004; Frattura \& Capper, 2007). In Ohio, of five standards for principals, Standards 4 and 5 include language referring to 
social justice, insomuch as it relates to the achievement gap (learning and achievement of all students and culturally responsive practices; Ohio State Board of Education, 2013).

Standard 4. Principals establish and sustain collaborative learning and shared leadership to promote learning and achievement of all students.

- Principals promote a collaborative learning culture.

- Principals share leadership with staff, students, parents, and community members.

- Principals develop and sustain leadership.

Standard 5. Principals engage parents and community members in the educational process and create an environment where community resources support student learning, achievement and well being.

- Principals use community resources to improve student learning.

- Principals involve parents and community members in improving student learning.

- Principals connect the school with the community.

- Principals establish expectations for the use of culturally-responsive practices, which acknowledge and value diversity.

Inequalities in and among schools persist today. For a variety of reasons, school children experience unfairness in their education. Some schools and districts are not funded properly (Kozol, 1991). Schools are increasingly segregated (Kozol, 2005). Some have nearly all teachers certified in the content area they teach whereas other schools and districts cannot even fill high-need areas such as special education and ELL classes (Darling-Hammond, Berry, \& Thoreson, 2001). Some schools and districts have a 
disproportionate number of students with an IEP whereas others fail to provide legally mandated special-education services. Some inequalities facing students are beyond the control of school personnel, such as school funding. Data presented in this study proactively assumed teachers and administrators can make a difference in countering these injustices in schools and work for a more just and fairer learning environments for all students.

This is not to say personnel working in schools dislike children and are actively engaged in harming children academically. Although there may be staff in schools who are not compelled to uplift and inspire students to become caring and high-performing students, most injustices that occur on a daily basis are unintentional; that is, teachers and administrators do not feel personally responsible or even aware that some groups of students are marginalized. The difference would appear to be that leadership for social justice makes this commitment explicit to all. Consider the evidence of persistent injustice in public schools in Furman's (2004) work on an ethic of community:

No social arrangement is neutral. Every social arrangement, no matter how it presents itself as natural, necessary or simply "the way things are," is artificial. It is usually structured to benefit some segments of society at the expense of others. The ethical challenge is to make these social arrangements more responsive to the human and social rights of all the citizens (as cited in Starratt, 1994, p. 47).

\section{Leadership for Social Justice Addressing the Achievement Gap}

Some questions to ask could be What does leadership for social justice mean to schools? What does it look like in schools? How would one recognize and distinguish it from traditional leadership? Because the body of literature on leadership for social justice 
continues to grow, there is no one, all-encompassing definition of leadership for social justice (Furman, 2004). For this reason, the body of literature that portrays the basic tenets in the concrete and daily practice of school administration is useful. Some of these basic tenets exist for social justice in schools (fairness, democracy, dialogue, etc.) and can work to lessen or eliminate the achievement gap. Fairness, for example, may mean how school leaders address the marginalization of particular groups of students, perhaps those who have been traditionally underserved. However, fairness in school also addresses ensuring all students are served well. Democracy is important in schools that are trying to enact social justice. "Deep democracy" includes valuing members' full participation and inquiry, and everyone working for the common good of social justice. Because of the centrality and importance of the classroom teacher, dialogue plays a significant role in social justice in schools. An absence of dialogue, or silence, can work against enacting social justice in school. School-based practitioners have the liberty and latitude to construct meaningful and just learning institutions with their staffs, contextualizing theory into practice. Given the basic tenets of fairness, democracy, and dialogue, it is probably best for school leaders to construct their own models of leadership for social justice.

Social justice has a multiplicity of meanings for leadership. Caring leaders for social justice need a broad understanding of racism, sexism, heterosexism, poverty, and disability (Gerstl-Pepin, Killeen, \& Hasazi, 2006; Marshall \& Gerstl-Pepin, 2005). Furman (2004), a leading theorist in the field of leadership for social justice, stated that to date, there is no "static, agreed-on definition of social justice" but an evolving one. Furman cited other researchers who reported similar findings, such as Bogotch (2002): 
"Constructs such as social justice acquire a shared, though imprecise, meaning during certain periods of time" (as cited in Furman, 2004, p. 228). Furman (2004) summed up well the evolving meaning of leadership for social justice by stating, "taken together, these shared meanings of social justice suggest that working for social justice requires a deliberate intervention that challenges fundamental inequities and works toward better educational and economic outcomes for marginalized children" (p. 228). The most commonly occurring word or phrase in all literature dealing with social justice is “marginalization” (Capper et al., 2006; Furman, 2004; Furman \& Starratt, 2003; Larson \& Murtadha, 2002; Shields, 2004). School leaders working to eliminate this marginalization and striving for a good, just learning place for all students is the complex, meaningful work of leadership for social justice.

Leadership for social justice practices involve the democratic processes that Dewey used a century ago. Furman (2004) cited the concept of "deep democracy" as foundational to the practice of leadership for social justice. Furman (2004) cited the concept of deep democracy (as developed by Green, 1999; Gutmann, 1987) as having three key points: “(a) the processes for knowing, understanding, and valuing; (b) the processes for full participation and inquiry; and (c) the processes for working toward the common good" (p. 224). Furman (2004) theorized that leadership for social justice consists of several components: an ethic of care, an ethic of critique, an ethic of justice, an ethic of profession, and an ethic of community. Furman (2004) proposed that the ethic of community anchors, or complements, the other ethics in education. The ethic of community is 
the moral responsibility to engage in communal processes as educators pursue the moral purposes of their work and address the ongoing challenges of daily life and work in schools ... an ethic of community centers the communal over the individual as the primary locus of moral agency in schools (Furman, 2004, p. 215).

According to Furman (2004),

The ethic of community is useful in mitigating one of the perennial problems of "traditional" research in educational leadership—-the unrealistic assumption that "heroic" leaders can provide the vision and expertise to overcome the many challenges facing public schooling in the twenty-first century and lead schools in transformative directions. (Bogotch, 2002; Heifetz, 1994 both as cited in Furman 2004, p. 222)

Avoiding heroic leadership and its particularly enticing aspects were integral to this study. Thus, the primacy of democratic practices cannot be overstated in the practice of leadership for social justice. Democratic practices by school leaders could follow those of the broader society. Democratic practices appear to contrast starkly with the heroicman theory. Democratic practices in school mean the free and informed exchange of ideas, popular and unpopular; the critical analysis and examination of problems and issues in such a way that reason and thoughtfulness prevail over emotional and prejudicial decision making by leaders; and a deep and genuine concern and caring for all students in advancing the common good among all (Apple \& Beane, 1995).

These democratic practices by school leaders have the potential to transform schools into more than just learning places. Freire (1998, p. 37) noted the importance of 
education in transforming society by stating, "it is true that education is not the ultimate lever for social transformation, but without it transformation cannot occur." Given Freire's extensive work with those directly affected by oppressive social and educational structures, viewing transformation and the compelling need for it to occur through education is at the heart of leading for social justice in schools.

School leaders must engage in "moral dialogue" to question and overthrow existing institutionalized structures that further marginalize minority students, lowincome students, students with an IEP, and others not benefiting from the status quo (Shields, 2004). In this process of establishing relationships and engaging in dialogue, Shields (2004) stressed the importance of school leaders working to avoid and therefore talking openly about the "pathology of silence." Because teachers are central to the overall creation of just learning environments for all students, school leaders have the responsibility to use democratic practices to help shape and maintain equality in the classroom.

This begs the question of where and with whom school leaders should engage in moral dialogue. The assumption is that because of the enormous influence classroom teachers have on the learning environment of all students, much importance should be placed on this area. The centrality of the classroom teacher for moral dialogue is important. To specifically question and dialogue with classroom teachers regarding whether all students are learning in the classroom is indeed meaningful. In contrast, by refraining from dialogue with teachers and other key staff member-that is, by remaining silent on issues of equality and justice for all students—school leaders could be viewed as 
complicit in learning inequities among students. Thus, avoiding a pathology of silence with the classroom teachers is integral in this study.

\section{Examples Needed of How Social-Justice Leadership Manifests in Practice}

Compared to traditional leadership in schools, leadership for social justice is a more equitable way for school administrators to lead. Presently, the model for leadership for social justice is largely theoretical. It is theoretically compelling but not fully developed in practice. This has revealed a gap or need in the field of leadership for social justice. Examples of the practice of leadership for social justice need to be documented. The literature lacks useful depictions of how leadership for social justice manifests in schools. Given the definition of leadership for social justice, the next logical step could be to locate practical accounts of leadership for social justice currently being implemented in schools.

The sense of urgency to increase academic achievement is pervasive in schools. Schools do not perform equally. At all levels of education, this inequality of achievement is based on race, class, ability/disability, and native language spoken. In the upper grades, inequality of achievement can be seen not only on standardized-test scores, but more importantly other key areas such as graduation rates, number of students enrolled in advance-placement classes, number of students taking ACT/SAT tests, and number of students enrolled in and entering college upon graduation. At the primary level, inequality of student achievement is also evident in and between schools. Elementary schools that do not perform well have a higher percentage of students who do not read at grade level, as well as higher rates of grade retention. Similarly, an inordinate number of students from traditionally marginalized groups are enrolled in remedial classes, special- 
education classes, or exclusive pull-out classes in K-12 schools (Education Trust, 2012). A simple cursory preview of the Education Trust website (2012) reveals the pervasive achievement gap in U.S. schools. Although perhaps focused too heavily on accountability and standardized testing, the massive legislation sign into law in 2001, NCLB, was, in part, an attempt to finally eliminate the achievement gap among all students in schools. At present, the achievement gap is arguably one of the main areas of focus in all schools, districts, states, and university preparation programs. The sense of urgency to improve education for all students continues to take precedence everywhere.

The main issue to address for the achievement gap is how it can be diminished, if not eliminated. The achievement gap is the disparity of academic-achievement levels between groups of students such as between White, middle-class, affluent students and their counterparts, students of color, students receiving free and reduced-price lunches, students whose native language is not English, and students with an IEP. Numerous studies in the last 50 years have attempted to uncover causes and solutions to the persistence of the achievement gap in U.S. schools. Thus, a persistent achievement gap in schools is a socially unjust situation.

Depending on which source one studies, one may understand and analyze the achievement gap through many differing lenses. For this review, the Coleman Report was one source. If the Coleman Report (Coleman et al., 1966) is used as a rough beginning point of social scientists' attempt to address the achievement gap and social injustices in schools, then this issue has been addressed for decades with little improvement. Researchers have studied several areas of schooling in attempts to lessen and eliminate the achievement gap: examining parental involvement (Desimone, 1999; Ramirez \& 
Carpenter, 2005), teacher quality and efficacy (Darling-Hammond et al., 2001; Stigler \& Hiebert, 1999), and curriculum (Beecher \& Sweeny, 2008; Tomlinson, 2001). Because of the urgency to eliminate the achievement gap and have equitable schools for all students everywhere, this review of the current literature focuses on relevant works published in the field of leadership for social justice. This literature review only touches on one aspect of addressing the achievement gap: current research on leadership for social justice regarding bringing about equitable learning environments for all students.

\section{Literature on Ethical and Moral Leadership}

In the early 1990s, scholars such as Foster (2002), Murphy (2004), and Marshall (1995) called for a departure from school leaders simply managing schools to, instead, focus more on equitable and socially just outcomes for all students; and thus for more ethical leadership on the part of school administrators. Many others were writing on the ethical leadership in the early 1990s, such as Sergiovanni (1992). In Moral Leadership: Getting to the Heart of School Improvement, Sergiovanni offered another alternative to traditional leadership that departs sharply from what had always been done in schools, suggesting a moral dimension to school leadership based on values, purpose, and beliefs.

Moral and ethical leadership in schools is complex and diverse. When considering moral and ethical dimensions in school systems, leaders must be prepared for the challenges of leading in moral and ethical ways with the students, parents, and staff they serve. Complexities include political, social, cultural, and historical dimensions (Starratt, 1999). A challenge all school leaders face when trying to lead in moral and ethical ways is how to develop ethical principles together with students, parents, and staff to increase the quality of education (Beck \& Murphy, 1994; Sarason, 1996; Sizer, 1996). 
Ethical leadership in schools means administrators are working to ensure excellence and equity for all students. Ethical leadership tries to create more just learning environments for all students. Thus, in this review, the term "leadership for social justice" will be used to mean school leaders working to change the status quo of inequality to lessen the achievement gap between groups of students.

\section{The Theoretical Beginnings of Leadership for Social Justice}

Furman (2003a) used the term leadership for justice in an issue of the University Council of Educational Administration. Rather than focusing on "how to do" leadership, Furman continued the call for ethical leadership in schools by asking what leadership is for. The call for leadership for social justice continues today with many voices bringing to the forefront the importance of addressing the achievement gap (Cambron-McCabe \& McCarthy, 2005; Capper et al., 2006; Larson \& Murtadha, 2002, Marshall, 2004; Murphy, 2004, Skrla \& Scheurich, 2004). Although this call for social justice was initially theoretical, signs of increasing numbers of practical examples seem to be emerging.

\section{University Training Programs}

One of the practical examples from the initial theoretical beginnings of leadership for social justice has been the revamping of university training and preparation programs for aspiring school administrators. Examples abound of universities redoing their educational administration programs to better prepare aspiring school administrators to be leaders for social justice. Furman continued to be a leading voice on leadership training programs at the university. In a recent edition of Educational Administration Quarterly, Furman (2012) detailed leadership for social justice as praxis in leadership-training 
programs. Furman reiterated many concepts from previous works, however, highlighted the Freirean notion of reflection and action, or praxis, as an important component for university educational administration-preparation programs.

Other research on university preparation programs focused on leadership for social justice as a critical 21st-century skill (Jean-Marie, Normore, \& Brooks, 2009). Researchers are asking whether university preparation programs can prepare aspiring administrators to "think globally and act courageously about social justice" (Jean-Marie et al., 2009, p. 19). Given this overwhelming task, it seems daunting and extremely challenging for universities to prepare future school leaders to work against the status quo of unjust and inequitable systems currently in place in many schools. Moreover, some researchers have questioned whether it is even possible to prepare leaders for this task (Oplatka, 2009).

Aligned with 21st-century skills, some authors have suggested university training programs should place greater emphasis on skills such as collaboration, critical thinking, problem solving, and professional-learning communities to advance social-justice initiatives in schools (Mullen, 2010). Likewise, university training programs stress the importance and use of democratic practices as a way to lead for social justice (Davis, Skrla, Lindsey, Scheurich, 2011; Furman, 2012; Larson, 2010; Marshall \& Oliva, 2010; Schultz, 2010). Still others are calling for university preparation programs to closely scrutinize and critically examine how they train future administrators, studying university preparation programs designed to prepare school administrators in leadership for social justice. Such studies have examined the role faculty play in program developing and implementation, student recruitment, the consistent and enduring focus on social justice 
in all coursework, and instructional delivery models (Rodriguez, Chambers, Tehah, Gonzalez, \& Scheurich, 2010).

Recently, some university programs have begun to include a more global understanding of social justice in their coursework. Advanced educational leadership studies have included such areas as economic, ecological, and environmental components.

Literature and scholarship on preparing school leaders for social justice work in education has become concerned with equity and fairness in terms of economic opportunities, and ecological and environmental justice (Kennedy, 2012; Martenson, 2011). Some authors have called for a grassroots movement to change the paradigm of conventional money from one that has traditionally marginalized particular groups of people to putting people before profits and creating a stable and sustainable monetary system that will reflect real wealth, rather than speculative profit (Kennedy, 2012). While economic justice is not a new concept, it is considered radical and upsetting for the relative few that currently benefit from an unequal monetary distribution of our current economic system.

There is good reason why personnel currently working at all levels in education should be concerned with economic and environmental justice. According to author Chris Martenson (2011), the next twenty years will be very different than the last twenty years. The world is in economic crisis, and there are no easy fixes. Martenson (2011) identifies three areas in his book The Crash Course: The Unsustainable Future of our Economy, Energy, and Environment, that put society on a crash course by the twenty-teens. Martenson (2011) explains that our current monetary system places impossible demands 
upon a finite world. He predicts that unless radical change occurs, the rising levels of debt, based on assumptions of future economic growth to fund repayment, will come to a sudden stop, and quite possibly reverse. This could lead to a further widening of economic and social class stratification. Undoubtedly, certain populations that have been traditionally marginalized will experience even more acute oppression and despair.

In terms of energy, Martenson (2011) paints a bleak picture of diminishing fossil fuels and the desperate measures major companies are willing to use to secure new ore deposits such as having to drill in more remote areas, drilling deeper down, and soils being mined by the practice of removing essential nutrients without replacing them. Ecological injustices are advancing at a rapid rate. There as been a $40 \%$ decline in oceanic phytoplankton since 1950, birds, bees, and bats have been in serious decline, mercury levels in marine mammals continue to rise, and sterilized soils and advancing deserts pose grave danger to humans and other species (Martenson, 2011). It is important and imperative educators, school leaders, and students are not only made aware of our rapidly changing world, but equipped with the necessary tools of critical thinking, collaboration, communication and creativity to confront all types of social injustices now and in the future.

\section{Leadership for Social Justice Internationally}

One area in the research that continues to grow is that of international studies on leadership for social justice. International studies vary, but the theme remains consistent: Researchers are trying to study what school leaders are doing to assist in improving the life chances of students who are traditionally marginalized. One particular piece of research, for example, focuses on the life of Joan Wint and her work in a rural Jamaican 
school. The study is biographical and looks at Wint's life experiences that influenced her as a leader. The study looks particularly at how being a women impacts her role as a school administrator (Oram-Sterling, 2009). Turkish researchers have written several studies in the past few years. One such study examined the roles and responsibilities of school administrators in social-justice and just environments in schools (Turhan, 2010). Another research study, from Cyprus, examined the emotional aspects experienced by school administrators trying to practice leadership for social justice (Zembylas, 2010). The author studied a school principal who struggled to transform a school into a more just and inclusive learning environment for students. Using ethnographic methodology, Zembylas (2010) detailed the daunting task of the principal to change the mindsets and ingrained belief systems of teachers and the community regarding including students from all cultural backgrounds. The author also detailed the importance of school leaders paying proper attention to their emotional responses in trying to practice leadership for social justice.

Many other international studies on leadership for social justice have come out of Canada, Australia, New Zealand, and England. In these countries, some studies have attempted to address issues of the struggle of equality in schools. In England, one study examined the values and commitment school principals have for leading for social justice but found that the amount of resistance, particularly that beyond their control, was nearly insurmountable. Stevenson (2007) investigated some of England's education policies that push for the privatization of schools in England and questioned whether these policies are fully committed to equality and social justice. Stevenson noted that the goal of education 
policy should be to ensure full alignment with social-justice values and equity in all schools.

Ottmann (2009) offered a Canadian perspective in the context of the First Nations of Canada. The author argued consistently, aligned with other literature on leadership for social justice, that leaders need a new vision to counter the pervasive impact of the status quo. Ottmann questioned how emerging leaders in schools should be prepared in values, beliefs, knowledge, skills, and attitudes. Ottmann pointed out the importance of educational leaders understanding the particular histories (local, regional, and national) of oppressed peoples with whom leaders are working.

\section{Autoethnographic Examples Informing this Study}

Garza (2008) conducted one study that offered perspective on my goal; Garza is a first-time superintendent working in a small school district in southern Texas. In this study, Garza detailed the resistance faced as a superintendent trying to enact social justice. Much of the resistance took the form of in-fighting in the board of education, as well as with the community. This study helped inform my work as it addressed school leadership—albeit at the central-office level, not the building level—and used autoethnography to detail such experiences. Garza offered points learned when trying to enact social justice:

I learned that it is not easy to be a leader for social justice. Leaders for social justice consistently challenge the hegemonic culture, and this often results in an adversarial relationship between the superintendent and those who use their power to demand and create privilege. And finally, I learned that my naïveté got me in trouble. However, I also learned that being naïve was not necessarily negative. 
Being naïve made me less cautious of the negative consequences and allowed me to look at the possibilities. I learned that my philosophy of social justice was constantly challenged, and it required great ethical stamina to withstand the negative pervasiveness of a deficit-thinking society. (p. 176)

Clearly, trying to practice leadership for social justice in any school district is long, difficult, and contentious work.

The theoretical literature on leadership for social justice is strong. Many scholars and researchers in social science have written and researched extensively on the pervasiveness of unjust, unequal, and oppressive outcomes of many students who have been traditionally marginalized in schools (Blackmore, 2002; Bogotch, 2002; Furman, 2003b; Furman \& Gruenewald, 2004; Larson \& Murtada, 2002; Marshall \& Ward, 2004; Rapp, 2002; Shields, 2004). A growing body of literature describes the practice of leadership for social justice. For this project, a study by Theoharis (2007) detailed, in ethnographic and autoethnographic form, the learning experiences of seven school principals. Because of its similarity to this project, Theoharis's study will be reviewed in greater detail, as it provides many helpful reference points.

Theoharis (2007) conducted a study in which seven principals (one being the author himself) were the primary units of analyses. The study, published under the title Social Justice Educational Leaders and Resistance: Toward a Theory of Social Justice Leadership, qualitatively examined three key areas: (a) ways the principals enacted social justice in their schools; (b) resistance principals faced when enacting social justice; and (c) in the face of resistance in and out of school, what strategies did principals use to sustain and maintain social justice. 
Theoharis (2007) detailed several ways principals enacted social justice including raising student achievement; improving school structures by reducing or eliminating pullout programs in favor of more inclusion classrooms; and recentering and enhancing staff capacity through conversations on race, class, gender, sexual orientation, and Whiteness. They offered professional development in these areas and focused on strengthening school culture and community. One example was a concerted effort for staff to be more open, friendly, and inviting to traditionally marginalized families.

Although principals noted successes in enacting social justice in their schools, particularly in raising student achievement, Theoharis (2007) uncovered much resistance opposing the principals' goals. The consequences of the resistance they faced-although most acute early in their careers in their schools-included physical ailments, mental and emotional pain and anguish, and a relentless effort on the part of some staff and community members to resist social justice.

In the face of resistance, principals used a number of strategies to overcome, develop, and sustain social-justice work. The strategies were proactive and focused on such aspects as maintaining authentic communication with staff and parents to move the momentum forward for social-justice work. Similarly, principals explained that communicating and reaffirming with the people around them their belief in social-justice work was a helpful strategy. Developing and sustaining a network with other administrators that functioned for change toward social justice was also helpful in combating resistance. Finally, principals found that prioritizing their work, participating in professional learning, and building relationships were effective counterresistance strategies (Theoharis, 2007). 
The Theoharis (2007) study provides several helpful reference points for my autoethnography. First, it is one of the only studies focusing on the principal as the unit of analysis. This positions the concept of leadership in an important place in schools and the work of social justice. The author, Theoharis, although remaining anonymous as one of the principals in the study, wrote autoethnographically. This contributes to the representational merit of autoethnography methodology.

The study differs from my autoethnography in a few key areas, and the hope is my study can contribute to the growing body of research in leadership for social justice. It also differs in that all seven principals were working in urban schools with varying degrees of student diversity. All schools were considerably more diverse (by race, class, and native language) than the school and district where I presently work. Finally, and most importantly, Theoharis (2007) chose these principals in a specific way:

For this study I sought participants who did not fit the traditional understanding that school leaders are essentially managers. Additionally, I sought participants who operated from a place beyond the newer understanding that principals are instructional leaders, principals who embodied a commitment to enacting justice and equity. (pp. 226-227).

This is important and different from my autoethnography. My study cannot make the assumption that there is a level of minimum learning competency, even commitment to social justice, such as the study conducted by Theoharis (2007) "operated from a place beyond the newer understanding that principals are instructional leaders, principals who embodied a commitment to enacting justice and equity" (pp. 226-227). Rather, my autoethnography shows the learning process in trying to "embodied a commitment to 
enacting justice and equity" by a White male of privilege working in an affluent, homogeneous, suburban school district.

In conclusion, authors have assisted me in learning how to practice leadership for social justice. In this chapter, I drew a contrast between two distinct models or theories of leadership in schools. Unlike traditional models of leadership that may be closely associated with business models of leadership, social justice and leadership for social justice are committed to fairness, equality, and opportunity for not only students who have been traditionally marginalized, but all students. Practices such as deep democracy, moral dialogue, and avoiding silence are key to any school administrator tying to enact social justice in schools. Potentially, great professional risk awaits principals trying to enact social justice in schools; however, it is an important risk to take as the pervasiveness of the achievement gap by race, class, native language, and ability/disability continues to diminish positive learning outcomes and overall life chances for all students. The theoretical call for moral and ethical leadership in schools has set forth a search for more examples of what leadership for social justice looks like in practice. To date, very few examples exist. 


\section{CHAPTER III}

\section{RESEARCH DESIGN}

In this chapter, I discuss my research design in the context of my evolving interest in educational practice for social justice. As my interest settled into leadership for social justice, it seemed most appropriate that I seek to answer my research question using the method of autoethnography. Although I believe autoethnography is a very meaningful way to study leadership for social justice in school, this particular methodology is not without criticism, addressed below.

In this chapter, I begin by establishing a rationale as to why I chose autoethnography as a methodology. I then provide a broad overview of research paradigms; then focus on where autoethnography lies on the interpretivist side. I then narrow down autoethnography with a definition and show that it is appropriate for this research project. Because autoethnography involves both self-reflection and close introspection of how one fits into the "same" culture the author is researching, some discussion needs to occur regarding my position and privilege. I present a description of my administrative background and show how researching myself can serve to answer the research question in this study. Further discussion takes place, connecting autoethnography and studying leadership for social justice, including the intimacy, legitimacy, researcher commitment and investment, embracing subjectivity, reflexivity, and questioning the status quo in education. 


\section{Why I Chose Autoethnography}

I provide a rationale for choosing autoethnography as the means of inquiry for this study. Initially, I had a profound interest in studying schools and their leaders working effectively with students with an IEP. Had I pursued this interest, it would have taken the form of an ethnographic study, investigating the entire culture of the school. Appropriate schools were difficult to find. Confounding this approach were the myriad of variables involved in distinguishing which schools' students with an IEP were considered high performing. Even simply examining achievement data to locate a school or district that consistently scored well with its IEP population was difficult. In northeast Ohio, there are not any such schools. Moreover, this dearth was consistent with my brief search of schools and districts all over Ohio.

As I became increasingly frustrated with my search for schools effectively educating students with an IEP, I noticed other trends that consistently emerged from my search of high-performing schools. Some of the trends included other achievement-gap issues such as varying levels of academic performance between students of color and their White counterparts. The achievement gap was also by class and in some cases gender. I realized my search to find one or two schools exclusively serving well their students with an IEP was problematic. Although my search may have been sufficiently narrow, in retrospect, I had been missing the broader ideal of social justice in schools.

At the same time, as I delved deeper into the literature on leadership for social justice, I found myself highly energized, as this particular literature named an orientation to practice I found extremely compelling. Complicated design issues for the IEP study 
combined with my enthusiasm for the leadership-for-social-justice topic and how it manifested in practice led me to this study.

There were two choices in undertaking a study to examine how leadership for social justice manifests in schools: find someone else practicing leadership for social justice and study him/her, or recognize and study my own attempts to practice leadership for social justice. By choosing the latter and studying myself, an added dimension occurred. In short, from the beginning of this study, it appeared that I would undertake a study to try to learn to be a better school leader as well as potentially add to a growing body of literature of practical accounts about what leaders for social justice try to accomplish. Thus, the link between narrative and experience seemed to be a natural one (Freeman, 1998). The narrative can be thought of as the words, phrases, and language I use to describe my experiences in working toward becoming a better leader for social justice. An autoethnographic approach seemed to be a good fit for studying leadership for social justice.

Schools are social institutions comprised of complicated human relationships and intense interpersonal interactions. Studying social phenomena such as leadership for social justice in schools is complex work. Studying myself and using the methodology of autoethnography seems appropriate and meaningful for at least two reasons. First, qualitative inquiry seeks to holistically capture the complexity of a social phenomenon in its richness. Second, use of a more embodied form of writing such as narrative will, hopefully, give readers a better, more accessible understanding and notion of the ongoing learning process of trying to practice leadership for social justice-an apparent gap in the literature to which I hope to make some contribution. 


\section{Research Paradigms}

Positivism means to "posit" or "put forward" and "conceive." Positivism addresses quantifying and objectifying participants and data. In the positivist paradigm, knowledge and reality are secured through quantitative measurement. To understand reality, positivist research involves forming and testing a hypothesis, controlling variables through the use of deductive reasoning, and systematically observing with the scientific method. The main goal in positivist research is to explain, predict, and control the phenomenon being studied (Denzin \& Lincoln, 2005; Lincoln \& Guba, 1985; Ponterotto, 2005; K. Williamson, 2002). Patton (2002) best summed up the positivist historical tradition of research and knowledge: "Thus, real knowledge (as opposed to mere beliefs) was limited to what could be logically deduced from theory, operationally measured, and empirically replicated" (p. 92).

Interpretivism attempts to "interpret" and construct meaning from the social world. Whereas positivists work under the assumption that the reality of the social world can be discovered and explained with objective realism, interpretivists rely on the promise that reality and the social world are elusive and ever-changing. Interpretivist research aims to understand a phenomenon in the holistic context in which it exists. The centrality of relationships and construction of meaning by researcher and research participants is paramount in the interpretivist paradigm (Denzin \& Lincoln, 2005; Lincoln \& Guba, 1985; Ponterotto, 2005; Schwandt, 1994, 2000). Returning to Patton (2002), it may be best to summarize the interpretivist paradigm with a question: "How does my own experience of this culture connect with and offer insights about this culture, situation, event, and/or way of life?" (p. 84). 
Each research paradigm serves a valuable purpose. Depending on the phenomenon studied, sometimes the positivist paradigm is appropriate. Other times the interpretivist paradigm is appropriate. Positivist research has greatly influenced and contributed to the advancement in the fields of medicine and biotechnology. In this aspect, positivist researchers aim to control and objectify variables, form hypotheses, and come to some type of empirical answer. In contrast, interpretivist researchers work under a different assumption, one of understanding and interpreting the complexity of meaning(s) in a given phenomenon. Interpretivism is better used in studying social phenomena and thus the interpretivist paradigm seems a better fit for studying leadership for social justice. The autoethnography undertaken in this study lies in the interpretivist paradigm of research. The succeeding paragraphs consider autoethnography more closely and how it falls under the interpretivist paradigm of research.

\section{Autoethnography Background}

Some criticism has been leveled against the use of autoethnographic methodology. Because the researcher is the primary source of data, questions of subjectivity sometimes arise. In this study, I embrace subjectivity_as well as my own academic tentativeness - as I am aware that to deny my influence and interpretation is tantamount to disingenuous work. Lau (2002) saw subjectivity as pluralistic, having multiple voices that actually produce a more complex text of "competing subjectivities" (p. 254). Berger (2001 citing Bateson, 1972) and Fasching (1992) described the importance of embracing subjectivity, as no human experience is ever free of subjectivity: 
Bateson (1972) has said, all human experience is subjective ... that rather than proceeding through a scientific method, which requires that a hypothesis or a set of questions be answered, researchers cannot know what to explore until they have finished exploring (p. xvi). This method unlayers the world of the field to readers, providing them with a deeper comprehension not only of the people being studied but of the researcher as well. These multiple and linking narratives are the mode of moral reflection that illuminates the lived texture of human existence. (Fasching, 1992, p. 93)

\section{Definition of Autoethnography}

Autoethnography is a method of inquiry in qualitative research that is usually autobiographical; displays multiple levels of consciousness; recognizes emotion, art, and dialogue as legitimate forms of representation of inquiry; and attempts to connect the personal self with the broader culture being investigated (Ellis \& Bochner, 2000). Because of the postmodern nature of the autoethnographic construct, autoethnographers write using first-person narrative and attempt to place themselves in a particular social context (Reed-Danahay, 1997). Three distinct components comprise the holistic concept of autoethnography: auto, meaning self or coming from within; ethno, meaning race or people; and graphy, meaning of or relating to written or pictorial representation (American Heritage Dictionary, 1994). According to Ellis and Bochner (2000), Hayano (1979) first used the term autoethnography in the 1970s to describe cultural anthropologists studying their "own people." Hayano termed the researchers as such because they were full participant members in the group studied. 
Autoethnographies provide psychological reporting/research space. For example, autoethnographic accounts have become increasingly popular in the fields of medicine and ethnic identity (Chiu, 2004); pain, illness and sexual dysfunction (Neville-Jan, 2004); and racialization and Whiteness (Vidal-Ortiz, 2004). In traditional research, whole groups of people seem to have been locked out of researching particular phenomena such as pain, sexuality, and Whiteness. For a variety of reasons, the parameters of traditional research in the past did not provide the psychological/reporting space for people and researchers because of what was dictated to be "normal," mainstream culture. Social justice, while not a new concept, is fairly new as a primary direction for administrators to lead schools. Therefore, autoethnography, like leadership for social justice, is an emerging method of inquiry that seems particularly useful in studying social phenomena like leadership for social justice.

\section{The Use of Autoethnography for this Study}

An autoethnographic methodology appeared to be a meaningful form of inquiry to use for this study for many reasons. Autoethnography serves to connect the personal to the cultural (Ellis \& Bochner, 2000). In this study I attempted to set forth and report not only the culture of schools in which I have worked, but to afford an interested readership a practical story on how I am learning to practice leadership for social justice. A meaningful way to do this is to relate my personal stories of trying to learn to practice leadership for social justice to the larger culture of public schools. Autoethnography and leadership for social justice seem like natural bedfellows.

Autoethnographic writing may not "look" standard. Because autoethnographies can be different things to different readers-representational, evocative, embodied, 
sensual, emotional (Bochner \& Ellis, 2003) — the nonstandard presentation of text is important in developing a powerful and meaningful written work. The reading and understanding of autoethnography requires effort and active participation on the part of the reader. In some cases, deliberate forms of text arrangement and text format create a level of disruption, discomfort, and even confusion and disorientation. This is done in large part because of the long history of static text in social science writing.

Finally, like other autoethnographies, I continually question five important areas in this study. According to Richardson (2000a) the following criteria should be applied to any autoethnographic work: substantive contribution, aesthetic merit, reflexivity, impact, and expression of a reality. These five essential qualities of autoethnographic work are revisited at the end of the study.

\section{Position and Privilege}

My positionality must be addressed. As a White, middle-class man in a position of authority, I cannot take for granted either who I am or how I am perceived by the people with whom I work: teachers, parents, community members, and students. I leverage considerable symbolic and formal authority. In one sense, knowing and understanding my positionality is important not only to me, but to those who have been traditionally marginalized and oppressed by White, middle-class men in positions of authority. It is important I realize that my history is a history of privilege.

My history of privilege is personal as well as representational of the class/race group to which I belong. By realizing I have personally benefited and continue to benefit from being a White, middle-class man, I hope to work against these subtle and overt privileges, maintained and reproduced in the school setting. McIntosh (1988) described, 
An invisible package of unearned assets that I can count on cashing in each day, but about which I was meant to remain oblivious. White privilege is like an invisible weightless knapsack of special provisions, maps, passports, code books, visas, clothes, tools, and blank checks. (p. 165)

\section{My Positionality and Autoethnography}

Being who I am has paid great dividends over the years. The U.S. educational system is set up to directly reinforce those cultural values that are exemplified in Western culture and perpetuated by patriarchy. For example, the drive to possess knowledge and compete academically is paramount in schools. Knowing a lot academically creates particular advantages of power. Perhaps a better way of viewing this phenomenon is to look at its opposite, or working to give away power in communal groups of learning whereby mutual relationships are built, trusted, and respected. Knowledge would no longer be an item to be possessed and used to gain power over another individual or group; rather, it would be shared and constructed equally to directly benefit the group. The difficult question to answer is how do I use my position and privileged status to affect change for social justice? How could I use the advantages and privileges of being a White male in a position of authority to empower those traditionally marginalized in the public schools? There seems to be a natural connection between exposing one's positionality and authority with autoenthnographic writing. The following is a more explicit explanation.

To be clear, I am fully disclosing that as a White male of privilege in a position of authority (school administrator), I have certain advantages. The claim I am making is that my experiences may be a good example of what is perceived by others when they see a 
White male in a position of authority in school. If this is the case, then connecting my personal experiences of my positionality by the way of autoethnographic methodology may prove to be meaningful. I am asking, "how does my own experience of this culture connect with and offer insights about this culture, situation, event, and/or way of life?" (Patton, 2002, p. 84), and the use of autoethnography seems most appropriate to answer this question. Alexander (2003) described what I hope to be accomplishing in this study through the use of autoethnography:

And to what degree are all scholarly documents messy? The nature of what we do as teachers and scholars is always messy_messy with self disclosing personal insights and disguising them as research; messy with supporting our own felt experiences with a litany of other voices in the reference pages, footnotes, or the backstages of our own scholarly performances. They are messy because when we deal with anything related to human nature, we are mandated to get our hands dirty, to get involved and process through experience. (pp. 437-438)

For me to "get my hands dirty" is to portray an honest description of who I am and what I do in attempting to become a better leader for social justice. Getting my hands dirty in this autoethnographic project signals working out the interplay between my patriarchal Whiteness and my deep desire and commitment to help those groups of students traditionally marginalized by a system that has directly benefited me and who I am. Because my intention in this project is a practical one, the hope is that my contribution will assist me and others in continually learning to be better leaders for social justice. Moreover, I feel it imperative that this project affects the reader through substantive contribution, aesthetic merit, reflexivity, impact, and expression of a reality 
(Richardson, 2000a). Through the use of autoethnographic methodology, I hope to stimulate social action (Ellis \& Bochner, 2000), thereby creating change in schools, and the leadership practices that take place in schools.

\section{Administrative Background and Experience}

It seems appropriate that because I used the methodology of autoethnography, a brief overview of my school administrative experience is necessary. As a teacher, I never wanted to be an administrator. Teaching was far too exciting, fun, and rewarding to consider being a school administrator. For a long time I simply could not give up the awesome profession of teaching to be an administrator. I loved having the opportunity to work with children each day because I knew I could assist in their becoming better learners and people. This does not happen in the position of administrator. Although I fully knew going into administration I would not be able to work with students on a daily basis, I never thought I would miss teaching as much as I do.

I started teaching in the area of special education. I worked in the Toledo Public Schools in Ohio for little more than 6 months in a 4-6 grade classroom in what was then termed Behavior Disorder/Developmental Disorder. The school was an African American school, my first job out of college, and I did not really know what I was doing.

In the early 1990s, I joined the Peace Corps and was assigned to Ecuador. I spent nearly 3 years living and working in a small town, assisting teachers and administrators in a school of students with disabilities. This was probably my first leadership role. With about 6 months of teaching experience in the United States, I was charged with teaching teachers in Ecuador. In the beginning, I gave lectures in broken Spanish on how to teach (the U.S. way) on such concepts in mathematics as place value, long division, and 
measurement. I progressed to more technical subjects in the teaching methodology, such as how to differentiate instruction with students with disabilities. Soon, I learned Spanish with the help of many friendly Ecuadorians and colleagues at my host school. I learned an enormous amount about education through patient team teaching with my understanding Ecuadorian teachers, but still really did not know what I was doing.

After the Peace Corps, I was attracted to DePaul University and working in the Chicago Public Schools. While studying at DePaul, I was placed at Cesar E. Chavez School on Chicago's south side in the stockyard/back of the yards neighborhood. This was a very positive experience. I taught there 9 years, and had many opportunities to be a leader. The school was nearly all Mexican American, and like the friendly and patient Ecuadorian teacher colleagues, the Spanish-speaking community on the south side took me in and accepted me with patience and kindness. I worked for a principal who believed strongly in teacher autonomy and made it possible for us to work in collaborative teams with shared leadership. I probably did not take full advantage of the leadership opportunities presented to me during my 9 years teaching at Cesar E. Chavez, as I was very much enjoying teaching eighth-grade students at the time. Despite being bilingual, being married to an Ecuadorian, and being accepted by the Mexican American community on Chicago's south side, in retrospect, I believe I still did not know what I was doing. Why did I not know or believe I knew what I was doing in those earlier years? What was "carrying me" to "look like" I was performing adequately? I believe it was the “invisible knapsack” of privilege (McIntosh, 1988). Perhaps I unknowingly was able to move into places that really do not need White males of privilege living and working. 
While working at Cesar E. Chavez, I discovered the possibility of pursuing my doctorate at Illinois State University. Upon finishing my coursework at Illinois State University, I needed to move back to Cleveland, Ohio. The 2 years in the Cleveland Municipal School District began my first formal administrative work. I worked as the dual language coordinator at a K-5 school in the Cleveland Municipal School District. It was the first of its kind in Ohio. At the time, I worked in a K-5 school building located in the heart of the Latino community on Cleveland's near west side. Shortly after I left Buhrer Elementary School, the building was razed and a new $\mathrm{K}-8$ building was erected in its place.

The position of dual language coordinator was a good administrative beginning for me. I was not fully an administrator, as I was still considered part of the teachers' union. However, I was able to perform various administrative tasks such as coordinating curriculum across grade levels, scheduling, and conducting in-service trainings. I still could consider myself a teacher. I was still able to work with students on a regular basis.

In 2005, I left the Cleveland schools and began working in the suburb in which I presently live, Brecksville. I was hired as a part-time assistant principal at a middle school that serves students in Grades 6-8. This was my first official administrative position. At this position, I began with very simple administrative tasks as I was very new to this role. I mostly disciplined students, attended to locker assignments, updated the school website, patrolled lunch and bus times, and analyzed student-achievement testing data.

It was around this time that I became interested in the leadership orientation of leadership for social justice. Perhaps there was a vacuum in my belief system when I 
officially became an administrator, or maybe because I had begun reading literature by those theorizing about a particular leadership orientation styles in schools (Furman, 2003; Marshall, 2004; Shields, 2004, and others), I was energized to read about the theoretical construct of leadership for social justice. I was energized because the theoretical literature called for equality in education. It departed from what I had known; what I had pieced together reading literature on traditional leadership as well as formal university classes on educational leadership.

At some point during the part-time administrative position, I undoubtedly started down a path of leadership that was markedly different from mainstream, traditional leadership. I was not necessarily practicing leadership for social justice, as I had just begun reading the leadership-for-social-justice literature; rather, my mindset began to change. I eventually became a full-time assistant principal at the middle school, and it was from this time that a portion of the data came to be in this study.

Since 2008, I have been the principal of an elementary school in the same district. Some of the data also come from this time of being an elementary school principal. On a daily basis I try to practice leadership for social justice. That is, on a daily basis, I try to lead in favor of improving the life chances of those students who have been traditionally marginalized: students of color, students speaking languages other than English, students with disabilities, and students receiving free and reduced-priced lunch. However, I also continue to try to best serve all students. Although data and research clearly show which students in schools are underserved, all students are important. To date, my experiences with marginalized students still outweigh my time in the suburbs. I have spent more time in Ecuador, Chicago, and Cleveland public schools than in my current suburban district. 
The school district in which I am currently employed differs dramatically, and demographically, from my other experiences. At present, this school is nearly all White. The single largest minority group is Asian at about $6.5 \%$ in a district of 4,400 students. About 1\% are African American, almost 2\% Hispanic, and a little over 1.5\% multiracial; $8 \%$ of all students districtwide accept free and reduced-price lunches, and $9.5 \%$ of students have an IEP. At any given time, between 3 and $4 \%$ of students can be considered ELLs.

On a daily basis, I sometimes fail miserably at being a leader for social justice. This happens for a variety of reasons. Sometimes I think I am successful in working in favor of not only traditionally marginalized, oppressed students, but all students because I seem to see small successes with students and staff. One of the more difficult aspects for me to reconcile is trying to practice leadership for social justice as a White male of privilege in an affluent, nearly all-White suburb. At times, I can dwell too long on detecting or exacting instances of oppression and racism, rather than acting and trying to do something about an inequitable circumstance. I am reminded of Starratt's (1994) notion that no social situation is neutral. Schools are social situations and thus not neutral. At present, my understanding of the meaningful work of leadership for social justice is not to make my school racially, economically, and linguistically neutral, but to work to increase the likelihood of overall success for all students, not only those that have been traditionally marginalized. Sometimes I think I fail miserably, and sometimes it would appear I'm doing this meaningful work well.

Although it is difficult to reconcile trying to practice leadership for social justice as a White male of privilege in an affluent, nearly all-White suburb, I try to do so in this 
study. A synopsis of what I am attempting to accomplish is, through the use of autoethnographic data (vignettes), to contribute to the growing body of literature on how it manifests to try to learn to practice leadership for social justice in a public school setting. It is clear that some students in school are served well and others are not. The literature on leadership for social justice lays out theoretical frameworks on how to bring about more equitable and just learning environments. In the following chapters, beginning with the data vignettes, I try to show my attempts at learning to practice leadership for social justice as a White male of privilege.

\section{Natural Connection of Autoethnography and Social-Justice Leadership}

This autoethnography presents/represents/exhibits how it manifests to learn to practice leadership for social justice to be a meaningful method. Autoethnography and leadership for social justice have several natural connections. One such connection is their purposeful intention of critique and resistance (Furman, 2004; Larson, \& Murtadha, 2002; Neumann, 1996; Rapp, 2002). At present, autoethnography methodology is a promising and growing research field. Patton (2002) succinctly described autoethnography as a natural "bookend" to ethnography: "Ethnography and autoethnography might be thought of as bookends or opposite ends of a qualitative continuum" (p. 84). Clifford (1988) noted a shift in traditional ethnography by calling attention to the Westernized stance in traditional ethnographic research of studying the exotic "other."

Much of the work presented in this study is, and will continue to be, evolving, as my understanding and learning to practice leadership for social justice in my daily administrative role also evolves. I am not likely to reach a state of complete mastery as a 
leader for social justice, as this would signify the antithesis of my work; that is, being heroic.

As a school leader I am unable to claim to have all the answers. First, because I do not have much experience as an administrator, I am still learning all the managerial procedures that are important in ensuring the school runs well. This inexperience also takes away from focusing more on tasks that fall under the umbrella of leadership for social justice (e.g., attending all team meetings, engaging in critical dialogue with all staff, etc.). Therefore, by virtue of "time put in" as an administrator, I am still learning all of the intricacies of policies and procedures. I want be a better leader, and autoethnography helps me do this because autoethnography provides a methodology that allows for a close examination of oneself and how that examination can better inform practices in the larger society. In short, I feel it imperative this project affects the reader by the way of substantive contribution, aesthetic merit, reflexivity, impact, and expression of a reality (Richardson, 2000a). Through the use of autoethnographic methodology, I hope to stimulate social action (Ellis \& Bochner, 2000), thereby creating change in schools and the leadership practices that take place in schools.

\section{The Intimacy of Autoethnography}

Bochner and Ellis (1999) described autoethnography as "offering a divergent rationality, creating a sense of reality, intimacy, economy, accessibility, verisimilitude, and their capacity to evoke and provoke identification, feeling, empathy, and dialogue" (p. 492). Because I am compelled to the action and practice of leadership of social justice, using autoethnography can make more accessible how the learning process manifests for leadership for social justice. Autoethnography helps make more concrete the abstract 
theoretical ideas of leadership for social justice. Because of the transparency, closeness, and "intimacy" autoethnography offers, my efforts in trying to learn to practice leadership for social justice may be more accessible to others. Therefore, although the use of autoethnography is very personal, it may have the potential to inform a larger audience, perhaps by enabling others to try to practice leadership for social justice. This point is made even more critically when I ask myself the following two questions: "How many social science researchers have no personal investment in the research they do? How long can one last as a researcher without loving the work?" (Ellis, 1999, p. 670)

\section{Two Questions about Autoethnography}

How many social science researchers have no personal investment in the research they do? In this study, I am a public school principal. I do not consider myself an expert social science researcher. However, I am researching myself and have a fairly large personal investment in the research I am conducting. It is personal because I peel back layers of who I am and what I do as a school leader. I expose my pitfalls, embarrassments, shortcomings, challenges, and successes in trying to learn how to practice leadership for social justice. As I am the one collecting the data, this entire study is centered on my subjectivity as a person and professional. I embrace this subjectivity in collecting data on myself because—-knowing this and examining data—it can only serve to help me learn more about trying to practice leadership for social justice. It does not seem possible to not have a personal investment in this research project.

How long can one last as a researcher without loving the work? With this particular topic of what the learning process looks like in trying to practice leadership for social justice, it becomes difficult, if not impossible, to detach oneself from the work and 
the research. Total detachment from the study is not a problem as autoethnography requires the opposite of detachment; that is, full submersion into the research study. "Loving the work" as an elementary school principal is about trying to better serve all students in school. Learning to try to practice leadership for social justice is difficult; but loving that all students may benefit from one's efforts is meaningful.

\section{Questioning the Status Quo in Education}

Longstanding educational inequities by race, class, native language, and students with an IEP not only exist, but are maintained and reproduced over and over again in schools and society, present in schools everywhere. As many scholars and theorists in leadership for social justice have called for resistance and transcendence of the status quo - rather than maintaining it — this is an appropriate time to change the style of educational leadership (Marshall, 2004). Grogan (2004) cited Foster and Starratt in questioning the status quo in becoming meaningful leaders for social justice:

We have a moral responsibility to ask probing questions about who benefits from our educational policies and practices and who loses out ... The point of this critical stance is to uncover which group has the advantage over the others, how things got to be the way they are, and to expose how situations are structured and language used so as to maintain the legitimacy of social arrangements. (Starratt, 2003, as cited in Grogan, 2004, p. 223)

I realize the importance and complexity inherent to this study. I also think the goal is immense. I am trying to tell a useful story about a White, middle-class man of privilege in a position of authority who is learning how to practice a mode of leadership that explicitly places social justice for all students at the fore. In a way, I am trying to 
have an impact. I am trying to avoid being heroic, or simply a manager of personnel. Moreover, I am using a Freirean theoretical framework to analyze my data, which is new and challenging for me.

\section{The Risk of Reflexivity}

I am attempting to make a substantive contribution with reflexivity to refute most of the traditional models of school leadership I have studied in the past. What I mean by "reflexivity to refute most of the traditional models of school leadership" is the circular cause and effect inherent to this study. Although the exclusive use of traditional models of school leadership in schools today would not be helpful to my leadership, the total abandonment of all aspects of traditional ways to manage schools is not the answer either. In this study, perhaps transforming — sometimes radically— that which is "transformable" in traditional leadership to something that serves all students better could be promising. Thus, I am narrating a story, in the form of vignettes, that is moving in the direction of school leadership that incorporates communal learning and critical dialogue among teachers and administrators; of deep democracy and relationships focused on renewing teachers' ownership and agency in their own profession; and ultimately of a genuine expression of reality that is risky and not silent.

\section{Data Collection}

The stories in the next chapter constitute my data collection. They are practices, ideas, events, and conversations that have continually occurred and been collected as part of my practices as a school administrator over time. Occasionally, other experiences in my past have been incorporated that stretch back several years. In this autoethnography, the data were collected in a variety of ways. My direct experiences of trying to learn to 
practice leadership for social justice were written in formal and informal scripts; that is, notes in a professional journal. Other experiences were noted and later written up in a narrative form. Some experiences were detailed as direct literary efforts in which a naturally occurring story came from a particular experience or practice of mine. In other words, I tried to type what happened in rich detail. Still more, other data are the product of field "head notes": the constant running dialogue or memories regarding what I have hoped to accomplish in my attempts at practicing leadership for social justice. All names of people in the vignettes are pseudonyms.

The data are collections of vignettes that illustrate my attempts to learn to lead for social justice. The italic is the actual vignette from my experiences over the years and come directly from my field notes (journal, nightly write ups, head notes, etc.). Setting off each vignette is a title in bold font followed by an adjective or category/theme. There are 17 vignettes in total.

\section{Methodology}

I have tried to carefully consider a meaningful arrangement of the data collected in the study. Other than the first and last vignettes, the data are not arranged in chronological order. The starting point is the first vignette I wrote, "Lance Armstrong Analogy to Leadership for Social Justice." The ending point is the last narrative I wrote, "Dinner Conversation." The ending point in the data only represents the last data piece written. The vignettes span a lengthy time period, so it seemed logical to have these data first and last. The first shows a baseline of where I began in this study in learning how to practice leadership for social justice. The last narrative, "Dinner Conversation" represents the endpoint in the data collection for this study. I want to emphasize that the last vignette 
does not represent a "perfect accomplishment of leadership for social justice" on my part. Rather, it was simply the last time formal documentation was made in this autoethnographic story.

The data consist of 17 vignettes. The vignettes were intentionally chosen to attempt to reveal how my learning process manifested when trying to lead for social justice. They are arranged by adjectival categories. There are six adjectival categories. For each category, I have assigned one or more adjectives that I believe best describes the learning process of trying to lead for social justice. First, I give a brief explanation of the intentional choice of the vignettes included and those excluded from the study. Next, I provide a more comprehensive rationale for why the vignettes are placed into the six adjectival categories.

\section{Initial Data}

There is some small literature on qualitative data analysis explicitly for autoethnography. Partly due to the nature of autoethnographic research and data collection, as well as the relatively short time it has been an established research methodology, no detailed, explicit, step-by-step set of strategies exist for analyzing autoethnographic data. Some literature on autoethnographic data analysis addresses how to examine data, but most works state researchers should be self-reflective and "explore personal experiences when analyzing data (Ellis, 2004). Ellis and Bochner (2000) used the following:

I start with my personal life. I pay attention to my physical feelings, thoughts, and emotions. I use what I call systematic sociological introspection and emotional recall to try to understand an experience I've lived through. Then I write my 
experience as a story. By exploring a particular life, I hope to understand a way of life. (p. 737)

Part of the uniqueness and authenticity in autoethnography requires it not to be a "how to" guide on analyzing autoethnographic data, although analyzing autoethnographic data is not simply the ethnographer analyzing autobiographical data; rather it is holistically viewing the culture-sharing group and ethnographer in data collection and in data analysis (Schwandt, 2001). This relationship between the researcher, shared group or phenomenon, and data analysis is an important one and will be distinct, depending on the focus of the researcher (Anderson, 2006). Still, one must not understate the extreme difficulty and agonizing honesty that must occur with data analysis in autoethnographic work. Wall (2008) noted,

My experience of writing an autoethnography about international adoption has shown me, however, that autoethnography can be a very difficult undertaking because this form of scholarship highlights more than ever issues of representation, objectivity, data quality, legitimacy, and ethics. (p. 39)

The practices of self-reflection, introspection, reflexivity, honesty, and paying close attention to one's emotions are all very important when analyzing data for autoethnography. Thus, data analysis is the systematic search for meaning (Hatch, 2002). Wolcott (2001) stated this is “"mindwork.' ... Researchers always engage their own intellectual capacities to make sense of qualitative data" (p. 148). In the following paragraphs, I attempt to make explicit how I initially analyzed the data. 


\section{Toward a Method of Data Analysis for Autoethnographic Data}

Based on what I have read and researched on data analysis for autoethnographic data, I decided to use the basic method from qualitative research data analysis, constantcomparative analysis (Glaser \& Strauss, 1967). For this study, I considered my entire data set to identify underlying themes present (Coffey \& Atkinson, 1996; Miles \& Huberman, 1994). I attempted to analyze the data deductively, assigning two labels of "believability" and "painful authenticity"; then inductively, looking for themes to emerge from these two categories (Glaser \& Strauss, 1967).

The data were sorted and analyzed as an entire dataset. Originally, there were more than the 17 vignettes in this study. I conducted multiple readings of all that I had written over the years. This is when I first assigned the labels of "believability" and "painful authenticity." I had to narrow down the many vignettes written over the years to a manageable number. More importantly, in this narrowing process I attempted to try to reveal an honest depiction of how the learning process manifested in trying to practice leadership for social justice. I now explain in greater detail what I mean by assigning the initial deductive coding labels of believability and painful authenticity to the vignettes.

\section{Believability and Painful Authenticity}

I begin with the label believability. While reading and reviewing all vignettes, I asked myself a series of questions regarding the believability of the vignettes. Because I am the author of the data, I thought it reasonable to begin with the question, "Do I believe this is how it really happened?" For example, after reading a piece of data regarding an interaction with a teacher, I thought back to the time it occurred and tried to recall and reconstruct if indeed that is what had happened. I checked my notes as I reconstructed the 
particular dialogues and compared them with the label of believability. Next, I asked "Do I believe this still holds the same weight now as it did when I wrote it?" In other words, did I capture something that "really happened" that day/time? Given what I was doing, was it meaningful back then? Was I writing my experiences of trying to learn how to practice leadership for social justice accurately and honestly? This was a difficult first step in the initial analysis of the data, as I did not want to think I was inaccurately describing my learning process. Examining my writings for inaccuracies and inconsistencies was challenging, as I wanted to believe I was accurately portraying events as they occurred in the past. It was difficult to ask myself these questions, but they had to be asked.

The next label I used in the initial analysis of the data was painful authenticity. What I mean by painful authenticity is that data were deliberately chosen to reveal what my learning looks like. In considering myself a lifelong learner, I am essentially a student through my life. I learned, and continue to learn, more about myself and being a school administrator because of the work I have conducted in this study. The drawback sometimes is that learning can be very personal. There are personal risks involved in learning. By revealing oneself as a learner, especially in written form, there is a risk of being viewed as a failure, or at least being judged or compared to a particular standard. This may not always be the case, but it is, at times, the perception when one opens up and explains a learning process.

I use the label of painful authenticity when initially analyzing the data. I asked myself questions such as, "Do data accurately portray my learning to practice leadership for social justice in its entirety? Do the data paint a complete picture of "learning," even 
though that picture is not what I want? Do the vignettes show various aspects of my learning-moments of encouragement, disappointment, and frustration? Does the learning show a real person (me) and all the complexities, uncertainties, impediments, and shortcomings that go along with learning something? Because I wrote up this one experience, does it mean it happened only once? Does it recur? Does my learning to practice leadership for social justice reoccur?" These questions, like the ones for the code believability, are difficult to ask. The questioning required constant analysis and referring back to the data, each time with new insights and a painful authenticity, sometimes wrenching, self-reflection. After selecting data pieces that seem to fit the labels of believability and painful authenticity, I analyzed the data to see if any recurring themes emerged.

\section{Moving Toward Settling on the 17 Vignettes}

Including all original vignettes would not have told a coherent story of my experiences. After reading each of them, I narrowed the analysis down to about 20 pieces to examine further. I read the 20 again and made note of what seemed to be good examples of believability and painful authenticity; of what the learning process looked like in trying to practice leadership for social justice. The pieces I chose seem to be the best representation of what I was experiencing in learning to practice leadership for social justice. These vignettes were not necessarily one-time occurrences. The vignettes appear essentially the same way they were originally written. The next part in the initial data analysis was more complex.

As the deductive codes of believability and painful authenticity seem to naturally go well with the vignettes, the 17 data vignettes that were initially analyzed and included 
bore some recurring themes or rough patterns. Some explanation is needed as to the meaning of recurring themes.

\section{Why Vignettes Were Included; How Recurring}

\section{Themes and Painful Authenticity/Believability are Related}

Once I was able to code all data by painful authenticity and believability, I began to reread the data for more themes to emerge. Some recurring themes emerged. Because autoethnographic data analysis can be messy (Alexander, 2003), I continued the process of returning to data and reanalyzing under the two deductive codes of painful authenticity and believability.

By recurring themes, I mean a "theme of learning" that emerged upon further rereading of the data, and constant, sometimes painstaking, comparisons and reflections to what I was learning at the time the data were written. During this time of data analysis, I sought patterns that recurred. I was unable to answer questions as to why such patterns recurred during this portion of the data analysis. It seemed apparent that certain recurring themes were emerging as patterns. I could not be certain they were a "theme of my learning" at the time but I knew they were painful to read over and over. They exposed a vulnerable self (Ellis \& Bochner, 2000), which convinced me something "believable" was emerging. The following are some examples of recurring themes, but they are not the ones that I finally settled on. I eventually transformed themes into adjectival categories.

For example, one recurring theme in the vignettes is the use of data in dialoguing with teachers and staff regarding issues of social justice in school. Several vignettes included descriptions of my use of all types of data to try to lead for social justice. In each of the vignettes, "My First Real Attempt at a Team Meeting." and "Data Dave is 
Born.," data are a centerpiece to the overall theme of the vignettes. Another recurring theme, frustration, manifested in sarcasm, anger, and short-temperedness. This is clearly evidenced in the vignettes "Sarcasm Is Not Effective. People Want Me to Make a Decision.” and “I Don’t Know What I'm Doing. Sarcasm Doesn't Work.” In several vignettes, I used sarcasm or was upset as I tried to practice leadership for social justice. I did not analyze more deeply at this time to try to figure out the origin of my frustration; however, that may be evident. Deep analysis of such behaviors as sarcasm did occur later and will be discussed in later chapters. Finally, I continued to analyze back and forth between the codes believability and painful authenticity, checking for recurring themes as part of my learning process of trying to be a better leader for social justice.

\section{My Positionality and the Initial Data Analysis}

As a White man of privilege in a position of authority, it is absolutely essential that data in this study reveal an honest account of how it manifests to try to learn how to practice leadership for social justice. Data must be vetted through believability and painful authenticity because it is hard to believe a White man of privilege in a position of authority can lead for social justice in a school. This needs to be questioned. By attempting to continually scrutinize my data through believability and painful authenticity, I was forced to include data that revealed unsuccessful attempts at practicing leadership for social justice. This was important in choosing the data to include in this study. It was necessary to ask if a White man in a position of power could practice leadership for social justice in an affluent, mostly homogeneous suburb. This is why such vignettes as "I Question Myself." and "Still Struggling With the Who, How, and Why of Leadership for Social Justice." appear as part of the data. I believe these types of data 
move toward an honest depiction of how it manifests to practice leadership for social justice.

Some reasons have been given as to why data were included. In the following paragraphs, a brief discussion addresses data excluded from this study.

\section{Why Vignettes Were Excluded}

The data consist of 17 vignettes, however, it is important to note that not all written vignettes were formally coded. There were vignettes that were excluded prior to the initial data-analysis phase of this study. It may be best to describe how these data were chosen with examples of vignettes left out or not chosen to be included in the study. Following is a summary of vignettes not included in the 17.

One of the vignettes not included was one on which I changed the title a few times in an attempt to reflect what was happening in the story. The first title was "Project-Based Learning," a take off on a popular, sometimes faddish, instructional practice. After working with this vignette over a period of time, I changed the title to “The Moral Use of Power." Succinctly, this vignette was about working directly with students in an attempt to lead for social justice.

The vignette featured three students, one Latina, one African American, and one White student. As the first title indicates, I tried, at some level, to make each student a "Project." This is not unusual, as other administrators with whom I work devote extra time to form solid relationships with particular students. I had a solid relationship with all three students. I wanted to assist in their academic improvement. Two of the students faced serious academic challenges. The Latina student had an IEP and was placed in a self-contained resource room. The White student missed more than 100 days of school 
thereby putting him in grave danger of not passing any of his classes. He was also a student receiving free and reduced-price lunches.

Because my label "project" stirred up enough negative connotations in my own mind, I decided to change the title to "The Moral Use of Power." This title seemed to better match what I was really trying to accomplish, which was to describe the use of my position as administrator to help the students academically. One such use of my position was to allow the students unfettered access to my office. For example, I detailed in the vignette how the White student, Jim, would be allowed to carry a laminated, signed office pass from me. This pass could be used to visit me-should he need to-during the day. One of Jim's difficulties when he did attend school was that he tended to get into trouble. I made an arrangement with him and said he could remove himself from a situation he knew would lead to getting in trouble. Essentially, the office pass I issued him gave him this ability. The Latina student would use her pass when she was experiencing some difficulty translating from Spanish to English.

Although this vignette may have been promising in showing a glimpse of the learning process in trying to practice leadership for social justice, it was, like many others, not included for two main reasons. First, there was little or no interaction with teachers regarding the students. That is, there was little or no dialogue with staff. Second, there was neither explicit nor implicit dialogue on issues of social justice such as race, class, gender, or ability/disability with any students or teachers.

At some point during the analysis of the data contained in this particular vignette, I came to the conclusion that it did not seem to "fit" with what theoretical literature says is leadership for social justice. I had to question myself as to whether I was truly 
improving the life chances of those students who hailed from traditionally marginalized groups (Larson \& Murtada, 2002). I concluded that giving carte blanche office passes to students did not reflect my overall learning process in trying to lead for social justice. Finally, for this particular vignette, I came to the conclusion that perhaps the only reason I wrote up this vignette was because I happened to be working with an African American (albeit minimally), a Latina, and a White student.

Other vignettes were similar to "Moral Use of Power" and not included for the similar reasons. Another vignette not included detailed my dialogue with community members regarding social justice. This would appear to have been useful as it contained explicit dialogue regarding social justice; however, after much analysis it was not included because the political tone of the vignette seemed too far removed from the classroom, teaching, and learning.

I asked myself many times when writing notes/narratives/stories from my experiences whether my experiences in trying to practice leadership for social justice were the data or the data were the experiences. For example, when I was analyzing my data I felt compelled to ask whether an experience happened the way my writing depicted it. I greatly wanted to discard some pieces of writing, as they seem embarrassing. Likewise, I wanted to keep pieces I knew were not realistic or part of an overall recurring theme. I wanted to keep a vignette because it depicted me as being more successful at leading for social justice. One vignette that stood out as not realistic but seemingly favorable to portraying me as a good leader for social justice was one titled, "The Apartment Complex." 
In this vignette, I detailed an apartment complex in our affluent suburb where many students live who receive free and reduced-price lunches; perhaps the most transient sector of our school district. A student named Will moved to our school district and lived in the apartment complex. I got to know him well and discovered his love of office supplies. Will loved examining, gazing at, taking apart, and reassembling all types of pens and mechanical pencils. I discovered he would work harder in school and to better his behavior if a few office supplies were available to him. Soon enough, we had a bona-fide behavior program, and Will's grades and behavior improved. I remember that teachers and staff thought fairly highly of this; I was able to "reach" an at-risk student. The vignette also detailed something about wanting this to be some sort of exemplar in leading for social justice. This was a one-time occurrence. The theme in this vignette, when compared to all data collection over time, does not recur.

In sum, the story I wrote made me look like a Pied Piper, giving away gifts in exchange for one's upward social mobility through academic achievement and good behavior. In contrast, this particular vignette could have been useful to include, as I suspect it may be a typical response from any White male school administrator in a position of power. We tend to reduce social justice to a stimulus-response arrangement whereby those in power (me) over others (marginalized students) are able to quantify the good they do. By trying to sort through the data with painful authenticity and believability as critical lenses, choosing to not include such vignettes as "The Apartment Complex" and others, I believe, added a closer, more honest portrayal of how the overall learning process explained practicing leadership for social justice. 


\section{Reading Autoethnographic Writing-Repeatedly}

Writing autoethnographic research requires careful self-analysis that can be painful and revealing. It can reveal a vulnerable self (Ellis \& Bochner, 2000). One way to closely analyze data in this study was through repeated readings of the vignettes. Analyzing oneself is difficult and painful. It is difficult to be critical of oneself. It is painful to self-criticize, as this would imply less than excellence in one's performance. Trying to analyze the vignettes was challenging on at least two fronts. First, reading something one has written in the past is uncomfortable. As time goes by, the hope is one experiences professional learning along the way. This learning can be reflected in writing. Not noticing any learning in one's writing could present the frightening possibility of emotional and professional stagnation. Therefore, to look back and read about oneself in the past, assuming there has been learning, can be uncomfortable. One does not want to read how immature one was in the past, or the mistakes one made. It is emotionally painful to read how naïve I was just a few years ago. However, it is equally painful (but somewhat informative) to think that in 5 years I will look back on the present time and again see ignorance, naivety, and immaturity. Thus, while analyzing oneself through writing can be painful, it can equally be a powerful learning experience.

\section{Implications for Self-Analysis Through Repeated Readings}

Getting beyond the initial shame of reading one's writing, and reflecting on learning or the lack thereof, can be an extremely powerful and transformational process. Much of the literature on educational leadership focuses heavily on the "Top Ten Things Principals Can Do to Turn Around Schools." Most often appearing in these top-10 lists are traits and characteristics associated with traditional forms of leadership such as 
charisma, decisiveness, problem solving, and efficiency. An example is the work of Marzano, a prolific author who is frequently cited in literature on educational leadership. Marzano has written extensively about "what works in schools." In a highly publicized book, School Leadership that Works; from Research to Results, Marzano, Waters, and McNulty (2005) used a meta-analysis of 69 studies of hundreds of schools to formulate the 21 responsibilities of the school leader. These 21 responsibilities Marzano et al. have linked to student achievement and include such behaviors as situational awareness, flexibility, discipline, outreach, monitoring/evaluating, culture, order, change agent, focus, and contingent rewards. Similarly, Cotton (2003) listed 25 principal behaviors associated with factors such as student achievement and attitudes, teacher attitudes, behaviors, and drop-out rates. Some principal behaviors included the following: safe and orderly environment, vision for high levels of student learning, self-confidence, responsibility, perseverance, visibility, and accessibility (Cotton, 2003). Rarely appearing in the educational-leadership literature is the kind of self-reflection used in this autoethnographic study. In this study, I believe critical self-reflection through the use of the methodology of autoethnography may lead to learning to be a better leader for social justice in schools.

Social justice in society addresses equality and a fairer distribution of resources. Similarly, leadership for social justice in schools addresses equity and fairness. One particular aspect of social justice in schools addresses administrators working to assist all students to succeed. That is, although many students may adequately access a school's curriculum, many students may not. For example, students of color, students receiving free and reduced-price lunches, students learning English, and students with an IEP are 
not achieving at the same rate as their white, middle-class counterparts. Leaders in schools, working for social justice, work toward a more just learning environment for all students.

Given that schools can be more than just learning places_-places in which revolutionary social change can be realized for all students-it may be appropriate to use a Freirean lens to view data in this study. Freire was a revolutionary educational theorist who grew up in poverty in Brazil. As an adult, Freire's work centered on helping poor people liberate themselves from oppressive social structures. For example, Freire was heavily involved in adult literacy (Shaull, 1970). Today, preservice teachers read and study Freire's (1970) theories and ideas, such as conscientização, "banking," and dialogics in teacher-preparation and graduate programs. In contrast to traditional leadership, leadership for social justice in schools could be an important conduit to move schools toward a framework of equality; especially its call for democratic relations and honest dialogue regarding social problems. Thus, Freire's (1970) theories seem to be an appropriate theoretical lens through which to view data gathered on social-justice leadership practices in this study. 


\section{CHAPTER IV}

\section{THEORETICAL FRAMEWORK OF A FREIREAN LENS ON THE DATA}

This chapter describes the data. The data were collected in first-person vignettes and initially analyzed through repeated readings and self-reflection. At times, this was a painful, but meaningful process. Settling on the 17 vignettes to include (and exclude) involved a process as well; one I will discuss, as this was an important piece in arranging the data in a meaningful way. Trying to understand the data and find meaning was difficult and time consuming; however, I believe the result is an authentic portrayal of my experience in learning to practice leadership for social justice. Much attention and discussion will be focused on the use of the theoretical framework of a Freirean lens. I propose the use of a Freirean lens for a theoretical framework because it seems to fit well with the topic of leadership for social justice and methodology of autoethnography. I use the theoretical framework of a Freirean lens to analyze the 17 vignettes by way of useful Freirean concepts under dialogical/antidialogical cultural action. These concepts include banking, manipulation, fear of freedom, paternalism, divide and rule, false generosity, problem posing, conscientização, praxis, and incompleteness.

By analyzing the data through a Freirean lens, I demonstrate how learning to practice leadership for social justice manifests in a school. The theoretical framework is based on Freire's work Pedagogy of the Oppressed (1970) because Freirean theories of dialogical and antidialogical action seem to fit with the topic of leadership for social 
justice as well as the autoethnographic writing approach-due in part, I believe, to the need to critically examine one's actions as a school leader. First, I provide a brief overview of Freire's life and work. I begin by defining and explaining various Freirean concepts from Pedagogy of the Oppressed such as false generosity, banking, dialogical/antidialogical, conscientização, and problem posing; I then use the specified Freirean concepts to examine my practice of leadership for social justice. Next, I draw on the implications of my analysis to the role of administrators in U.S. public schools. Given the meaning and value of leadership for social justice, I pose questions about how one might resolve those points I have illuminated through the use of the Freirean lens of analysis. The goal of this study was to answer the following question: What does learning to be a leader for social justice look like? After narrowing the focus, through the use of Freirean terms, I use the Freirean theoretical framework as a lens to view the data presented to draw conclusions from the analysis.

\section{Introducing Freirean Concepts}

To introduce Freirean concepts, I first present an overview of how they will be used in this study. First, it was important for me to understand who Freire was and how the author came to develop a philosophy on education, who influenced Freire's thinking, and what important Freirean concepts one can apply to education. Freire's ideas and concepts about being more fully human through authentic liberation brought on by critical dialogue are important to recognize and apply to this study.

Freire was born into a middle-class family in Recife, Brazil in 1921. Because of the world economic depression of 1929, Freire's middle-class family was subjected to acute poverty. Perhaps because of this exposure to poverty early in life, Freire dedicated 
his life to bringing about changes to improve the lives of those living in poverty (Shaull, 1970). The development of Freire's ideas and concepts were influenced greatly by a number of thinkers including Buber, Sartre, Marcuse, Schaff, Fromm, Aronowitz, and Hegel, as well as many French philosophers (Blackburn, 2000).

One important concept Freire borrowed from Sartre and others is ontological vocation, or the calling to become more human. Freire (1970) explained that "humans, unlike animals, have the capacity to consider the world, and, hopefully, help reform the world through one's actions" (p. 125). The reflection and action in reforming the world is what Freire called praxis (Freire, 1970). Praxis is an important concept in the Freirean view of the world. According to Freire, through praxis, oppression can be alleviated. It may be the only way oppression can be alleviated. Freire (1970) stated,

Any situation in which 'A' objectively exploits ' $\mathrm{B}$ ' or hinders his and her pursuit of self-affirmation as a responsible person is one of oppression. Such a situation in itself constitutes violence, even when sweetened by false generosity, because it interferes with the individual's ontological and historical vocation to be more fully human. (p. 55)

Human liberation was at the center of Freire's theory of education. This theory identified the oppressed and an oppressor. Freire asserted a dialectic analysis, because without it one can focus exclusively on the oppressed without recognizing there must also be an oppressor. Human liberation is the aim to resolve the dialectical contradiction of being people but living in oppression. According to Freire (1970), social situations may present themselves as the dialectic oppressor holds power over the oppressed. Without a resolution, the oppressed can take the role of the oppressor's consciousness and be the 
oppressor (Freire, 1970). This then becomes the reproduction of oppressive relations. Freire sought not to have this cycle repeated, but rather the oppressed would become aware of their situation through conscientização and liberate not only themselves, but the oppressors as well (Freire, 1970).

Concepts from Pedagogy of the Oppressed may be used as part of the lens to analyze the data in this study. The following is a brief discussion of Freirean terms (based on Pedagogy of the Oppressed, 1970). False generosity occurs when the oppressor moves to isolate the suffering of those being oppressed and alleviate their suffering. This type of help does not empower the oppressed, but only temporarily addresses the situation of suffering until the oppressor pulls back. This gives the appearance of a compassionate response without altering the fundamental structure of the relationship among people. The opposite of false generosity implied by Freire, is that of true generosity. True generosity does not simply appease the conscience of the oppressor by soothing the suffering of the oppressed. It is not temporary; rather, it works to resolve the structure of oppressive relations. Similar to false and true generosity, the next two terms are also dialectical.

According to Freire (1970), dialogue can be defined as "founding itself upon love, humility, and faith, dialogue becomes a horizontal relationship of which mutual trust between the dialoguers is the logical consequence ... which leads the dialoguers into ever closer partnership in the naming of the world" (p. 91). This dialogical cultural action is used in education to liberate. Trying to learn to practice leadership for social justice, dialogical cultural action was the ideal to which I strove in this study. Dialogical cultural action inevitably brings about situations in relationships among people that can be filled 
with tension. This tension can include disagreement, conflict, and even anger. Some of my experiences in trying to learn how to practice leadership for social justice included situations filled with tension. I believe entering into a genuine dialogue and relationships at school, in the hope of creating more equitable learning environments for all students will inevitably involve tension. It has to because each person brings a unique worldview to school with him/her.

The opposing theory/concept to dialogical cultural action is antidialogical cultural action. According to Freire, the use of antidialogical cultural action in education serves to oppress, not liberate. Antidialogical cultural action includes conquest, divide and rule, manipulation, and cultural invasion. This was what I attempted to avoid, but found myself performing in traditional leadership roles. Freire's concept of "banking" in education is the key means of antidialogical cultural action.

The banking concept is perhaps Freire's most readily understood concept in its concrete practice. This is the process in education by which the teacher deposits knowledge into the student. The teacher owns the knowledge and the student receives the knowledge (Freire, 1970). To extend the meaning of banking to this study, it could be used in the sense that the school administrator deposits knowledge into the staff. However, the alternative-problem posing—seems challenging to imagine as Freire describes it. The opposing concept to banking in education is problem-posing education. It is an approach based on the Socratic method of questioning in which the lives and experiences of the students are used as the primary content. As the concept implies, posing problems as inquiry and making meaning in learning can be more meaningful. In problem posing, people are positioned as agents empowered to act upon their world; 
engendering a fundamental transformation of the oppressed. Conversely, the banking act of depositing emphasizes a passive position. Problem-posing education can also be applied to the administrator/teacher/staff relationship as well.

The act of school administrators depositing knowledge into staff members does not fit. Banking does not fit. A school can only go so far in addressing real problems and issues through the use of banking. This would be similar to the great-man or hero theory. One person's knowledge will run out, is too narrow, and cannot garner broad-based support to address serious problems such as injustices and inequities in school. Posing problems with and among all staff members regarding these important issues is more promising. Rather than only one source of knowledge, as with banking (i.e., the administrator), posing problems empowers all involved to contribute critically and positively to the discussion. Through active-rather than passive-engagement, collaboration among many more people will increase, thereby increasing the chances of authentic change.

The last few concepts used in the lens to analyze the data are as follows: conscientização, praxis, and incompleteness. Conscientização is the awareness and critical thinking one gains to perceive contradictions in the world in hopes of asking meaningful questions on how to transform the world to be better, more equal, and just. Incompleteness is Freire's assertion that humans cannot know everything, that we continually become more human but are never complete or finished in the process. To be human is a state of incompleteness. Because we act upon our world, humans are always a "work in progress." In can become quite intimidating and overwhelming for teachers to work in this view and commit to the results. Similarly, administrators seeking to practice 
leadership for social justice have to relinquish some authority and yet are held responsible for results. This can be equally intimidating and overwhelming. Finally, praxis, as Freire argued, begins when one "reads the world" and reflects, then is moved to action to better the world. Freire also envisioned praxis as a bridging between theory and practice.

\section{The Organic Beginnings of My Data Analysis}

Trying to figure out how to analyze my data was not easy in the beginning. Analyzing autoethnographic data is time consuming and complex. I felt there was a natural connection to the theories and concepts of Freire; however, this connection was not apparent to me immediately. I needed to think and consider many different possibilities on how to identify an organic representation of the authentic connection between my data and Freire's theories. Much consideration, reflection, research, and study went into identifying an appropriate, natural, and authentic theoretical lens I could use to address my autoethnographic work and theories of social justice. Once I felt I had identified this authentic connection, I used it as my data analysis through the theoretical framework of a Freirean lens. Following, I detail what the data analysis encompassed after making this connection. It may seem repetitive, computational, or even mathematical, but it is none of these. It is an explanation of the method I used.

\section{Data Analysis Through the Theoretical Framework of a Freirean Lens}

Holistically, the data analysis went from, first, a discrete analyses of the vignettes through the Freirean lens, then a more holistic analysis of the experience of learning to practice leadership for social justice, as represented by the vignettes. The data were sorted and analyzed in several ways. I began with one complete reading with no notation. 
I did this to familiarize myself with the data. Since time had elapsed between writing the vignettes and choosing the 17 pieces, I had to ensure these were the ones to be included in the final analysis. The second complete reading was done in tandem with Freire's Pedagogy of the Oppressed. I first read my data then reread Freire's Pedagogy of the Oppressed. I took some notes during this reading, mainly on Freirean terms and definitions. I read all 17 pieces again then went back to Freire's Pedagogy of the Oppressed and chose several Freirean terms that seemed to build a theoretical framework to analyze the 17 vignettes.

I again read the individual vignettes. During this step of analysis, I carefully read each and made open handwritten notes on the hard copy. As I read each paragraph, I jotted down quick notes that included questions and comments to myself. The comment/question notations made during this stage of the analysis, like all comments to myself, were meant to assist in making sense of the data. I did not change the content of the data. I needed to be sure, however uncomfortable it made me feel, that I captured in writing what I intended to capture. For example, if I sounded brash at one point, I wanted that to stay because at the time of the writing of the vignette I was probably acting brash. This may be open to the reader's interpretation. This is to say, through my vignettes, I tried to mirror, as well as possible, my leadership behavior at the time.

I again read the individual data. This stage of analysis included another round of note taking on the hard copy of each vignette. For this reading, I made notes where I thought a concept from Freire's Pedagogy of the Oppressed was relevant. It was clear throughout this stage of analysis the most common note I made was dialogic/antidialogic. That is, I made a note next to examples in the data that seemed to show me a dialogical or 
antidialogical practice. The former, a dialogical practice, seems to fit well with learning to lead for social justice in school, but this round of note taking was quick. I did not elaborate on how I thought a particular Freirean concept specifically related to a piece in the vignette. I simply wrote "dialogical" or "false generosity" or "conscientização." I constructed a simple matrix to plot where Freirean concepts occurred in the data (see Table 1)

The final step in the overall analysis of the data consisted of one last reading of the data with an attempt to apply the Freirean concepts to the vignettes. Although I was able to apply Freirean concepts to individual vignettes (as seen in Table 1), this step involved more of an overall synthesizing of what appeared to be some commonalities in the data. Below, I summarize the process of data analysis, illustrated in Table 2.

\section{Analyzing and Organizing Data}

Analyzing and organizing the vignettes was difficult. When analyzing and organizing the data, I wanted to ensure their presentation showed a meaningful picture of my experiences. I wanted the organization to be compelling, not simply a chronological showing of events. There were many fits and starts, ebbs and flows along the way before organizing them into categorical adjectives that represent moments of learning rather than stages. In the following discussion, I explain how data were analyzed and organized. 
Table 1

Matrix of Freirean Concepts Occurring in the Data

\begin{tabular}{|c|c|c|}
\hline Title of vignette & Adjective & Freirean concept crossover \\
\hline $\begin{array}{l}\text { "Lance Armstrong Analogy to } \\
\text { Leadership for Social Justice." }\end{array}$ & Emotional /Euphoric & $\begin{array}{l}\text { paternalistic, hero, antidialogic, banking, } \\
\text { conquest, manipulation }\end{array}$ \\
\hline $\begin{array}{l}\text { "My First Real Attempt at a Team } \\
\text { Meeting." }\end{array}$ & $\begin{array}{l}\text { Emotional/ } \\
\text { Contentious/ } \\
\text { Tentative }\end{array}$ & $\begin{array}{l}\text { problem posing, dialogic, antidialogic, } \\
\text { cultural invasion, conquest }\end{array}$ \\
\hline "My First Data Road Show." & Euphoric & $\begin{array}{l}\text { banking, some evidence of my } \\
\text { conscientização }\end{array}$ \\
\hline $\begin{array}{l}\text { "I Don't Know What I'm Doing. } \\
\text { Sarcasm Doesn't Work." }\end{array}$ & $\begin{array}{l}\text { Emotional/ } \\
\text { Contentious }\end{array}$ & conquest, manipulation \\
\hline $\begin{array}{l}\text { "Sarcasm Is Not Effective. People } \\
\text { Want Me to Make a Decision." }\end{array}$ & $\begin{array}{l}\text { Emotional/ } \\
\text { Contentious }\end{array}$ & antidialogic, manipulation, paternalistic \\
\hline $\begin{array}{l}\text { "Stanford Testing, Race, and the } \\
\text { Importance of Teachers' Agency" }\end{array}$ & $\begin{array}{l}\text { Emotional/Euphoric/Cont } \\
\text { entious }\end{array}$ & $\begin{array}{l}\text { dialogic/antidialogic, problem posing, } \\
\text { paternalistic }\end{array}$ \\
\hline "Data Dave is Born." & Euphoric/Tentative & $\begin{array}{l}\text { banking, some evidence of my } \\
\text { conscientização }\end{array}$ \\
\hline $\begin{array}{l}\text { "What Do You Want Us to Do } \\
\text { Dave?" }\end{array}$ & $\begin{array}{l}\text { Euphoric/ } \\
\text { Contentious/ } \\
\text { Tentative }\end{array}$ & dialogic, fear of freedom, cooperation \\
\hline "The Tracking Debate Goes On." & Contentious & $\begin{array}{l}\text { dialogic, problem posing, paternalistic, } \\
\text { conquest }\end{array}$ \\
\hline $\begin{array}{l}\text { "It's Frustrating that Dave Doesn't } \\
\text { Answer Your Question." }\end{array}$ & Inconsistent & dialogic, fear of freedom \\
\hline $\begin{array}{l}\text { "The Manager Is in the Principal's } \\
\text { Office." }\end{array}$ & Uncertain & $\begin{array}{l}\text { paternalistic, manipulation, conquest, } \\
\text { antidialogic, false generosity, divide and rule }\end{array}$ \\
\hline "I Question Myself." & Uncertain & dialogic, my incompleteness \\
\hline $\begin{array}{l}\text { "The Reporter Gets Dave Centered } \\
\text { Again on What's Important in } \\
\text { School." }\end{array}$ & Uncertain/Tentative & paternalistic, dialogic/antidialogic \\
\hline $\begin{array}{l}\text { "Still Struggling With the Who, } \\
\text { How, and Why of Leadership for } \\
\text { Social Justice." }\end{array}$ & Uncertain/Tentative & $\begin{array}{l}\text { paternalistic, self-absorbed, my } \\
\text { incompleteness, my conscientização }\end{array}$ \\
\hline $\begin{array}{l}\text { "Intelligence Testing, Race and } \\
\text { Tracking." }\end{array}$ & Tentative & $\begin{array}{l}\text { dialogic/antidialogic, paternalistic, } \\
\text { manipulation, conquest, false generosity }\end{array}$ \\
\hline $\begin{array}{l}\text { "Teacher Swap, Teacher Agency } \\
\text { and the Teacher-as-Hero Notion." }\end{array}$ & Tentative & $\begin{array}{l}\text { problem posing, dialogic, conscientização, } \\
\text { some cooperation, some unity for liberation }\end{array}$ \\
\hline "Dinner Conversation." & Tentative & $\begin{array}{l}\text { dialogic, problem posing, praxis, } \\
\text { conscientização }\end{array}$ \\
\hline
\end{tabular}


Table 2

Summary of Data-Analysis Process

\begin{tabular}{ll}
\hline \multicolumn{1}{c}{ Data analysis } & \multicolumn{1}{c}{ Analysis action performed } \\
\hline $\begin{array}{l}\text { Beginning of the data- } \\
\text { analysis process }\end{array}$ & $\begin{array}{l}\text { I conducted two readings of all autoethnographic writings on practices of } \\
\text { learning to be a leader for social justice. }\end{array}$ \\
& $\begin{array}{l}\text { I narrowed all data (20 vignettes) for further examination. } \\
\text { I chose } 17 \text { vignettes to include in this project. These } 17 \text { seem to be good } \\
\text { examples of how the learning process manifested to practice leadership for } \\
\text { social justice. }\end{array}$ \\
& $\begin{array}{l}\text { I made some grammatical corrections, but no major modifications to the } \\
\text { original vignettes. }\end{array}$ \\
& $\begin{array}{l}\text { I reread 17 vignettes. No notation was made on this reading. Another reading } \\
\text { was conducted in tandem with Freire's Pedagogy of the Oppressed. I took } \\
\text { some notes, and chose several Freirean concepts/terms to build the theoretical } \\
\text { framework. } \\
\text { I conducted another close reading of each individual vignette and made notes } \\
\text { exclusively where I thought a Freirean concept/term applied. } \\
\text { For the final step in the analysis of data, I once more read the 17 data pieces. I } \\
\text { took more in-depth notes to try to apply the synthesis-the Freirean } \\
\text { concepts-to the data. }\end{array}$ \\
\hline $\begin{array}{l}\text { Ending of the data- } \\
\text { analysis process }\end{array}$ & \\
\hline
\end{tabular}

Analyzing the 17 vignettes in a chronological fashion, that is, analyzing them based on the date I wrote them, did not seem to give a clear picture of what was going on in learning to practice leadership for social justice. Even after applying the Freirean lens for analysis, there did not seem to be a logical, chronological progression of improvement on my learning to be a better leader for social justice. Thus analyzing these data solely by chronological order was not meaningful in attempting to piece together a potentially larger story of trying to learn how to practice leadership for social justice.

Similar to learning anything, chronological sequencing is the most obvious assumption of how one will see progression in one's learning, and seeing that progression in chronological order-a progressive narrative-is comfortable and easy. In learning to 
practice leadership for social justice, it could be argued that there is more of a need to want to view learning in chronological sequence. In certain ways, it would be satisfying to see how I could improve over time and, perhaps, come to that all important time when I could point to completion. Chronological order was not an accurate representation of my learning to practice leadership for social justice. My data in this study, I would argue, does not reveal me getting better over time. My learning in this study shows starts and stops, improvement and regression, ebbs and flows, successes and failures. These various learning experiences will be discussed in the last chapter.

If the data are viewed as stages described by the adjectival categorization and the Freirean lens, the interpretation of how the learning process manifests in leading for social justice is complicated. Moments in which positive dialogue occurred, where my relationship with staff members seemed horizontal and not hierarchical, could be described-in Freirean terms-as dialogical. However, other interactions with staff members could be equally antidialogical.

After arranging the data by the adjectival categories emotional, euphoric, contentious, tentative, inconsistent, and uncertain, and applying the Freirean lens to the vignette, there my learning process appeared to have many ebbs and flows, fits and starts, improvements and regressions. In general, there were times when great progress was made in getting teachers and staff to address issues of social justice in the classroom. Other times, I appear to be simply a manager of a school, not addressing social injustices. In the following paragraphs, I present a difficult and complicated juxtaposition of some aspects of the data that I believe are revealing. The data are categorized into 
adjectival headings but also show a dialectic of dialogical/antidialogical leadership on my part.

I am not certain if sorting the data by adjectival categories alone tells a complete story of the learning process of trying to lead for social justice. There was an incompleteness to the learning process in trying to lead for social justice. In my learning process, incompleteness was coupled with inconsistency in trying to lead for social justice. Sometimes my interactions and behavior seemed to show evidence of leading more toward dialogical cultural action. At other times, it would appear I led more toward an antidialogical cultural action. They are not stages of learning, rather moments of learning. Collectively, these moments of learning are not progressive stages; rather, inconsistent and incomplete occurrences that reveal a retreat, on my part, from leadership for social justice. Interpreting the data in the context of dialogical and antidialogical cultural action allowed for a meaningful story or learning experience to emerge that could shed more light on what the learning process looks like in trying to lead for social justice. Applying the dialogical/antidialogical lens when interpreting the data assisted in my understanding of the learning process as well.

In sum, there seemed to be two dynamics at work in the data. First, the data can be viewed in adjectival categories that show some learning-across the array of experiences-in trying to lead for social justice. Next, the data can also be viewed with a dialogical/antidialogical lens that reveals a reciprocity between my antidialogical and dialogical cultural action. In the last chapter I discuss the dialectic tension of antidialogical/dialogical cultural action and traditional leadership/leadership for social justice, to let a meaningful story emerge from the data. 
Using the Freirean lens on individual vignettes, my antidialogical interactions with staff, at times, seemed to occur simultaneously, or in tandem, with my dialogical intentions. At times I was dialogical (communicating in such a way that helped staff become more aware) and antidialogical (trying to push through my agenda and get people to think like me). Perhaps the closest parallel that can be drawn from this dialogic/antidialogic dynamic in the data is Freire's statement in Pedagogy of the Oppressed regarding revolutionary leadership (1970):

A revolutionary leadership must accordingly practice co-intentional education. Teachers and students (leadership and people), co-intent on reality, are both Subjects, not only in the task of unveiling that reality, and thereby coming to know it critically, but in the task of re-creating that knowledge. ... In this way, the presence of the oppressed in the struggle for their liberation will be what it should be: not pseudo-participation, but committed involvement. (p. 69)

In my case, it appeared I was oscillating in relationships where I was dialogical and antidialogical in communicating and interacting with staff members. According to the data, my leadership could not be completely revolutionary as I was both dialogical and antidialogical with staff members. At times, there was genuine participation that appeared dialogical. At other times, there was only a need on my part to get something done with little regard for genuine participation from staff. The promise is that my leadership moves in the direction of dialogical cultural action. Another possible way my leadership moves in the direction of dialogical cultural action is through the Freirean concept of problem posing, which will be discussed next. 
A commonality in the data was my use of problem posing, Freire's theory that dialogue is a meaningful path in bringing about human liberation for the oppressed. In several vignettes, I pose questions hoping to bring about critical thinking among staff members. Some vignettes vary in the authenticity of questions and problems I posed. The data indicated that at times I was sarcastic, perhaps out of frustration, when I posed questions to staff members. Other times, it would appear that I was interested in staff gaining some level of critical consciousness about social justice. Thus, some questions explicitly addressed matters of social justice. For example, in the vignette "Teacher Swap, Teacher Agency, and the Teacher as Hero Notion," the problem posed is whether teachers matter. I posed the possibility of swapping out teachers with those in the struggling inner city. Examining this vignette, it would appear that this type of problemposing dialogue did assist teachers in reclaiming their agency. According to the data, teachers seemed to think they could make a difference with all students in their classrooms. This has implications for creating more socially just learning environments in school. To some degree, Freire's theory that education for human liberation is meaningful and applicable; that teachers experienced some form of liberation in claiming their agency. Although it is difficult to determine if that became permanently part of their belief system. My interactions with teachers were dialogical, which may have led to some reflection on their part.

Another problem-posing question I used was the "All Blacks are Dumb, right?" question. At times, I seemed to ask this question out of frustration. It is a provocative question, and according to the data, I cannot be certain that it was a dialogical question asked out of mutual trust. There is a meaningful story emerging from the data about me 
trying to practice leadership for social justice. There is a sense of urgency on my part to try to bring about change in creating more social justice in my school. However, I question whether my sense of urgency is truly to lead for social justice or out of frustration, which could signal aspects of traditional leadership such as efficiency and being an effective problem solver.

According to the data, one problem-posing dialogue that seemed positive occurred in the last vignette, "Dinner Conversation." It was an alteration of the "plight of people of color question" I had asked before. This question linked the plight of people of color with that of the "glass-ceiling effect" for women in the work world. It seemed to have a small transformative effect on my colleagues. For that particular dialogical interaction with my colleagues, I appeared to be successful in communicating to them some of the "unjustness" in the world. In this case, because it was more personal, it may have been more accessible to them. According to the data, I may have assisted with the process of them becoming more aware of certain inequities in schools and society. This was a start. Although promising, the data stopped short of indicating whether my colleagues continued thinking this way subsequently.

\section{Six Adjectives to Describe the Learning Process}

I assigned one or more adjectives to each vignette: emotional, euphoric, contentious, inconsistent, tentative, and uncertain. These six adjectives emerged after long reflective readings and rereadings of the vignettes. While reading the vignettes, I tried to consider many other factors as well, trying to sort and develop the vignettes into comprehensible and accessible categories. I felt that when developing the adjectives, I came up with words that showed an honest and authentic picture of my learning process; 
but also words that were not boring. The adjectives, I feel, are authentic of autoethnographic work. They have aesthetic merit and impact, and are an expression of a reality: my reality as a person trying to learn to practice leadership for social justice (Richardson, 2000a). The vignettes do not correspond uniquely to the six categories; that is, not all vignettes fit neatly into just one category. Rather, some of the 17 can be categorized under more than one adjective. The data collected over time varied in complexity and in some incidences, simply could not conform to a single category. Even in one vignette, multiple categories emerged (see Table 3).

Table 3

Vignette and Corresponding Adjective Category/Theme

\begin{tabular}{|c|c|}
\hline Category/theme & Title of vignette \\
\hline Emotional/Euphoric & $\begin{array}{l}\text { "The Hero-A Lance Armstrong Analogy to Leadership for Social } \\
\text { Justice." }\end{array}$ \\
\hline Emotional/Contentious/Tentative & "My First Real Attempt at a Team Meeting." \\
\hline Euphoric & "My First Data Road Show." \\
\hline Emotional/Contentious & “I Don’t Know What I'm Doing. Sarcasm Doesn’t Work.” \\
\hline Emotional/Contentious & "Sarcasm Is Not Effective. People Want Me to Make a Decision." \\
\hline Emotional/Euphoric/Contentious & "Stanford Testing, Race, and the Importance of Teachers' Agency." \\
\hline Euphoric/Tentative & "Data Dave is Born." \\
\hline Euphoric/Contentious/Tentative & "What Do You Want Us to Do Dave?" \\
\hline Contentious & "The Tracking Debate Goes On." \\
\hline Inconsistent & "It's Frustrating that Dave Doesn't Answer Your Question." \\
\hline Uncertain & "The Manager Is in the Principal's Office." \\
\hline Uncertain & "I Question Myself." \\
\hline Uncertain/Tentative & $\begin{array}{l}\text { "The Reporter Gets Dave Centered Again on What's Important in } \\
\text { School." }\end{array}$ \\
\hline Uncertain/Tentative & $\begin{array}{l}\text { "Still Struggling With the Who, How, and Why of Leadership for } \\
\text { Social Justice." }\end{array}$ \\
\hline Tentative & "Intelligence Testing, Race and Tracking." \\
\hline Tentative & "Teacher Swap, Teacher Agency and the Teacher as Hero Notion." \\
\hline Tentative & "Dinner Conversation." \\
\hline
\end{tabular}




\section{Reading the Vignettes}

The vignettes exemplify how my learning process manifested in trying to learn how to lead for social justice. The vignettes constituted the data in this study. They are a collection of narratives, and should be read with an open mind. By reading with an open mind, the reader will discern I am learning something new. Inherent in all learning is failure, set backs, and obstacles. The entire project has been and will always be a learning experience. The vignettes may be difficult to read, particularly if one is looking for a manual or guidebook on practicing leadership for social justice. Similarly, they are not awe-inspiring but rather portray certain human emotions that could be considered opposite to popular notions of leadership, such as confidence, decisiveness, and hierarchy.

One possible way to read and understand the vignettes is in the context of the six adjectives and the Freirean lens. After each vignette title, there are one or more adjectives to describe the category or learning experience it most depicts. These adjectives portray authentic emotional states of being while learning something new. In this case, I was trying to learn how to practice leadership for social justice. At the end of each vignette, there is a Freirean commentary. I added these, as the Freirean theoretical framework guided this study.

My hope is that I have told a meaningful story through the 17 vignettes. I am learning to practice a way of leading that is new to me. Although the literature on leadership for social justice is extremely compelling, putting into practice the theoretical concepts of leadership for social justice is difficult for me. Sometimes I am not sure if I am practicing leadership for social justice at all. Other times, it appears, at least to me, 
that I am practicing a leadership that contrasts with traditional leadership: unheroic, subversive to the status quo, communal, democratic, and equitable to all students. In these vignettes I attempt to give narrative accounts of my experiences as a school leader that may show how the ongoing learning process manifests. Some data vignettes are in the form of stories that are typical of my attempts to practice leadership for social justice.

\section{Reading the Vignettes with the Freirean Commentary, Criticism, and Limitations}

There is a Freirean commentary following each vignette. Each Freirean commentary follows a uniform style. First, there will be a reiteration of which Freirean concepts each vignette most matches. Next, there is a brief discussion about how a particular Freirean concept occurred in the vignette. Finally, at the end of each Freirean commentary, I briefly sum what was discussed. The Freirean commentary should be read as a Freirean perspective on what occurred in each vignette. It becomes clear, when reading the Freire commentary, that the remarks focus on dialogical and antidialogical cultural action. Where appropriate, some Freirean suggestions have been included.

Some criticisms and limitations arose in using a Freirean commentary style. Some of the criticism for Freire's concepts include the use of abstract language, as well as the oppressor versus oppressed binary. Since the publication of Pedagogy of the Oppressed, many scholars have pointed out the absence of addressing gender and race as significant factors in Freirean concepts (Weiler, 1991). Criticism has been leveled at Freire as to the relevance of concepts and theories in today's complex system of education (Blackburn, 2000). However, in the Freirean commentary section after each vignette, I try to link Freirean concepts from the 1960s and 1970s to the work I am currently undertaking in my school. In some places the Freirean commentary appears to link Freire's theories and 
concepts to my leadership behaviors and actions. In other places the links may not seem as evident.

Finally, McLaren (1999), a leading scholar in critical pedagogy summed up the greatness and shortcomings of Freirean theories and concepts. In the following excerpt, McLaren elaborated on one of the biggest criticisms of Freire over the years: the lack of examples provided as to how teachers are to move from critical thought to critical practice.

Yet Freire's weakness is also a source of his strength and marks the durability of his thought. It is precisely his refusal to spell out alternative solutions that enables his work to be "reinvented" in the contexts in which his readers find themselves, thereby enjoying a contextually specific "translation" across geographic, geopolitical, and cultural borders. ... In fact, Freire urged his readers to reinvent him in the context of their local struggles. Freire writes that "the progressive educator must always be moving out on his or her own, continually reinventing me and reinventing what it means to be democratic in his or her own specific cultural and historical context." (p. 52)

Clearly, "reinventing" Freire decades later to address the "local struggles" in this study is relevant, important, and endorsed by Freire. 


\section{CHAPTER V}

\section{VIGNETTES}

\section{The Hero-A Lance Armstrong Analogy to Leadership for Social Justice.}

\section{Emotional/Euphoric}

My educational career as a school administrator started with all the right reasons and for all the wrong ones. From the outset, I would have described myself as being extremely eager to change the existing situation or status quo in education. I was anxious to be remembered as the leader who finally broke No Child Left Behind's back; who exposed it for what it really was; who saved education from standardized tests; who did the right thing and stood up for the little guy. In a word, I wanted to be the hero.

Facing the possibility of an early death, Armstrong offers a similar viewpoint on how he wanted to be remembered in his book It's Not About the Bike (2001):

I want to die at a hundred years old with an American flag on my back and the star of Texas on my helmet, after screaming down an Alpine descent on a bicycle at 75 miles per hour. I want to cross one last finish line as my stud wife and my ten children applaud, and then I want to lie down in a field of those famous French sunflowers and gracefully expire, the perfect contradiction to my onceanticipated poignant early demise (p. 1). 
Armed with recently completed doctoral coursework, passing marks on my comprehensive exams and a state certificate in administration, I wanted to descend on American public education at 75 miles per hour screaming, "Social injustice! Social injustice!" I wanted everyone (especially the poor, the oppressed, and children of color) to watch me single-handedly bring down the Goliath of NCLB then enjoy my (our?) sweet victory as the three P's (politicians, patriarchs \& privileged) scramble to fix a system broken by an unpopular, unfair and underfunded piece of legislation.

In the early stages of my short career as an administrator, it was rather simple finding what I needed to support my claim that NCLB was bad policy for students with an IEP. Nearly all preliminary searches yielded precisely what I needed to wage war and defeat NCLB. Everywhere I turned I was able to secure some piece of anti-NCLB literature. I found material on everything from the statistical impossibility of large scale numbers of students with an IEP ever achieving the status of proficient to dark and devious conspiracies the Federal government is plotting (via NCLB) to implode public education. I reviewed article after article from peer-reviewed journals that backed up my claim that NCLB went wrong somewhere with students with an IEP, that somehow at the end of the day "this subgroup" would be the antithesis of legislation originally aimed at absolutely, positively "leaving no child behind." I found information on the Internet and media outlets that were not so peer-reviewed that continually lambasted NCLB because of its Republican dominated support (even though Sen. Kennedy greatly influenced its crafting and passage). 
I had no trouble finding allies for my position. In fact, I spoke quite eloquently regarding how I knew best about what was best for students with an IEP. It didn't take me long to hone my skill in convincing anyone that NCLB was bad for our students with an IEP. Everyone jumped on my bandwagon. Teachers naturally agreed as they saw no immediate benefit to the massive amounts of standardized test preparation they were forced to do in their classrooms. University professors I e-mailed felt equally disgusted that precious instructional time is taken away from students (especially poor and minority students) to try and improve a "failing" school's status. I even found sympathy with non-education folks. I regularly would bring up the issue of fairness, standardized testing and students with an IEP. Within 15 minutes of explaining my version of how NCLB works, anyone - I mean anyone-was telling me to "keep on ridin' that road to glory and change that system for our kids!"

Unbeknownst to me, I was screaming down the administration mountain at 75 miles an hour bound for a head-on collision with uncertainty. Like the title of Lance Armstrong's book invokes something much deeper than a bike, I wasn't quite sure what my philosophy of school leadership was. I cannot say my philosophy was not about me in the beginning because it was. I wanted to bring down NCLB; I wanted to save education; I wanted to leave my mark on schools, underserved children, the oppressed and alike; I wanted to be the hero.

This was the first piece of data collected for this autoethnography. I wrote it during my first year as an assistant principal. It tells a lot about what I would like to accomplish and the orientation of leadership I planned to use to get there; however, it 
does not say much about doing anything. It is a little painful to reread. I think I sound brash in this vignette. It is also pretentious. I assumed I knew exactly what leadership for social justice entailed. At the very least, I believe it exposes my beginning point in trying to learn how to become a better leader for social justice. I appear extremely naïve. I felt it important to capture what was going on with my belief system at the time I officially became an administrator.

Freirean Commentary: From a Freirean perspective, some of the concepts I exhibited in this vignette include paternalism, portraying the hero, antidialogical (specifically conquest), and banking. Even though this learning moment is filled with emotion and euphoria, there are some insights and clues as to what I was thinking as a leader at the time. Freire's concept of paternalism seems evident throughout. In the beginning, I did not seem interested in anyone's input or ideas on how to address issues of injustice and inequality in schools. Freire (1970) associated paternalism with the culture of silence. In my emotional and euphoric learning moment, while not seemingly intentional, I may have been fostering a culture of silence; a culture that was saying a hero could perform social justice without any help.

From a Freirean perspective, there may also be evidence of antidialogical behavior, perhaps that of conquest and manipulation, in this experience. It appeared I was most concerned with my own agenda and oblivious to engaging in any form of sincere communication with anyone else. There is an absence of any attempt on my part to enter into meaningful dialogue. In a way, I am portraying some form of conquest, as I have made social injustices and NCLB a "thing" to conquer, by me, the hero. I may very well have been unknowingly manipulating people with whom I spoke. Additionally, and 
according to a Freirean perspective, my antidialogical behavior may be indicative of banking. As I tried to garner support through my rabble rousing against everything wrong in public education, I was hoping to "deposit knowledge" (my knowledge) to anyone who would listen.

In sum this vignette had some great initial intentions with a purpose to enact social justice in school, even though I was misguided. However, from a Freirean perspective, my approach to work toward equality in school was antidialogical; the emotion and euphoria may wear off and the difficult, messy, and complicated work of dialogical communication with many constituents would need to take over.

\section{My First Real Attempt at a Team Meeting.}

\section{Emotional/Contentious/Tentative}

I felt the tension as soon as I walked into the room. I wasn't sure how this meeting was going to turn out. This particular team of teachers consisted of leaders and veterans-many of whom were, and still are, department chairs with years of experience. My job was easy: Facilitate a conversation on how the team could incorporate data as part of its team goals for this year. My stance was the same for this meeting: Assist the team in moving along a meaningful path that would maximize the learning for all students. Together, we would examine, analyze and discuss student data and come up with some possible ways in which data could be used. In my own mind, I wanted the teachers to truly base their instructional decisions on data-whatever that means-rather than hunches.

From the outset, the various conversations seemed to be slipping away from me. Everyone had something to say and I wasn't so sure all the comments directly 
related to data. I told myself to just go with it, that the team would eventually get back on track and discuss data. A few comments later, and as the conversations progressed, I wasn't so sure this meeting had anything to do with data. I heard all kinds of comments; comments about students not turning in homework, or not even caring about homework, being late for class, etc. I knew these comments were unproductive. Why couldn't I simply put my foot down and stop this ventsession? Suddenly, I was taken aback by something one of the teachers said. There's no way the conversation should have ever gotten to this point. In retrospect, I blame myselffor allowing this comment to surface. The exchange went something like this:

Teacher: And what about Anudraha? She is completely lost in my class! I mean, she has no idea what is going on. She speaks like three words of English. Me: My wife spoke only three words of English when she came to this country! Teacher: No, no Dave, it's not personal.

A foreign language teacher quietly intervened and stated that there are varying levels of bilingualism in that some students spend more time in the language-reception stage before moving into the language-production stage. I walked away from the meeting feeling dejected and defeated. Questions swirled around my head. ... Was I out of line? Did I stoop to a lower level of dialogue? Is this the tough, important work of leadership for social justice? Did I destroy any chance of future dialogue? With my background of fifteen years in language acquisition, why couldn't I simply answer like the foreign language teacher did? Was it about time I let people know what I stand for? Am I too 
emotional? Am I a language-minority zealot? It was late, and I needed to get home.

I thought a good meal and great conversation with my wife would quickly erase my leadership debacle that occurred earlier at school. It didn't. The meeting, but particularly my comments, consumed my thoughts the entire evening. I kept hitting the "pause-review-play" sequence buttons in my mind. What could I have done differently? Was any good to come of the whole situation? What about the data? Couldn't I just do a mini-workshop on TPR (Total Physical Response) and effective strategies to use with ELL (English language learners) students? Should I approach the teacher? An apology? I had more questions than answers. I wrote this after being frustrated due to the meeting's unexpected outcome. This meeting was fairly typical of others I'd had with teams of teachers in the beginning. I was not getting anywhere as I did not get the sense teachers were committing to at least the spirit of NCLB. Even though NCLB has some severe shortcomings, particularly with its emphasis on accountability and high-stakes standardized testing, the "spirit" of NCLB was to close the achievement gap between all subgroups of students by race, class, ability/disability, and native language. The NCLB legislation was passed in an attempt to eliminate the achievement gap.

Freirean Commentary: From a Freirean perspective, some concepts exhibited in this vignette include problem posing, dialogic, antidialogic, cultural invasion, and conquest. From the outset of this learning experience, it is evident that I went into this meeting fully intending to participate in dialogical communication. I wanted to facilitate a collaborative, dialogical discussion that focused on hard data in hopes of assisting 
everyone to reflect deeply on their teaching practices to better serve all students. I did not achieve an awakening of consciousness in a pedagogical sense in that meeting; rather I became quite frustrated.

According to a Freirean perspective of leadership, what I was practicing may be considered antidialogical, particularly in cultural invasion and conquest, partly by me but partly by the teachers. Complaining about students and blaming them for not conforming to what we want them to do or be is a persistent pitfall in many schools. Indeed, teachers vent against students and what they are unable to accomplish. According to Freire (1970), with the possible exception of the ELL teacher, the dialogue did not approach dialogical cultural action, as no one was willing to consider what anyone else is saying. True dialogue must be open and based on collaborative learning (Freire, 1970). What was happening was some form of conquest and cultural invasion against students; one student's lived experience is even blamed and victimized. I tried to pose the problem of understanding the complexities of learning another language with a personal example of my wife's experience. From a Freirean perspective I attempted problem posing, but it was not out of a genuine concern to get my colleagues to become more aware; rather it seemed to be a strike back.

In sum, from a Freirean perspective, to best meet the needs of all students, educators must collaboratively participate in critical dialogue. The group in the vignette had the opportunity to do this but failed to do so completely. As a leader, I needed to stem off the antidialogical episodes of cultural invasion and conquest. There was no need to complain about students or their lived experiences, and I needed to say something about this. Finally, from a Freirean perspective, problem posing needs to be used in ways 
that serve to get educators to think more deeply about serious problems; not as weapons to silence them.

\section{My First Data Road Show.}

\section{Euphoric}

“This wasn't so bad!” I remember thinking to myself. Wanda asked me to sort of go on the road with her about the whole AYP/data thing. She set us up to visit the high school on an in-service day. Our mini workshop was going to deal directly with the subgroups of students not performing well in our school district. Our audience would be any teacher $K-12$ who had an interest in learning more about the achievement gap in our school district. It was short and sweet. We presented some pretty compelling data, and exposed some serious inequities on our school district. I used some of Andrew Hacker's work to help clarify just how systematically unequal schools can be, at least when looking at performance outcomes. Some of Hacker's work points to the complexities of race and class, particular in terms of the achievement gap. For example, we used a table that depicted as parental income rose, so did test scores. The table revealed this in all racial groups (African American, Hispanic, White, and Asian). Many participants naturally drew the conclusion that even though we are a high performing, affluent school district, those not performing well are unequally students of color (as well as ELL students, low income, and students with an IEP).

At least superficially, I can remember this minipresentation being fairly successful. Looking back on it now, I don't remember one single contentious moment. No one challenged us. No one was trying to make excuses. No one blamed the students. 
It could have been that people were tired and did not care. But they chose to attend our session. It appeared that everyone at least saw that an achievement gap exists in our district. Perhaps it was because I teamed up with my principal and we made a compelling argument with the Hacker material. It was hard to tell. From a social-justice-awareness perspective, it seemed like an effective start with good potential. But it ended there. What to do about inequality and the achievement gap in our district never came up during that session.

Freirean Commentary: From a Freirean perspective, some of the concepts exhibited in this vignette included banking and conscientização. Clearly, we exhibited Freire's concept of banking. I went to this miniworkshop with the purpose of "filling the minds" of attendees. In this case, I wanted teachers to be aware that there was an achievement gap in our district. I naïvely believed the only way to do this was to explicitly present to them that students of color, students learning English, and students receiving free and reduced-price lunches were not achieving academically at the same rate as their White, affluent peers.

From a Freirean perspective I needed to go deeper; I needed to ask more pointed questions about why an achievement gap exists. Perhaps I needed to push those in attendance to participate in a dialogue that included exposing the social, political, and economic reasons for such achievement gaps in the school and district.

\section{Don't Know What I'm Doing. Sarcasm Doesn't Work.}

\section{Emotional/Contentious}

Two whole days under my belt. Not sure what I'm doing. Sarcasm has gotten me in trouble before, probably will again. I ask myself, is sarcasm effective? Not 
sure. So I'm walking around, trying to visit classrooms when a teacher flies up to me and asks whether or not I think it important to get a child help if she really needs it. Of course I was a little suspicious. Of course I want to give all the help possible to a child. As it turned out, the student in need was one that just transferred from Cleveland to our nice upper-middle class suburban school. The story was she was a little rough in the beginning. Her attitude and academic performance was a little rough. So, I guess the word was that I wasn't sure when I should get the child help. This was not how I was feeling. All children deserve help, but not because they're faulty.

It was posed to me that if we could intervene early with this child, no time would be wasted. Suddenly, I had a gush of "I know what I'm doing." I went sarcastic. I said that we had it down to a science back in the day in Chicago. When I was teaching, I knew the first day (not the second) who was going to succeed and who wasn't.

I looked back in my journal and, although it's short, I saw this piece and thought it important to include. Clearly it was not appropriate to think sarcastically about knowing the "first day, not the second" about which students would be successful and which would not. This is important to include because sarcasm (either in one's own mind or verbalized) does not seem to add anything to bettering a particular situation. In this case, I was upset that someone could jump to such a conclusion and I chose sarcasm as a way to express it. One thing that concerns me more than my brash sarcasm is that I sounded like a braggart. Indeed, sarcasm got the best of me in this situation, but sounding 
like a braggart does nothing to breakdown hierarchical barriers between administrators and teachers who inhibit authentic dialogue on issue of social justice in schools.

Freirean Commentary: From a Freirean perspective, some of the concepts exhibited in this vignette include manipulation and conquest. The Freirean perspective may also suggest the brief interaction with this teacher was antidialogical. It is antidialogical because I failed to dialogically engage this teacher in a way that would have fostered open inquiry and questioning. From a Freirean perspective I may also have needed to "question back" rather than passively stand by and listen to what is wrong with the student in question.

This antidialogical interaction involved conquest and manipulation. I clearly remember this day and situation. I remember being very frustrated and impatient. I made the remark "We could figure out the first day of school who was going to succeed." out of both frustration and a lack of patience. However, I admit that it was a useful technique to gain control of the situation. Perhaps the teacher questioning me put me in an uncomfortable, inferior position. From a Freirean perspective I may have been trying to manipulate the interaction in my favor; and being in a position of authority, I was successful in silencing her with my sarcastic reply.

In sum, there may be a connection between the Freirean perspective and the sense of urgency for social justice in schools. Whereas I responded in an antidialogical way, the alternative could have been to press on, to question back, dig deeper, and use more problem posing with this teacher. However, to do this literally could mean that I am involved in dialogical discussions all day. From the Freirean perspective this may be exactly what school leaders should do, regardless of how much time each dialogical 
interaction consumes. Social justice is important work in school, but it is unclear how to reconcile the urgent work of social justice in schools with authentic dialogical interactions with all teachers at all times.

\section{Sarcasm Is Not Effective. People Want Me to Make a Decision.}

\section{Emotional/Contentious}

One of the things I've been trying to get a handle on as a first year principal is the committee work. Two days before the start of school, at the first staff meeting of the year, teachers sign up to serve on various committees. Throughout the year the committees meet. I am supposed to convene meetings for some of the committees. I have not been diligent about convening committees in a timely fashion and my staff has let me know about it.

One of the committees formed before I arrived this year deals with academic and behavior interventions. So it may be a team and not a committee. I'm not sure. It's probably on of the largest committees. At the first meeting, roughly 15 staff members attended. I had heard some grumbling in November when, after a couple months had gone by, committees had not met. I announced in a staff meeting that the reason committees had not met was my fault; that I needed to get a handle on the committee work around school. I finally convened a meeting in December.

I probably did not conduct the meeting in an efficient manner. I read over last year's file, thought about what academic and behavior interventions were all about, and made an agenda. After about five or ten minutes into the meeting, it was clear there was no clarity on what the committee was supposed to do. I spent 
the rest of the meeting trying to get a feel for where this committee wanted to go. I wanted to steer the committee in a direction that would benefit the entire school, but shortly into the meeting, it became apparent we just couldn't find a consensus on anything. Many of the teachers expressed a desire to pick up where the committee had left off the previous year. The previous year, surveys were conducted on student behavior throughout the building. According to this data, overall student behavior was pretty good except for the cafeteria and playground. This has been my experience as long as I've been in education. Children apparently do not behave as well during lunch and recess as they do in the classroom. I opened up the topic for discussion.

There were many conflicting opinions as to what the school should do about improving the behavior of the children during lunch and recess. It varied from "we should do nothing" to "we should have an elaborate training system in place for our cafeteria ladies." One teacher brought up the point that it really didn't matter to us how the children behaved in the cafeteria as no one is obligated to supervise them during lunch. Another asked if it would help if teachers ate lunch with their classes; however, she wasn't sure about the "buy in" on this initiative. Judging from the various sighs I observed around the room, I sort of felt this dialogue was not going anywhere. I asked about another touchy area, the hallway.

There seems to be a touchy subject at my school that some completely endorse while others absolutely loathe. "Zero voices in the hallway" is a touchy subject. Some staff members believe it an effective way to teach students self-control while 
others see it as an infringement on their wanting to greet colleagues and students in the hallway. Again, I went around the room asking for input on where the committee was in terms of setting such policy. And again, I received varying opinions on whether or not we should demand absolute silence in the hallway or let a little chit chat go while walking to and from classes.

The dialogue between teachers did not seem very fruitful. It didn't seem like people were asking questions to get at the root of the behavioral problems in the cafeteria, playground and in the hallways. I was a little frustrated. I didn't feel I was conducting a very meaningful meeting. I went a little sarcastic and regretted it later. After about 20 minutes of complaining and no consensus, I asked if anyone has heard gunshots. The effect was clear. Here we were complaining about how bad our White, affluent suburban students' behavior was when there really was no reference point of how "bad" it looked. I shouldn't have said it, but I didn't know how to refocus the team. The meeting quickly wrapped up after my sarcastic comment but I issued a homework assignment. They took my sarcastic comment at face value, but seemed a little indifferent at what I was about to assign. I said that our sole responsibility for the next meeting is to figure out who (what?) this committee is and where it needs to go. Judging by their facial expressions, either no one will do it or I'll have a revolution on my hands.

As usual, I walked out of the meeting feeling like I hadn't accomplished much. After all, one of the departing comments was "You know we're back to square one now, don't you. We talked and talked last year and nothing ever got done." The next day I began to receive a few e-mails regarding the meeting. Some 
teachers wanted to quit the committee while others needed to add two more cents to the conversation.

A few of the comments consisted of teachers not wanting to continue as members of the committee. They felt it a waste of time. I could understand this as they are accustomed to working hard and like solving problems. However, another major area of concern was with me. Some teachers told me that "decisions need to be made." I asked for an explanation. I sort of knew the answer but asked anyway. They never came out directly and said, "Dave, you need to make a decision." I can only infer that their wanting me to "make a decision" is what some of the teachers "really" want. Based on the dialogue after the meeting, I can only speculate that in some of their minds a "strong" leader who makes quick, fair and conclusive decisions leads to an effective way to run both committees and the school.

My standard response-because this is only one of many examples similar to this—is the following:

Me: "Well, I can go ahead and make the decision if you want, but it would be my decision."

Colleague: "Oh well, I guess they are just going to have to live with your decision."

Me: 'Yes, 'they' will have to live with my decision. But what if my decision puts you in the 'they'?

Colleague: Long pause...

Me: "That's what I thought." 
Colleague: (An attempt at saving face.) "Then you make the decision and we try it out for a year."

Me: “Wouldn't it be meaningful to attempt to work toward a consensus. Maybe to a point where at least everyone could walk away and live with whatever decision the team makes?"

Colleague: "I still think there needs to be someone making the decisions."

I went back to my office and thought about the contrast between traditional and nontraditional leadership. I though to myself, this instance probably best illustrates the contrast between traditional and nontraditional leadership. I think at least superficially, I attempted to try to accomplish a more democratic process to decision making. I cannot say that a week or so later all the committee members had committed to collective decision making. It was and still is a long process that, I believe, can better address the needs of the school. Would it be much easier and faster to make, what I think is an arbitrary decision? Although it would be likely to be faster and easier, but I do not believe it to be a sustainable process. That is, if I make all the important decisions, there is no way I can adequately represent those closest to the problem. Paradoxically, although some teachers "just want me to make a decision" I see my decision making in this type of process as unfair to the teachers.

Judging from my tone, I think I felt fairly strongly about a more democratic way of doing things at my school. It was over a year ago that I wrote this, and I still get these same comments. But I do not like resorting to sarcasm, which I find myself doing sometimes out of frustration, or sometimes because of immaturity. The democratic decision-making process is not the most efficient way of getting things done, but is 
productive because it brings to light so many more possibilities and solutions to addressing complicated problems. Moreover, much of the literature on leadership for social justice advocates a democratic decision-making process in schools.

Freirean Commentary: From a Freirean perspective, some of the concepts exhibited in this vignette include antidialogical, manipulation, paternalism, and fear of freedom, but also toward some dialogical interactions such as problem posing. From a Freirean perspective, the sarcasm I used in this vignette was inappropriate and probably antidialogical. To be certain, the sarcastic remark I used referencing gunshots was unfair and uncalled for. It was unfair and a form of manipulation and of paternalism because I knew no one in that room that day had the experience and background I did. This is to say that no one in the meeting had spent any time working in an inner-city school neighborhood where violence was commonplace. I knew making the comment would have a silencing effect; it silenced all hope of genuine dialogue during the meeting as well. Ideally, genuine dialogue could have followed my sarcastic remark had someone challenged me on it; however, I must have known—or used my position of authority to intimidate- they would not challenge my faulty comparison of inner-city and suburban schooling experiences.

From a Freirean perspective it would appear we were moving toward a dialogical experience, at least in the beginning, before the sarcastic remark. I presented a topic of discussion, that of student behavior at lunch and recess. I listened intently to what each person had to say; I believe everyone in the room was doing the same. However, based on a Freirean perspective (1970) the distinction was that we were simply discussing and not dialoging. We were talking about a problem, but there did not seem to be any genuine 
attempt at understanding the problem at a deeper level. Compounding this superficial attempt at dialogue is the idea that the topic of student behavior at lunch and recess may not have much significance with social justice. On the other hand, perhaps silencing children during their break time is an issue of social justice.

Finally, from a Freirean perspective there was at least one attempt, at the end of the vignette, to use problem posing. Although still experiencing frustration, I did want to pose a scenario of what would happen should the leader be in charge of making all decisions. I posed this scenario to the teacher, but stepping back and looking through a Freirean lens, one must ask why teachers would want decisions made for them. From a Freirean perspective, this may be a fear of freedom in which people are fearful to realize their own awareness, influence, and agency in such a way that could be meaningful and impactful to students.

In sum, from a Freirean perspective my novice attempt at dialogical cultural action in this vignette was an important start. According to the Freirean perspective, sarcasm is not effective in initiating genuine, open, and honest dialogue. Problems about which dialogue should occur must get at the broader social, political, and economic underpinnings directly related to education.

\section{Stanford Testing, Race, and the Importance of Teachers' Agency. Emotional/Euphoric/Contentious}

"So all Black kids are dumb! Right?" I said trying to get my point across about using the Stanford test for placement into accelerated classes. Mr. S. looked at me quizzically. I wasn't attacking him, nor did he feel I was attacking him. I think he 
was just a little thrown off by my bluntness. I blurted out the statement after 20 minutes of what could be considered solid professional dialogue.

He made several great points during our exchange. He stated that in his tenure, all students "rightfully placed" into accelerated classes always are the ones with the highest Stanford scores. He went on to say that he has noticed throughout the years that even though students with a Stanford score of 75 percent but straight A's and high teacher recommendations, still do poorly in his class. I asked about students that just happen to be poor standardized test takers. To no avail, he was not convinced. I asked about the reliability of the Stanford. Still, he came back to the point that there is indeed a direct correlation between a Stanford percentile score and achievement in accelerated classes. I was inching closer to the atom bomb statement but I wasn't there yet. I was, however, running out of counterarguments.

I started going down the path of what the Stanford has historically meant for some and not meant for others. I asked if he was familiar with how the Stanford was first normed, how questions were manipulated so Native Americans would be confused and not able to answer them and that this was all to ensure White supremacy. He reeled me back in and reminded me it was 2008, not the turn of the century ... the last century. Mr. S wasn't buying what I was selling. I didn't know what else to do.

We use the Stanford/Otis Lennon Test as one of the criteria in our district for placing students into accelerated track classes. At the early elementary level, it's used to screen students for possible placement into the gifted program. At fifth 
grade, students scoring in the $90^{\text {th }}$ percentile in language arts and the $95^{\text {th }}$ percentile in math are seriously considered for accelerated placement the next year at the middle school. Some students have already been in the accelerated math or language arts program for some time before coming to the middle school. Some of the other criteria for acceptance into accelerated classes include grades, teacher recommendations, work ethic, love of math/reading etc. What gets tricky sometimes is when a student has all but one of the criteria for placement into the accelerated track class. Many times, the Stanford percentile score is the only criteria holding a student back. My interactions with teachers and staff on the use of the Stanford percentile score for this purpose has brought up a whole host of other complex issues surrounding such "ability" tests as the Stanford.

"So all Black kids are dumb! Right?" I said it again. I had to say it again. Now I had to explain it; and his again quizzical look asked for an explanation. I laid out my logic argument. I said if what you're saying is true, and we don't deny the infallibility of the Stanford test, there's really no way African American students should be placed into accelerated classes-at least at the same rate as their White counterparts. I went on to say that students of non-native English background and with cultural heritages other than the mainstream are also more susceptible to not being placed into accelerated classes based on a Stanford score.

Mr. S didn't dispute my reasoning. In fact, he agreed with it. He said he knew that students of color and non-native English students were underrepresented in accelerated classes both here at our school as well as nationwide. He gave me the 
impression that he was fully aware of the inherent cultural and linguistically biases built into the Stanford, or any standardized test. But then he went down a familiar path. One that we all travel.

Mr. S calmly stared at me with a look of contemplation. His next comment was not to be off-the-cuff or vindictive, but rather he began to give reasons why such inequalities exist in school. I have to admit, these are the moments I yearningly wait for. Not because it's some deep, philosophical conversation that's stimulating, but because it represents thoughtful professionals trying to do the "good work" of educating all students. Mr. S started by saying he did not imply that "All Black kids are dumb!" However, he did think that students of color did not score as well on the Stanford for a variety of reasons, one of which is directly correlated with home life. He claimed that if a child does not have academic support at home, he's really doomed at school. Mr. S acknowledged that our mostly all-White student population does well on tests because they come to school more academically prepared and receive the kind of support from home that fosters high performance and academic excellence in school.

I thought to myself, "Aw, screw it. Is it worth it?" I contemplated my next move. "Is it worth dropping another atom bomb?" I questioned myself. I mean, I could have split hairs for the rest of the period, but we only had a few minutes left. I could have whipped out some demographic data that suggest there is nothing wrong with Black families. I decided to do what I've done in the past; which is cut to the chase, drop an atom bomb and see what happens. I mean, at this point, it seemed like the temporary barriers of hierarchical teacher- 
administrator relationship had been broken down. (Although with Mr. S I'm not so sure he's ever recognized some fear factor in the hierarchical teacheradministrator relationship thing.)

The bell did ring and it was the end of lunch, a very busy time. So, since Mr. S decided to do a commentary on life in American society and public schools, I did, too. I dropped the royal A-Bomb. "Well, then, I guess if you're poor or Black or both in a U.S. public school, you're doomed, eh." I did it. I know it was a farreaching, generalizing, all-encompassing, sweeping commentary on American society, but, I guess you have to start somewhere.

This interaction with Mr. S made me think. I'm not so sure what Mr. S walked away with from our minidialogical workshop on race, class, ability, and standardized testing. I think we both knew what each other was trying to accomplish, though. He wanted the best and the brightest in his classes, and he felt that the use of the Stanford test was the way to justify those ends. I, on the other hand, was looking to point out a particular educational structure that may need reexamining, especially as the face of U.S. schools change and educational iniquities persist by race, class, native language, and disability. I'd had other similar conversations with both Mr. S and other teachers on the very same topic. Many have proceeded in the same way. What's frustrating for me is I don't know what my effect on people has been. I can't really say that I know Mr. S is a changed man. Maybe his belief system has been affected by our interactions, but maybe not. I've thought about how I've changed, though. It seems to be getting easier for me to participate in these types of conversations. Because I am 
explicitly talking about equality in education, the easier it seems to be to orient myself toward leadership for social justice. Almost like the old saying "practice makes perfect" (although I'm far from perfect). I think about how effective peer coaching and cooperative groups are when students are asked to teach something to their classmates. And like another old saying, "If you really want to learn something, teach it." The more I engage in meaningful issues surrounding social justice and equality in school, and the more I explicitly say it, the more I know I'm changing as well as possibly assisting others to change as well.

An unintended outcome of my interaction with $M r . S$, as well as the interactions I've had with other teachers and staff on this topic, has been one of “innocent shifting of agency.” By this I mean teachers (and administrators) sometimes do not realize or understand the enormous influence we have on children. It's an influence that can greatly help or hinder student achievement. Thus, the shifting of agency is something we all do. Teachers can be quite modest folk, so any credit or kudos directed toward them can often be deflected. But where do we deflect? Like a mirror checking the sun's rays, they have to be deflected somewhere else. So, what I often hear is teachers receiving a compliment on how well a particular student's grades are, and in response the teacher states, "She's a hard worker. She deserved the A." Sometimes when I hear a teacher trying to deflect his/her agency, I counter the deflection. If a teacher tries to deflect credit for a high performing student in class, I say, "So the teacher has nothing to do with Hannah's good grades?" It follows a similar pattern each time I say it. The teacher will say "Well, Dave, come on, it's all part 
of the overall equation of a successful student. ... Parents, student work ethic, teacher, and yes, the administration. They're all important." To which I then state, “Wow, you teachers really don't know how much influence you have, do you?" The "supportive parent deflection" is very popular.

I wrote this story about a week after I had this conversation with Mr. S. I have added and modified material in this vignette along the way, as many similar conversations have taken place with many different people since my interaction with $\mathrm{Mr}$. S. In fact, over time, there have been near duplicates of this very same dialogue on the very same topic. It is a story that continues to happen repeatedly.

Freirean Commentary: From a Freirean perspective, some of the concepts exhibited in this vignette include antidialogical/dialogical, paternalism, and problem posing. From a Freirean perspective this vignette has great opportunities for genuine dialogue; in that it contains a series of interactions in which all the "pieces are in place" for substantive, open, and honest dialogue that can attack the problem of ability tracking that continues to plague education. There were sincere opportunities for dialogue as this topic had direct implications for this particular teacher's classroom: receiving students into the classroom with less than high scores on an ability test.

Freire's (1970) concept of problem posing is quite apparent as I posed questions that required more than a superficial response, and the content of those questions directly addressed social justice. However, I grapple with not going far enough with problem posing. The interactions seemed antidialogical, but maybe a little different from the Freirean sense of antidialogics. By this I mean the teacher and I are posing problems to each other but not really trying to see each other's points of view. I may even be banking 
a little in that I am imparting knowledge about the history of standardized testing. I need to ask myself what exactly is my responsibility with the level of knowledge I need to impart to sheltered suburban teachers? Can problem posing alone accomplish critical consciousness? Freire (1970) stressed the importance of contextualizing dialogue so that participants can critically consider their situation and understand the source of the oppression. Although suburban teachers may not be the ones oppressed in this situation, their critical awareness and understanding about ability tracking, as well as their influence as a classroom teacher to make a difference, could be meaningful in challenging the status quo.

In sum, from a Freirean perspective there were opportunities for in-depth dialogue. It is apparent that we needed to collaboratively go deeper in the dialogical process to fully realize Freire's concept of dialogical cultural action and authentic awareness of social injustices. By listening and considering each other's worldview we may have begun to gain conscientização.

\section{Data Dave is Born.}

\section{Euphoric/Tentative}

I'm not sure exactly when Wanda (the principal) made the call to "make me good at something." Maybe she saw a particular strength in me. From the outset, Wanda gave me the responsibility of working with the staff in terms of getting teachers to understand [adequate yearly progress] AYP, NCLB, and data. It was a rather huge undertaking as we had not made AYP at the middle school the year before I arrived. Wanda believed this important. She knew accountability was here to stay, so better sooner than later the staff embraces it. Another possible 
reason Wanda placed this responsibility on me could have been my interest and background in working with students with an IEP. Nonetheless, I knew it would be a daunting task to try to get all teachers and staff not only knowledgeable on $A Y P, N C L B$, and data, but marching in the same direction. The subgroup/cohort not to make AYP in the middle school in my district was students with an IEP.

I busily got to work when Wanda gave me the nod to work with the staff regarding $A Y P, N C L B$, and data. I had the opportunity to present for about 20 minutes at the very first staff meeting. I was the brand new assistant principal. I was boring. I had to go over all the mundane lingo such as "safe harbor," "weighted aggregate target," and nasty things that happen like "reconstitution" when a school does not make AYP for five consecutive years. With over 70 teachers in the meeting, neither time nor interest was devoted to any interactive dialogue. It was something I needed to do, I guess, but I could tell what the teachers really wanted was to get back to their rooms and start setting up for the first day of classes.

Although I knew the teachers didn't walk away with much from my AYP presentation in that first staff meeting, I would have more opportunities to work with smaller groups of teachers in the future. Since I had already broken ground on the subject, I had a starting point. Shortly after the beginning of the school year, my first year, I began to attend team meetings. These teams were organized by grade level and usually included one of each of the following teachers: language arts, math, science and social studies. 
This vignette described events in my first year as an assistant principal. It seems a little presumptuous because it places me at the center of getting my school out of AYP trouble. Nonetheless, there seems to be something about student data that can have the potential to draw in and engage staff members. It may be presumptuous to state that data and evidence on student performance do not lie, however, as a starting point for critical discussions on the achievement gap between particular groups of students, it does seem effective to present data for professionals to consider. Analyzing student-achievement data, having dialogue surrounding that student data, and trying to keep emotions at bay (particularly mine) may be a meaningful learning experience for all. However, as will be evidenced in the next vignette, it is difficult to remain emotionless at all times regarding issues of social justice.

Freirean Commentary: From a Freirean perspective, some of the concepts exhibited in this vignette include banking and conscientização; in this vignette, banking was fairly evident because I owned the knowledge (data) to impart to the teachers. Although imparting important student-achievement data can be meaningful, Freire may suggest turning this dynamic around; specifically, handing over the data completely and letting the teachers collaborate and dialogue to make contextualized sense of how students are achieving.

In this vignette, turning over the knowledge to the teachers may have been difficult. A closer look using the Freirean lens may reveal that the binary of oppressor/oppressed is already set up going into this meeting, as I was known as Data Dave from the outset. From a Freirean perspective this hierarchical arrangement can be changed, altered, or even eliminated all together; true dialogue cannot be realized to its 
fullest extent. Thus, according to Freire (1970), in this vignette knowledge is a "gift bestowed" on the teachers (p. 72).

Looking at my attempts to lead for social justice, from a Freirean perspective there is some evidence of conscientização on my part. That is, I am understanding a particular inequality in society (an achievement gap between groups of students), becoming critically aware of its persistence in schools (conscientização), and trying to act on it by sharing out at a staff meeting. Although using Freire's concept of conscientização, I was not taking action against an oppressive action in my own life (I am not oppressed), rather I was attempting to take action against the injustice of the persistent achievement gap.

In sum, according to Freire (1970) my attempt at dialogical cultural action is noteworthy but limited. From a Freirean perspective what was lacking was my working toward cooperation among all staff members; that fostering authentic dialogue among teachers around student-achievement data could work toward a "cooperation" and "unity for liberation" (p. 173).

\section{What Do You Want Us to Do Dave? \\ Euphoric/Contentious/Tentative}

“What do you want us to do? Just tell us what you want and we'll do it!" I often heard this rather forceful comment/request/demand from teachers during gradelevel team meetings. I avoided answering this question, which, I know now, made people even more frustrated. Retrospectively, however, I can't help but wonder just how uncomfortable I made people feel by not answering their questions 
definitively. The source and focal point of this frustration came from my attempt to have the teachers incorporate the use of data in their instructional practices.

The utilization of data was to become one of two goals all grade-level teams would develop and submit at the beginning of the school year. The premise was simple: Data were to be incorporated into the decision-making process in terms of classroom, grade-level and departmental planning instruction and assessment. I had a few ideas to present to the teams in terms of developing these data goals, but I essentially had no overall, one-size-fits-all plan in mind. I wanted to facilitate dialogue that was meaningful and practical; dialogue that could be called authentic and inform instructional practices in their classrooms.

Because we made our AYP (based on achievement scores), our principal, Wanda, was determined to maintain this status—a status of "not" being "At Risk." She set forth the agenda at the opening of the school year that all teams set data goals. My job was to provide the information for the teams and assist in their developing of data goals. Most grade-level teams meet twice a week and are interdisciplinary — a language arts, math, social studies, science and if possible the special education teacher. Specialty teachers such as health and art do not attend grade-level team meetings. To begin the data focus, I presented, at the opening staff meeting, a case study of a hypothetical middle school with fairly challenging achievement score data. I didn't say much then, as I tried not to say much during the grade-level team meetings. I simply gave the case study to the groups of teachers and they were to analyze particular data; e.g., demographics, 
scores, etc. As this was a large-group presentation, the real work would be done in smaller, grade-level teams.

At my first team meeting, I showed the teachers how and where to retrieve our achievement data from last year. I also presented a somewhat interactive website that ranked students into the five state-mandated designations: 1. Advanced; 2. Accelerated, 3. Proficient, 4. Limited, and 5. Basic. I showed them how to download last year's achievement tests from the Ohio Department of Education website and do a quick item analysis. One of the teams of teachers showed me an idea they had regarding common assessments.

Common assessments surfaced from a team of teachers as an effective way to use data to inform instruction and ultimately better serve the students. The teachers explained that they give commonly constructed assessment tests every two weeks. In an effort to customize the teaching/learning process, they meet to tweak assessment items as well as compare results. Finally, all the dialogue and not "telling people what to do" seemed to have been paying off. I felt the multiple uses of data these four teachers were involved in were genuine, authentic and directly aimed at better serving all students. These four teachers came up with a way to track what they teach, how they teach it and the degree to which students learn it. They were using common assessments to continually improve their craft. This was real progress. I shared what these four teachers were doing with Wanda. It seemed as if the data initiative had finally gotten off the ground. We could finally see-systematically—which students were falling behind on which standard. I was excited, and so was Wanda. A week or so passed and the emotion 
was still running pretty high. I envisioned my entire school doing what these four teachers had done with data. This would pack quite a punch behind that old cliché "all children can learn." Not only could all children learn, but we know who is falling behind and what we can do about it. Could the utilization of common assessments school-wide be "the answer" to better serving all students ..." the path" to genuine social justice and equality for all? There were only a handful of teachers utilizing data to better inform instruction. Only a handful. ... Wanda is okay with this. Wanda is patient.

"So Dave, what exactly are we supposed to do?" Again, I heard these comments, both directly and indirectly. I was beginning to feel a bit frustrated. How could this process be so difficult for teachers? I've deluged them with data for a long time now. Accountability, test scores, state report cards are nothing new for them. I was having a difficult time understanding why teams were having trouble coming up with data goals. What is so hard about incorporating data into instructional planning and practices? I kept saying "data-driven decisions" over and over in my mind, but maybe I thought too much. ... Maybe I was getting down on the teachers. ... Maybe I was turning too negative. Thinking I could motivate them better, I used cute little clichés like, "What did they do before all this data was available to them? How did they make decisions then? If they are not making instructional decisions based on data then what's the alternative? ..."Hunchbased decisions?" The way I see it is if one team of teachers can set data goals, can come up with a way to use data to truly inform instruction (common assessments), then everyone can. 
When I wrote this up, I was trying to push through the setting of data goals for all teachers. It seemed fairly clear then that I felt strongly about the use of data to drive the social-justice initiative. To some degree, I was following orders from my principal, as it was her initiative to have all teams of teachers set these data goals. Although my level of frustration seems fairly apparent, my brashness seems to have declined. Perhaps my brashness diminishes in this vignette as using student data as evidence to illustrate the achievement gap seems to decrease my reliance on emotion and personality.

Freirean Commentary: From a Freirean perspective, some of the concepts exhibited in this vignette include dialogical, fear of freedom and cooperation. From a Freirean perspective, it seems obvious in this vignette that for some reason teachers were fearful of data and setting data-based goals. Although it may appear that due to teachers not wanting to set data-based goals they were exhibiting Freire's concept of the fear of freedom, this vignette also contained examples of dialogical cultural action and cooperation.

Freire's (1970) ideas and concepts of dialogical cultural action, specifically that of cooperation, point out that cooperation occurs only when there is a high level of authentic communication and trust among members of the group and the leader; members do not allow the world to be revealed to them by anyone else; and a common belief among members that they are capable of pursuing liberation together. In this vignette, at least one group of teachers indeed felt empowered enough to work collaboratively to understand what the data from students were telling them. From a Freirean perspective my leadership was exhibiting dialogical cultural action with this particular group of teachers. 
One point on Freire's concept of cooperation in dialogical cultural action needs further discussion: Freire's (1970) idea regarding no one revealing the world for anyone else. This seems relevant and applicable to this vignette. First, it would appear leaders can never "force" followers to do anything. I could not force teams of teachers to set authentic, meaningful data goals. I could point them in the direction of analyzing studentachievement data, but they needed to carefully consider the data, reflect, analyze, and let it "reveal" something meaningful that would ultimately assist them in better serving students. However, it is understandable that there would be real fear in going through this process; for teachers to actually understand and accept problems associated with the achievement gap.

In sum, from a Freirean perspective there exists authentic dialogical cultural action through cooperation with at least one team of teachers in this vignette, which I believe is not an easy process for anyone; neither leaders nor followers. From a Freirean perspective, I should refrain from telling teachers what to do, as this would perpetuate the oppressor/oppressed structure and not move adults toward freedom and liberationalthough moving in this direction would undoubtedly require greater responsibility, commitment, acceptance, and most likely, risk.

\section{The Tracking Debate Goes On.}

\section{Contentious}

"Come on, I'll walk down with you." I said to Mrs. W. as the fourth period bell was about to ring. In anticipation for their next class, students were busily gathering their things from their lockers and getting a few extra seconds of precious social time with friends before the tardy bell rang. We couldn't walk side 
by side. This would take up too much all-important space in the hallway, and we'd end up being bumped into by an unsuspecting, uncoordinated preadolescent.

We made it to Mrs. W's room and continued our conversation on tracking students by ability. She wasn't confrontational or belligerent about tracking students by ability. Her arms weren't flailing about. Her voice wasn't highpitched. But she was adamant about separating and removing students based on ability. Statements such as "But Dave, come on, you have to agree that if I only had one true level of students to address I could meet all their needs in my classroom." I listened as she continued. "Dave, it would be so much more effective to have an 'in-between-track' of students that aren't quite ready for my class." Mrs. W had thought about this proposition for some time. This was evident from the elaborate description she put forth to me. She was passionate about tracking students, so I wasn't about to shoot down her ideas ... right away, that is. Some of her argument contained the usual reasons for tracking students by ability such as "Students can't learn complex concepts if they haven't mastered the basics." and 'Tracking enables the students to learn at their own pace."

I waited and listened. I was anxious to jump in and give all the reasons why tracking is bad for students. Something was different with Mrs. W and the nearly all-White affluent school where I found myself an assistant principal. While many teachers have not had the experiences I've had in places like the southside of Chicago and inner-city Cleveland, I felt a distinct "difference" in working through complex issues such as tracking with Mrs. W and the teachers and staff. I could remember trying to work through complex issues such as tracking at my 
former school in Chicago, however, one particular issue could never stick around long enough to really capture our attention. Initiatives, even good critical discussion, were always fleeting in Chicago. Tracking does capture our attention here and it is addicting to think of it as a solution to low achieving students. At least outwardly, Mrs. W never bashed me for going against her thoughts and ideas on how tracking was good for students. Conversely, I gained a real appreciation and understanding for teachers that actually can stand up for something they believe in, even though an administrator disagrees. Strangely, even though tracking is kooky in my mind and belief system, I felt that the teachers naively espousing it because they genuinely believe it good for students, may be getting a bad rap. How dare I think less of them for always putting students first. I guess I rationalized it as simply a "misguided" commitment.

Although on the other hand, wanting to track students by ability is like a drug addiction. I know this is a bold statement to make, and I didn't have the heart to tell Mrs. W. this, but tracking students by ability always comes up as a possible solution to academic achievement problems. Sometimes it's the first solution to come up. Sometimes I hear it so much I start believing it a viable solution. That's why it's like a drug addiction. Whenever students do not achieve, or groups of students such as students with an IEP do not achieve at a level commensurate with their non-IEP counterparts, removing and separating—or tracking—-them into a slower paced or more "basic skills" class seems to be the answer. There are serious problems with tracking and I've tried to assist teachers and staff in 
understanding these dilemmas through dialogue and the presentation of research and data.

Students began to file into Mrs. W's classroom as we continued to converse just outside her door. She knew this tracking thing could work. She, like most teachers, was committed to meeting the academic needs of all students. "And Dave, if we track them by ability, the students will finally enjoy the success which will make them feel so much better about coming to school each day." I felt I needed to say something.

"Okay Mrs. W I get your point, but how can we be sure all students will benefit from ability tracking? The research is loud and clear on this one, and has been for some time. Who do you think benefits most from ability grouping?" Mrs. W didn't need to answer, she'd heard this counterargument before. I proceeded. "Okay, okay, so if we track by ability, do you realize how small we need to make class sizes to be truly effective? It's impossible. There's no way we can reduce class sizes to 10 students per class." Mrs. W had heard this counterargument, too. Her response? "Dave, I'm not saying the entire school should track, I'm just saying baby steps, that's all. Start with one subject or one grade level or even one team and just try it out."

The fourth period bell finally rang and not one of Mrs. W's students was late. I got a call on my walkie talkie to swing by the main office when I get a chance; something about a student needing to talk to me regarding a schedule change. Mrs. W leaned into her classroom and reminded the students to begin the bell work that was displayed on the SMARTBoard. Mrs. W and I weren't finished. I 
only had about a half minute to really say something meaningful. It was evident that we both respected each other, but disagreed on a particular educational issue. But I'm the administrator and I needed to leave some "food for thought."

Mrs. W exhaled and said "Well, that's just how I feel Dave." She put one foot into her doorway of her classroom when I said, "Mrs. W consider this. What if we tried your plan and tracked students based on ability. Who do you think would end up in those low/slow track classrooms? And while I know we're not by any means diverse, what would happen if the few students of color that we do have ended up in those classrooms? Or what if the low tracked classrooms were comprised of students on free and reduced lunches and students with an IEP?" Mrs. W retorted, "How many would we be talking about, Dave?" I inched backwards away from Mrs. W's door as the hallways calmed down and became dead silent. It was clear we ran out of time. At a distance of about ten feet, I went a little global on her as I was trying to frame this rather complex problem in a much broader context. I answered, "Well, traditionally, these are the students that end up in low track classes. And they don't succeed mainly because there is some degree of social and academic isolation and depravation that can lead to lower expectations, lower achievement, and higher behavior problems."

"I gotta go Dave. We'll talk later." Mrs. W said as I disappeared down the hallway heading back to the office to talk to a student about scheduling.

This piece is something I wrote as a compilation of experiences with teachers and staff regarding the subject of ability tracking. It is the bits and pieces of many experiences I have had with many colleagues. This conversion happened many, many times. There is 
no "real" Mrs. W per se, and yet, we have all been Mrs. W at one time or another. She is symbolic of the teacher-administrator interactions I have had with staff about ability tracking. I can remember not feeling good about using my past experiences in inner-city Chicago and Cleveland when working with teachers on complex issues such as tracking. I felt I was throwing a trump card of sorts to best a colleague. I also felt I was "using" the very children I was purporting to help; namely those who have been marginalized and not served well by public education, to make a point in a professional argument.

Even now, I believe, at times, there is an "experience gap" between my staff and me. Because I may have more experience working with students of color or students with an IEP, and I may have more knowledge about their educational reality, I get the sense sometimes that I am automatically at some advantage when working through these issues with teachers and staff. It is almost as if I have the last word. I could be confused on this point. I'm not sure. I am rather new as an administrator. To counter my feelings of inexperience, I rationalize that social injustices did not happen over night; therefore eradication of such injustices will not happen over night either. I feel a little suspect, though. I have asked myself, what if $I$ worked in an all-African American school? What would the response be of African American teachers? In Chicago, when I worked at a nearly all-Mexican American school, I naively blamed the "oppressive suburbs." Now I work in one of those suburbs I used to rail against. This was not the only time ability, race, class, and student achievement came up in discussions.

Freirean Commentary: From a Freirean perspective, some of the concepts exhibited in this vignette include dialogical, problem posing, paternalistic, and conquest. Because this vignette was written as a compilation of literally dozens of similar 
interactions I have had with many teachers, I believe from a Freirean perspective the idea of tracking is well entrenched, and something educators truly consider a solution to student-learning problems. Regardless of the benefits and drawbacks of tracking, many educators immediately consider tracking as a remedy to students' lack of academic achievement.

From a Freirean perspective, this vignette illustrated dialogical cultural action and problem posing, because there seemed to be a degree of sincerity on my part and that of the teacher, to listen and consider the possibilities and realities of what each was posing. For example, there were many occasions on which teachers seemed to almost plead their case for tracking students by ability. I listened and considered what a "tracked" school would look like. Similarly, when I posed problems with tracking students by ability to teachers, they listened and tried to envision what their classrooms would look like completely free of tracking; maybe even what it would take to meet all their students' academic needs. From a Freirean perspective the dialogue may have fallen short and begun to look a bit paternalistic, with some elements of conquest. Following, I look more closely at this vignette.

First, there may be some concern with the way in which I "present facts" during dialogical interactions with teachers. According to Freire (1970), paternalism and conquest directly address the imbalance of power. In this case, the imbalance may be that I am the administrator and I may be perceived as trying to control the situation by the selection of facts I choose to use and experiences I choose to present. The imbalance occurs when a teacher may not want to challenge my assertions regarding tracking. If there is a level of fear and intimidation occurring, however subtle, the teacher and I 
cannot get at genuine dialogue that leads to authentic collaboration to understand tracking students by ability until that barrier is completely broken down.

From a Freirean perspective, to stay clear of paternalism and conquest, the school leader must allow for free-flowing problem posing to occur, without recourse, regarding very meaningful issues in education such as tracking. Tracking has direct implications to social justice in schools. The leader, by using problem posing, allows teachers to "figure out the ills" of tracking. This could take a long time, perhaps months or years. However, if the teachers cannot "own and understand" what tracking students by ability means, then meeting the academic needs of all students will remain elusive and difficult to accomplish. If, through dialogical cultural action, teachers and administrators pose problems collaboratively in the absence of self-interest and the coercive presentation of one-sided facts and experiences, the possibility exists for better meeting the needs of all students.

\section{It's Frustrating That Dave Doesn't Answer Your Question.}

\section{Inconsistent}

I don't want to frustrate people. It's not my intent to have frustrated, unhappy people working in our school. This happens sometimes, though. Much of the frustration seems to be centered on my decision-making ability (or lack thereof). Where I think most of the frustration comes from is when I put questions back on people. They are not the simple issues or questions I put back on people. In a way Ifeel guilty because I usually take care of the trivial stuff like deciding whether or not staff members should sing the Twelve Days of Christmas for the children this year. To me, those are not the big questions that need to be asked. I'd asked my 
staff once to take up a dialogue with a colleague or two regarding how students learn best. In essence, I asked them to argue it out. So in a way, I'm taking the easy way out. I take care of the really easy stuff like singing songs, should we purchase the yellow and/or magenta color ink cartridges this year, and where the recycling bin should be located. I guess all these "easy decisions" have (directly or indirectly) to do with student learning and achievement.

People want me to make the easy decisions, and most of the time I do. Perhaps I "look” more like an experienced, assured administrator. I don't know. Back to the difficult questions, that I never answer. (My staff jokes that "Martin never answers your questions.") Two staff members said they had actually deleted an e-mail they planned on sending me because it contained questions they knew I'd put back on them. I guess it is good they're joking about something that is important to me. The one difficult question I asked, "How do children learn best?" was never really tackled. I'm not sure why people did not feel compelled to explicitly dialogue and debate this issue. Ultimately I heard rumblings that there is no time. Time. I guess we could say there's no time for anything. We simply do not have enough hours in the day to complete everything we need to complete. True, there is a lot to accomplish in schools, and we need to prioritize based on need, so why not make issues such as how students learn best a top priority.

My aversion to telling people an "answer" to a difficult question can have unintended outcomes, though. For example, one of my teachers thanked me for helping her become more self-reliant. She said I make her think and solve 
problems for herself. Superficially, I guess this sounds great. However, I wasn't quite sure how to accept her "thank you." I felt a little like a patriarch dispensing valuable life knowledge so she could fend for herself in the wilds of public education. Maybe I'm overanalyzing a simple, kind gesture; overanalyzing a simple "thanks." I'm not sure. I do know that I want to build capacity in our school. If I leave tomorrow, I can be relativity certain the place would flourish without me. I also would like to see all of us get to a point where we're not "thanking" but rather collaboratively working together to collectively benefit the school as a whole. It would be very meaningful if we all asked each other "big" questions like, "How do students learn best?"

I extracted this piece from my journal. Looking back now, I know I have changed course a bit in a year. For example, one of my goals was to be more decisive in my decision making, mostly because it exasperates people when I keep putting questions back on them. I struggle with the degree to which I should make decisions, which decisions to make, or which dialogic engagement I/we should pursue as a school. I have considered making the decisions for little issues, like the 12 Days of Christmas, but leave the big issues to a more democratic process. By big issues, I mean I could use the questioning process to perhaps get staff to test their own assumptions. I know this can be a little frightening, as many people have difficulty admitting a long-held belief may not be the best way of doing something or even necessarily true. I think about Freire's theory of the "fear of freedom" and see how this really does happen in decision making.

Freirean Commentary: From a Freirean perspective, some of the concepts exhibited in this vignette include dialogical and the fear of freedom. In particular, the 
concept of fear of freedom seems evident in this vignette because I want teachers to dialogue about important issues directly related to student learning, and teachers do not immediately want to do this. There may be more going on here, which warrants further discussion.

In a dialogical sense, viewing this vignette from the Freirean perspective, there may be questions as to why teachers are seemingly comfortable with me making all or most decisions; questions how and why this arrangement came to be, and why having no decision-making power is not an issue of concern for teachers. Viewing this situation through a Freirean lens may reveal that the oppressed are so identified by their oppressor's role that the thought of letting go and gaining the responsibility of freedom becomes risky to attempt. Although I do not believe this particular Freirean dialectic plays out exactly this way in my school, that is with me being the oppressor and the teachers frightened to be free, it may take on a unique meaning which will be explained next.

In this vignette, perhaps it is the "notion" or "image" of administration that complicates empowering teachers to make important decisions for dialogical arrangements. Without exonerating my complicity in this arrangement, I do not think the teachers identify me personally as the oppressor; rather, they identify the group to which I belong as the oppressor. Perhaps because I am an administrator, I am associated with traditional beliefs of what administrators are expected to do. If administrators have traditionally been viewed as the sole decision makers - that it is their primary purpose to make decisions on all matters big and small—teachers and staff could naturally be 
hesitant in assisting in the decision-making process, as they do not want to be accused of overstepping their authority.

In sum, from a Freirean perspective, my intention to engage teachers in dialogical cultural action to discuss important issues of social justice, such as how students learn best, the fear of freedom may be preventing this from happening. Additionally, from a Freirean perspective, traditional roles of what administrators and teachers are "supposed to do" need to be rearranged. On the topics of how all children learn best and decision making, Freire may suggest a format that promotes open dialogue and exploration, one that enables teachers to take professional risks that do not rely on administrative approval or heavy oversight.

\section{The Manager Is in the Principal's Office.}

\section{Uncertain}

I'm a little mad. I seem to be evolving into that leader I don't want to be. Lately, my leadership could be described as a computer screen, the master schedule, and a calculator. I'm a manager; and judging by what some folks think, not a very good one.

I'm not doing what I want to do. False veracity—I work my ass off. I'm relentless in trying to make my school run smoothly. I want it to be efficient and effective. I work so hard trying to make sure everything is running right that I don't even realize what I'm forgetting; forgetting important things. I'm trying to be a great manager. The funny thing is I don't think my staff even agrees with me. Many staff members may even say I'm a poor manager. I'm not sure, but I sense my staff feels that since I work so hard, the joint should run perfectly; that there 
should never be a glitch in any schedule, any procedure, or any routine. After all, if I work so hard, what am I doing? Shouldn't a well-run school be indicative of the principal's hard work?

Yet, I'm on amphetamines (figuratively) about getting shit done. Getting it done becomes the end, and it never ends. There will always be another schedule to make, another routine to develop, another policy and procedure to review, another something to manage.

This was in my journal, written early in my first year as an elementary school principal. I wrote it after a long drought from the literature on leadership for social justice. I had literally gone months without reading a single article, book, website, or blog on social justice. Worse yet, the orientation of leadership for social justice as an approach to leading my school had not yet entered my mind. It is important to stay connected to the literature on leadership for social justice. Perhaps reading and staying connected to the literature on leadership for social justice helps keep me grounded and gives a sense of purpose, conviction, and focus on how to better lead in my school. If I do not stay connected to the literature, I could get overwhelmed with the busy work, and it overtakes me. Additionally, I have come to learn, since being introduced to the leadership for social justice literature, that if I stay away too long it gets more and more difficult to use the theories in practice. In my situation, as I am learning to lead for social justice, I feel I may be wasting other people's time by starting and stopping the dialogue on how to best serve all children. Thinking back now, I can say that one of the reasons I again began to read the literature on leadership for social justice at the time of the journal entry was that I was angry about what I was doing, that is, I seemed to be doing exclusively managerial 
work. The false veracity I mentioned is real and persistent. If I don't actively acknowledge and try to avoid it, it becomes quite easy to slip into a managerial role that never addresses issues of equity and social justice in my school. The work of leadership for social justice is never over, never ending.

Freirean Commentary: From a Freirean perspective, some of the concepts exhibited in this vignette include paternalistic, manipulation, conquest, antidialogic, false generosity, and divide and rule. Although brief, this vignette was very meaningful in my learning process, as it provided several points on which to reflect and gain insights into leadership. For the application of the Freirean concepts to this vignette, I must first provide some background knowledge.

Before trying to overlaying the Freirean perspective on this vignette, it is important to know how and why these Freirean concepts were assigned to this vignette. What may not be readily apparent in this vignette are my actions and behaviors in carrying out the managerial roles in my school at that particular time. The Freirean concepts of paternalism, manipulation, conquest, antidialogical, false generosity, and divide and rule are closely tied to traditional forms of leadership: managing a school could include any and all of these Freirean concepts. Managing a school so that it runs smoothly and efficiently could involve any or all of the antidialogical Freirean concepts.

I alluded to the term false veracity at the beginning of this vignette. False veracity is the term that may best sum my behaviors and actions in trying to manage my school in this time period. Working hard as a manager may appear outwardly sincere, but if it is to the exclusion of dialogical cultural action, it is only superficial and perhaps even temporary. It is a good way to keep everyone content. An example of this is scheduling. 
To build a master schedule, many variables need to be met. Inevitably, these scheduling variables in the building of a master class schedule can be traced back to staff preference, even staff comfort. For example, if someone likes to have classes scheduled a certain way, perhaps around recess or lunch, there needs to be a decision about whether this benefits students in academically positive ways. If it does not, antidialogical techniques could occur. For example, in the absence of critical, open dialogue, the manager begins to find ways to manipulate the schedule so that staff members may be content with the flow of their classes. This many include false generosity, as there is an effort to "make people feel good." Scheduling is just one example of the many managerial roles administrators must perform. As this brief exampled indicated, there are many challenges to performing managerial tasks in ways that promote social justice through dialogical cultural actions with all staff members.

In sum, from a Freirean perspective, managerial practices by a school administrator can be antidialogical and include such concepts paternalistic, manipulation, conquest, antidialogic, false generosity, and divide and rule. Similarly, from a Freirean perspective, this is no surprise in education, as I belong to the "established class" of oppressors. Moreover, because I belong to this established class, which is in many ways tied to traditional leadership roles, I will constantly struggle against leading in antidialogical ways.

\section{Question Myself.}

\section{Uncertain}

We had an in-service/records day on Halloween. In the morning, the teachers completed mandatory on-line safety training and in the afternoon worked on 
report cards. It was about 4:00, time to leave, when a teacher came in asking about a student she has who is performing poorly in her class. I asked a few questions and it was quickly discerned that this student lives in a home where a language other than English is spoken.

The teacher described the girl as having poor grades due to lack of motivation. The teacher has done anything but give up on this student. She's constantly looking for ways to intervene and help; ways to motivate and engage her. We discussed what could be done. She gave me a little background.

The teacher, Mrs. Mays, said Maria lives with her Peruvian grandmother and possibly great-grandmother. She knows that Spanish is spoken at home, but Maria doesn't seem confused at school in terms of language. She is relatively new to our district.

I must say that Mrs. Mays is a motivator. I feel motivated when I walk in her room. She's always looking for the positive angle on how to best work with her students. She's been around. She's no rookie. I think she has over 25 years of teaching experience. So when we began the conversation about why Maria is performing so poorly, the first few questions went directly to the home culture; specifically, the home language. When I raised the question of whether or not "living in two worlds" could be affecting Maria's academic performance, Mrs. Mays joked, "Oh, I forgot I was talking to 'Bilingual Dave." I was happy that Mrs. Mays felt comfortable enough to joke with me. However, I wanted to be certain that Mrs. Mays and I were understanding each other as it pertained to 
Maria's academic situation. Again, I knew Mrs. Mays was just joking; however, I wanted to see if my ideas were being dismissed as overzealousness.

I pursued it a little farther and simply rephrased what I had just said. "So, do you think it's possible for a student to struggle academically if she is essentially caught between two worlds, a home world that may not be like the middle-class world called 'school' she attends every day?” This didn't anger Mrs. Mays, rather she seemed genuinely pensive by my question. I can't explain the reaction, but the "wheels started to turn." I don't think my interaction had much to do with it, as I know Mrs. Mays to be a motivator.

About three weeks later, we conducted parent/teacher conference night. At Maria's conference, both her mother and grandmother attended, along with me and a reading teacher. She opened with, "Can we work together to make sure Maria succeeds?" Mrs. Mays had a plan. The plan was that Mrs. Mays had enough of Maria coming late to class every morning. She was not going to accept mediocre effort out of Maria any longer. Not that Mrs. Mays ever did accept these things before, but now it seemed different.

[Sometimes I confuse myself. I'm trying to learn to be a better leader for social justice in an affluent, nearly all-White suburban elementary school. I don't latch on to situations like that of Maria and Mrs. Mays; however, I confuse myself because I don't know if these are the situations that I should latch on to. It's confusing to me because sometimes I don't believe myself. I ask myself, why would I have this conversation with Mrs. Mays? I try to think about what social 
justice means and come back to notions of equality. So I ask myself if I'm leading for equality. The answer is I don't know.]

After this exchange with Mrs. Mays I got to thinking that maybe I'm having this conversation because I'm trying to learn to practice leadership for social justice, not because it is innately "right" (or righteous, whatever) to somehow stick up for those that may not be in the "norm." And what the hell is the norm anyway? I should stick up for those that aren't like me. Well, that's confusing. This experience with Maria and Mrs. Mays reminded me of a similar one with a team of teachers at a different school. In comparing the two experiences, I noticed a few similarities and a few differences. One similarity was that, for some reason, in both situations, we were talking about second-language learners. One difference I noticed was that I was less emotional in the second conversation. It would be naïve to draw a sweeping conclusion that by virtue of caring about and placing second-language learners at the fore, somehow I am practicing better social justice in my school. Ironically, though, I am hard pressed to say these issues are not in the fore of many of my conversations with staff. I think the staff also knows that these are important to me. Yet, I cannot say I know what I am doing or that I am certain that because these are important to me it must be an example of practicing leadership for social justice. Looking back on when I wrote this and thinking about it now, a year later, Mrs. Mays has not changed. She is still a great motivator.

Freirean Commentary: From a Freirean perspective, some of the concepts exhibited in this vignette include dialogic and incompleteness. There is clear evidence of dialogical problem posing in this vignette. This could be seen when I asked Mrs. Mays 
the question, "So, do you think it's possible for a student to struggle academically if she is essentially caught between two worlds, a home world that many not be like the middleclass world called 'school' she attends every day?" From a Freirean perspective, the problem posed of living in two worlds had the potential to be democratically discussed whereby mutual inquiry could reveal meaningful and multiple understandings of how to best meet Maria's academic needs. Shor (1992) wrote extensively on the power of mutual inquiry. However, somewhat more salient—and most disruptive—is my incompleteness in this vignette; specifically my questioning of what I am attempting to do as a leader.

According to Freire (1970), incompleteness is an authentic approach to education that allows people to strive to be more fully human. Being critically aware, reflecting, and hopefully acting on one's incomplete learning can be a powerful experience for school leaders. In this vignette, there is evidence of me being critically aware, reflecting, and acting. From a Freirean perspective, questioning my efforts in trying to practice leadership for social justice moves me toward a more critical awareness and understanding of social justice. Thus, from a Freirean perspective, learning is never complete. If I can question what I do and believe as a school leader, and continue to critically learn and reflect on my practice, I should grow and improve.

The Reporter Gets Dave Centered Again on What's Important in School.

\section{Uncertain/Tentative}

It was a parent-teacher conference night at my school and I was trying to catch up on answering some e-mails. There's usually not much to do on these nights except sit in on a few conferences should the teachers request my presence. My presence usually signals there's something wrong, like a testy parent. I didn't 
have many of those this night, so I was following up on a phone call that I needed to make.

Sue is a community reporter who's doing some practicum work at my school for her university class. She had sent an e-mail a few days earlier inquiring whether or not she could ask me a few questions on the topic of motivation. I always think it a good thing to inspire the next generation of teachers (puke!). We ended up speaking for nearly an hour, and I'm not sure she came away with what she was supposed to accomplish for her university class.

Sue asked if I wouldn't mind answering a few questions "off the record" regarding motivation. I said if it's off the record I'll say anything once! She opened with the usual, "Do you think there's an issue with motivation?" I countered with "What's your definition of 'issue'?” We both laughed after Sue's huge sigh. We laughed again when we both referenced the famous Clinton line of "It depends on what your definition of 'is' is." I wasn't trying to be a jerk and Sue certainly knew that. Likewise, she's "reporter savvy" and can pick up on a line crap in a heartbeat.

The conversation moved pretty quickly after that first joke. In fact, Sue seemed to move off script as soon as she detected that I was going to question every preconceived, packaged, canned, sanitized, have-to-do-this-to-complete-therequirements-of-my-university-class-assignment question. Our conversation went something like this:

Sue: Do you think motivating students is important?

Me: $\quad$ Oh yes, it certainly is. 
Sue: What's the best way to motivate students?

Me: $\quad$ Oh, one must have a strong external reward and students will respond.

Sue: Well, then are all children motivated the same way?

Me: $\quad$ Oh no, one must differentiate his/her motivational techniques.

After about five minutes of my ornery non-answers, Sue tossed in the towel.

"Alright Dave, what do you really think?" I had a thought in my head and I had to get it out. I suggested to Sue that maybe motivation is intrinsic; that maybe the problem is not about material rewards, inspiring speeches, stickers or interesting curricular games (the opposite of the very things I was being sarcastic about moments earlier). I suggested that maybe true motivation for students could be about empowerment and a sense of the world around them. I dove into all kinds of fancy academic things. I spoke eloquently about how we're the 11th highest academic performing school district in Ohio and that we ought to teach our kids about perceiving the political, social, and economic contradictions in society. I talked in-depth about when children can realize these contradictions in society, they will be moved to act and work against injustices. I went on for a good long while.

Sue's next question was "So, what's the role of the teacher in motivating our junior souls in schools?" I was waiting for this question. I had a good answer to it. I proudly said that $80 \%$ of the teaching force in the United States is White middle-class folks. I was even more proud of my next posit. ... "Sue, it's not enough to have everyone on the bus. It's far more important to have everyone in the right seat on the bus." [I don't know how I did it, but I somehow linked that 
weak-ass bus analogy with my lily-White school district's need to hire more teachers of color.] I told Sue some more good academic stuff. I said there's no way a White teacher of middle-class background can know how to motivate a child from a traditionally marginalized/oppressed group, i.e., a child of color, a child with a disability, a child of economic disadvantage, etc.

I explained how I'm on top of the social food chain; that I stand to gain the most in NOT preparing our junior souls to be aware of those political, social, and economical contradictions in society because if I did, it could mean that White kids may begin to not replicate the status quo. Or better yet, through education, White kids of privileged may work to tear down barriers that have maintained an unjust educational system/society. I whined a little, too. I said it's hard to be a principal for social justice. Her next question was definitely not scripted, nor was about motivation ... or maybe it was ... my motivation.

Sue asked, "What are you doing here? Why aren't you in the inner-city or something?" I think I whined a little more after that question and maybe even got some sympathy. I launched into the "how" of things. How I needed to enter into dialogical relationships with teachers, how we needed to question each other in professional ways so we could try to create a more just learning environment for all students. I quoted some of Freire's work. Sue said she'd like to see this stuff I'm quoting.

Sue is pretty close to our school still. She is a former parent and still volunteers once in a while. This piece is also fairly symbolic of a few recurring themes I've noticed about myself trying to learn to lead for social justice. First, I can make an abstract 
argument about how one should practice leadership for social justice, but the practice is lacking (hence Sue's comment). I do not know why I can make the abstract argument without practice. I do know I have to make a concerted effort to avoid making the abstract argument and get on with doing something. Awareness is an effective starting point, but I cannot stay there forever. Second, this dialogue with Sue represents another layer of leadership for social justice: specifically, it appears inverted in my school/district. That is, those traditionally marginalized in public education are not represented in great numbers, as they are in the inner city. This realization does not dismiss my responsibility in trying to lead for social justice, but it would appear I need to at least do a better job in raising the awareness in students—in particular-toward greater social responsibility. However, in contrast, I cannot simply equate leadership for social justice exclusively with the inner city. There is important social justice work to be accomplished in all schools everywhere. For example, the privileged in my community need to be enlisted to support social justice, similar to my work with teachers, in dialogical ways. Finally, this interaction with Sue and the way she got me to think and reflect could be similar to Freire's (1970) idea of praxis: refection on dialogue, followed by action.

Freirean Commentary: From a Freirean perspective, some of the concepts exhibited in this vignette include dialogic/antidialogic and paternalism. My conversation with Sue was somewhat paternalistic and antidialogical, as my contributions to the conversation did not seem genuine, humble, or sincere. In a way, albeit harmless, my interactions with Sue were a bit sarcastic and self-centered. However, from a Freirean perspective we were engaged in critical dialogue at some level. 
In sum, from a Freirean perspective we engaged in dialogue that would be considered important in getting at the structures of oppression in society. In our interactions we questioned the status quo of education and White privilege. Most importantly, from a Freirean perspective, my written reflection after the vignette indicates I am considering the world in which I participate, have identified the problem, articulated what to do, and all that is missing is taking effective action to do something about injustices.

\section{Still Struggling With the Who, How, and Why of Leadership for Social Justice.}

\section{Uncertain/Tentative}

"I'm struggling with identifying who's poor." I say one day in a conversation I had with a teacher in my office. I go on to explain in very deconstructing terms what I mean by my opening sentence "I'm struggling with identifying who's poor." I say it over and over, about ten times. I ask if I have the right to sort folks into rich and poor? I ask the question again, "Who's poor?" I'm beginning to sound a little arrogant. I ask what's poor, how is it defined? I say, I think I'm being a little presumptuous. I am struggling to figure out just who is poor when I'm not even poor! She interjects, "Sounds pretty top-down to me Martin." She bursts out laughing. I laugh, too. She got me on that one. I say, "Wait, wait, wait. I'm trying to help, am I not? I have to start somewhere, move forward, to help, which would inevitably mean some level of identification of who the poor are, right?" I ask again, "So who are the poor?" She says, "Martin, why don't you just treat everyone the same?” I retort with, “No, no, no! Total equality on paper equates to inherent inequality in real people's lives. You're making the colorblind 
argument!" I ask one more time. "Who's poor?" I take a deep breath, sigh, and once again, reconcile myself to just wanting to help the poor.

I tell her, "Here's how bad I get. While I know at least I want to help the poor, instead of fighting through my pitiful little mental struggle of who's who in the world of poverty, I take a stand and act on my core value of wanting to help the poor. And this is what I decide to do. I help those who are nice poor people." She asks, "Okay, Martin, what does this look like in school?" I go on. I say, "This is what I think it looks like. I think nice poor children are ones who follow the rules but don't have much money. They respect me and other adults in the school, are kind of shy and reserved, but just don't have a lot of money. They may or may not be on free and reduced lunches, may wear second hand clothes, and try to do their homework every night. They'd be much better students if dad were not on disability and unable to work, or if mom had graduated from college and been able to get a professional white-collar job. Nonetheless, these poor children come from hard working families because mom works 13 hours a day at a menial job. They struggle, but they're kind, respectful, meek, reserved, and don't have much money. They're the type of children teachers say 'Oh, don't you just want to take him home with you?' Or, 'You know, if I could just adopt her for a year and give her some stability, I know I could develop those study habits. "” I take a deep breath and continue. The teacher is listening closely.

As the economic downturn has wrecked havoc on jobs in northeast Ohio, some families have gone from relative financial comfort and security to momentary poverty. At times, my heart especially goes out to the children in these 
families. Are they poor? Technically, yes. But they are the sweetest, kindest, most respectful and hard working children. They're never in my office because of discipline. They've always got smiles on their faces. These poor children get good grades, too." She interjects a brief thought to slow me down. "I think it's about striking a balance Dave." She has used this "striking a balance” argument before, but I don't listen. I keep ranting. "Then there are those few families that are seemingly choosing a life of relative poverty, or at least modesty. These families would appear to be of low income compared to the affluence of the community around them. The parents of these children are usually well educated, more liberal than their conservative counterparts in my community, politically informed, sensible, polite, helpful to the school (volunteering) and definitely hard working. The children are different because there is a noticeable gap between what is important to them and what is important to the mainstream (i.e., material wealth is of little importance to these children because, it would appear, parents refuse to (or can't) shower them all with the latest gifts and gadgets.) Still, these children live in 1,100 square foot homes with no sidewalks. They don't wear the latest fashion in clothes or shoes, and may or may not qualify for free and reduced lunches. Yet, no one feels sorry for them. They are summed up as good, sensible, hard working children who know what's important in life. I guess when I help these children and their families, it makes me feel good. So I guess my struggle continues. I ask myself, 'Are any of these children really poor?' I don't know. I struggle because I can't answer it. Sometimes I believe I need to simply 
draw the line in the sand and boldly proclaim: 'This is who is poor. Here they are. Here is how we are going to help them. Done."

The teacher again says, "I still think it's about striking a balance, trying to help those you can, and feeling okay about helping those you can." Again, I don't listen. I rant on. "But it's complex. Not only do I think about the 'who' but also the 'how' in helping the poor. What about the not so nice poor in my school, the ones who make my life difficult but are just as (even more) needy than some of the ones I've just told you about? And what about the poor students with parents who aren't so nice? What about the parents who always seem to be working an angle and trying to 'get something' from the school? I wish it were as simple as boiling it down to 'here's our group of students on free and reduced lunches.' I wish I could make it that simple and say that all we have to do is check the free and reduced list and have them. Not only can't we do that, due in part to confidentiality issues, but it wouldn't tell the whole story. So I'm back to my patriarchal struggle of trying to decide who's poor in my school. I know some of the not so nice folks are poor, but they are difficult. I say they are difficult because it rarely is the student that is difficult insomuch as the parent. Children are great."

The teacher is being very patient with me, but I'm also trying to accomplish something with her. I want to raise her awareness as well as other teachers' awareness of the complexities of working with students of poverty. I continue. "Maybe it comes down to my understanding their plight and, in turn, helping teachers understand their plight. I often thought it a class problem and not a lack 
of caring/compassion problem. By class problem, I mean that nearly all our teachers come from middle class backgrounds. They tend to bring with them middle class values: efficiency, punctuality, respect for authority, perseverance, competitiveness, frugality and alike. I don't think these are so bad, but it could mean a clash at any given time, should a child/parent not ascribe to these middle class values. What do you think?" She says, "This is a great discussion, but I have class in thirty seconds and need to go to the bathroom first."

I thought to myself ... So the struggle goes on. As everyone knows, children with less financial resources tend to be marginalized and negatively impacted by public schools; I get frustrated with my indecisiveness of trying to figure out if one student/family is more worthy than another.

Stepping back and analyzing this vignette, the intent to practice leadership for social justice seems to be evident, but something appears to have gone astray. While I am trying to dialogue with the teacher regarding the important social justice issue of class, my retreat away from leadership from social justice is noted. To think or consider, as a school leader, serving only the "deserving poor" students is not leadership for social justice. I've had many discussions like this about the relatively few students of poverty in our school. The discussions of class are very important and complex with staff. Equally complex is my position in these types of exchanges, such as this one with this teacher. It appears she is helping me clarify my belief system, although I am clearly exhibiting a retreat from leadership for social justice.

Freirean Commentary: From a Freirean perspective, some of the concepts exhibited in this vignette include paternalism, incompleteness, and conscientização. From 
the outset, this exchange with the teacher is too one-sided. By this I mean there is not enough listening, considering, and responding on my part. The teacher does, from a Freirean perspective, seem to engage in problem posing with me; and I may be behaving paternalistically by setting up a situation in which the teacher does not have the opportunity or environment to engage in dialogical cultural action..

Ironically, although it seems the teacher is trying to engage me in authentic problem posing to better understand and clarify the meaning of being poor, I respond by persisting with paternalistic behaviors. First, I may not be "banking knowledge" with this teacher, as it would appear I incessantly talk myself into thinking I understand the problem of poverty at my school. If I were truly banking knowledge, I might look on this teacher and situation as an opportunity to "bestow gifts of knowledge" unto her. I do not seem concerned with changing her way of thinking as much as I want to figure out the problem of poverty for myself. This is where, from a Freirean perspective, the teacher helps me.

Despite my paternalistic behavior, from a Freirean perspective there is evidence of the oppressed (teacher) trying to liberate the oppressor (administrator). In Freire's dialectic of oppressed/oppressor, true liberation only comes when the oppressed and the oppressor together are engaged in dialogical cultural action and pose problems together to gain a critical consciousness, or conscientização, that leads to reflection and praxis (Freire, 1970). What was missing in this "almost dialogical" interaction was my problem posing back to the teacher. I am not certain what the teacher took away from the interaction. It would appear I was able to recognize my incompleteness in understanding poverty specifically in my school, and perhaps society in general. 
In sum, for this vignette, and from a Freirean perspective, my paternalistic behaviors have again interfered with authentic dialogical cultural action; however, some good may have been accomplished. First, I recognized my incompleteness in learning. Next, although difficult to ascertain, the teacher may have learned from this interaction as well. From a Freirean perspective, although indeed the teacher used problem posing and was interested in my critical consciousness, she too may have benefitted from this experience.

\section{Intelligence Testing, Race and Tracking.}

\section{Tentative}

Jane, our school psychologist, is a great person. I enjoy working with her, and I think the feelings are mutual. Jane knows her stuff. She's the "go-to" for any and all questions on [Individuals With Disability Act], IEPs, intelligence testing, suspected disabilities, etc. I've often asked Jane to explain one thing or another to me, and I know, with a great deal of certainty, that she's got the information I need. Jane is often called upon by teachers when there is a suspected disability. Since we are a middle school, rarely is there a "genuine" disability that is detected in one of our students-especially if the student has been in our district since kindergarten. Jane also splits time at a feeder elementary school, so for Jane to miss a disability in a $K-3$ student, and to have that student arrive at the middle school without an IEP, wouldn't, well, be Jane. Jane knows her stuff.

Occasionally we get a transfer student from Cleveland. One student we received was an African American seventh grade boy. Sam loved football. He was in our school exactly two weeks when Jane was called upon. One of the teachers 
was convinced Sam was learning disabled. Admittedly, Sam had some academic gaps and holes. Jane attended the meeting to discuss possible placement into special education. Jane wouldn't have any of it. She didn't think testing this early was a good idea. She stated that accommodations and adjustments to the curriculum needed to be made first. This was Thursday. I didn't say anything in the meeting. On Monday, the teacher said that she provided all the accommodations and adjustments, but Sam was still failing. Jane was livid. She refused to test him stating that the proper time was needed to assist in Sam's adjustment to a new school, curriculum, teachers, etc. Sam left our district a short time later. I saw Sam in the lunch room the day he left. This time I did say something. I remember wishing him well with his football career.

A few months later I had lunch with Jane and we struck up a conversation about intelligence testing. I told her I didn't put much faith in those instruments as they are culturally, linguistically and racially bias tests. I told her I could get proof that these instruments were biased; that the verdict is out on these things. I went home and got right to work. I gave her everything from Steven Jay Gould's work to the evil origin of the Bell Curve. I compiled a healthy list of websites and other resources that Jane could explore. I was certain I could win her over.

I anxiously awaited Jane's arrival Monday morning to ask if she had not only received my homework, but actually read and investigated it. Jane looked at me and said, "Yeah, yeah, yeah ... so they're biased tests. It's all about the interpretation. Why are you so anti-establishment?" It felt good to be called "anti-establishment." It conjured up images of me as a hippy flower child in the 
sixties protesting government cruelty to our poor, minority students. "Yeah, I'm all about standing up for what I believe in; standing up for the oppressed." I thought to myself.

How easy it seemed to form an academic argument against an oppressive educational structure such as intelligence testing but not say a word on behalf of a Black student who needed a voice? And how ironic it is that Jane refused to test Sam but reluctantly and half-heartily admits that the very instrument he puts so much faith in is flawed.

This experience fundamentally changed me. What do I believe? What am I scared of? Had I spoken up on Sam's behalf, would he still be at our school? Who cares about my argumentation ability anyway? So what if I can logically tear something apart like the Bell Curve but not defend the very children being harmed by it. Isn't practice more important than rhetoric? I screwed up by remaining silent. Retrospectively, I guess I was scared to say something because I cared more about myself, about what people would think of me if I rocked the boat too much. I'm still trying to figure out how to do this thing called leadership for social justice.

Jane services multiple schools in our district. The previous vignette is based on interactions in the past at our middle school. What strikes me after reading this is my tone of sounding too much like a "social justice crusader." I really did send her a myriad references on the cultural and linguistic biases of intelligence testing. I started with the default mode of passionately "sticking up" for the oppressed. But shortly thereafter, I know I became smug and arrogant. I admit it felt good to hurl statistics about the 
numbers of poor and oppressed in public schools. I once had a teacher tell me after a staff meeting in which I presented on poverty, "Dave, you never once mentioned anything about the poor farm boy living in rural America and what he needs to do to overcome obstacles such as breaking out of poverty, getting a good education, and doing better than his parent did." I remember coming back with, "Well you know that's not a fair comparison. While there are more poor White folks in American schools, poverty in the African American community runs a much higher percentage, something like 33 percent to only 12 percent for Whites." This was a typical response of mine, which probably earned me the nickname of "Data Dave." It's hard to discern whether these types of interactions actually affect behavior and translate into a better understanding of social justice on the part of teachers and staff. It seems I need to keep my ego in check; that my sense of success and accomplishment should be derived from helping see that all students are served well and achieving. As the data show in my vignettes, I catch myself feeling good to dazzle people with numbers and statistics.

Freirean Commentary: From a Freirean perspective, some of the concepts exhibited in this vignette include paternalism, dialogical/antidialogical, manipulation, conquest, and false generosity. From a Freirean perspective, there are antidialogical elements in this vignette. One that is most concerning is that of the silence associated with paternalism.

There were clear opportunities for me to say something on behalf of Sam during team meetings or other interactions with staff. From a Freirean perspective, any silence is antidialogical, however, I believe the effect—even symbolic effect—created when an administrator fails to say something regarding an injustice in education is antidialogical. 
School leaders wield considerable symbolic influence in various settings, so to not communicate dialogically on the misguided "test and place" practice of students of color is tantamount to being a paternalistic oppressor.

From a Freirean perspective, the way I gathered resources to present to Jane to "win her over" was also antidialogical; specifically that of conquest, manipulation, and false generosity. Why did I take such a time-consuming interest in putting together an elaborate argument to "convince" Jane that certain aspects of testing are bias? In a classic Freirean sense, I believe I was trying to manipulate and conquer the situation through false generosity. Not only with Jane in this vignette, but many times administrators feel compelled to "enlighten" staff members with the latest research. From a Freirean perspective, administrators objectify teachers and staff, believing they need to be enlightened by administrators, as they do not possesses the proper knowledge to think critically about complex, difficult issues such as testing. There is a patriarchal "feel" to meting out data and research to teachers and staff.

In sum, all is not lost in the vignette. Indeed, from a Freirean perspective, setting aside my antidialogical misgivings, there were real dialogical opportunities in this experience. Dialogue surrounding the topic of bias in testing is authentically trying to uncover an issue in education that directly impacts students who have been traditionally marginalized in public schools. Additionally, from a Freirean perspective, I have critically and sufficiently reflected and considered this problem and now it is time to act on changing it. I had such a dialogical opportunity with Jane in this vignette. I needed to continue the critical dialogue rather than trying to let research, data, and information do the speaking for me. 


\section{Teacher Swap, Teacher Agency, and the Teacher as Hero Notion.}

\section{Tentative}

John had that look in his eyes again. It was a look that signaled a dearth of predictability. I felt uneasy. I didn't know what to expect when I walked into the team meeting with John that day. I suppose John could be considered one who "shoots from the hip." At times I really love him, really like what he says. Other times, he annoys me, really gets under my skin. For some reason, I'm always on his radar screen. He's constantly feeding me a steady diet of one-liners: "You're on your way up Dave ... I'm on my way out." Under his name on his e-mails it reads, "you never know what impact you have on someone by what you say or do." Needless to say, I knew something was brewing when we walked into the meeting together.

I wasn't saying much during this particular meeting, just sort of letting the teachers discuss matters on their agenda. Today I was taking the Henry David Thoreau approach to school leadership: "those administrators who administrate least administrate best." I would just stay out of the way.

John fidgeted in his chair, flashing occasional glances at me and the other teachers. His playfulness was obvious, although at the time I had absolutely no clue about what he was concocting. Days before, I remember John asking whether or not I showed the Mexican students I taught in Chicago the movie "Stand and Deliver." I answered affirmatively. He asked whether or not this inspired my former students to do better. I warned him that "hero" worship is a dangerous path to travel in school leadership. I pointed out that Hollywood loves 
to paint the picture that all poor minority students need is a hero in the classroom. I told him Jaime Escalante was just another example of oversimplifying a very complex, messy problem of school improvement.

I'm not sure how John pulled it off, but during the meeting he threw out the possibility of whether or not a teacher like Jaime Escalante could reach all our at-risk students. One teacher piped up and said that if we tracked students he could get all the at-risk students "proficient or above." Another teacher chimed in and stated that it all depended on student's home life, that good parents determine whether or not a child succeeds in school. I was confused, but anxious to contribute to the dialogue. I asked one of the teachers to name her best student. She did so, and I asked the following question: "Okay, Gene is your best student, straight A's, top of the class, model citizen, etc. Now let's put Gene in the lowest performing school in Cleveland. How does he do?" I couldn't distinguish one particular answer as several teachers spoke at once. There appeared to be some confusion regarding my proposition. I was quickly posed with a counter question from the teachers: "Do his parents go with him?" I said, "You choose." As the teachers talked about this scenario and how Gene would actually do, there seemed to be a consensus forming. They agreed that Gene would do well in an inner-city school only if his parents followed him to the low performing school. I asked them why they were being so modest. Why not take credit where credit is due? There was a long pause, and they all looked at me with blank stares. They weren't following me. I asked them if Gene's doing well in school had anything to do with good teachers and good instruction? 
My next question to them came quickly: "Do you think a $K-12$ education in this district is pretty darn good?" Heads nodded up and down. I then asked, "What would happen if one of our students had an ineffective teacher one year? Would/could she recover, bounce back academically the next year?" The teachers related personal stories about what might happen. One teacher stated that in his previous position, he initiated a "lunch club" program in which students ate lunch with him each day in his room while receiving extra help. He said that the students that participated in this program preformed "super well" on both their report cards and standardized tests. It was powerful and inspiring to hear him talk about how well his students did. The bell rang and we continued our conversation in the hallway. He noted that when he left his former school at least he knew those students who were with him during his "lunch club" benefited enormously. He couldn't say that of the students who never came to see him. His final comment was, "So ... yeah."

As I walked back to my office, my mind was racing a mile a minute. What did he mean by, “So ... yeah?” Yeah, good teaching trumps all educational obstacles? Yeah, take the hero out of the equation and kids don't learn? Yeah ... what? Did the teachers make some kind of connection between "hero theory" and student achievement? Did I make some kind of connection? What was John up to anyway? Did I dignify their work with my questions and prodding? Did they walk away thinking that their teaching makes a difference in all students' lives? I wasn't sure where I was going with my line of questioning during the conversation. At the time, I didn't think it a strategic line of questioning. I 
imagine I was somehow projecting a belief that good teaching occurs everywhere, and that the "good parents/good home life" myth is, well, just a myth. I would learn, however, that for some reason, teachers give an enormous amount of credit to the parents in this community, a community in which I, too, am a parent.

If there's one piece of writing that has stood the test of time, this is the one. It was one of the first experiences I had written, but even rereading it now it seems to still have relevance. This type of dialogue was/is not isolated. I have had many similar conversations that follow the same (and predictable) story line.

Freirean Commentary: From a Freirean perspective, some of the concepts exhibited in this vignette include problem posing, dialogic, conscientização, cooperation, and unity for liberation. Indeed, this vignette has recurred in similar ways frequently in my tenure as a school administrator. I believe there are several Freirean concepts that are moving toward dialogical cultural action in this vignette.

From a Freirean perspective, meaningful problem posing was used when asking teachers to consider their influence and agency through a hypothetical exchange of innercity and suburban teachers. Posing the problem to teachers about whether they matter and make a difference seems trivial, as the answer should always be obvious. However, for as long as I have posed this hypothetical scenario to teachers, they almost inevitably divert credit for student academic performance. I believe, from a Freirean perspective, for teachers to achieve true conscientização and realize their full potential, influence, and impact on students, they must participate in concepts of cooperation and of unity for liberation. The following are excerpts from Pedagogy of the Oppressed (Freire, 1970) on these two concepts: 
Thus cooperation leads dialogical Subjects to focus their attention on the reality which mediates them and which—posed as a problem—challenges them. The response to that challenge is the action of dialogical Subjects upon reality in order to transform it. (p. 168)

Freire (1970) stresses the importance of unity for liberation:

Whereas in the antidialogical theory of action the dominators are compelled by necessity to divide the oppressed, the more easily to preserve the state of oppression, in the dialogical theory the leaders must dedicate themselves to an untiring effort for unity among the oppressed — and unity of the leaders with the oppressed —in order to achieve liberation ... one becomes a true individual by sundering the false unity of the divided self. (pp. 172-173)

Although the way events played out in my vignette are not a perfect match to Freire's concepts of cooperation and unity of liberation, there are a few key similarities. What I was trying to accomplish in this vignette was, through hypothetical problem posing, to get teachers to genuinely consider their collective and individual influence and impact on students. By collective impact, I wanted teachers to come to a collaborative understanding that the vocation of teaching can be a means to create more equitable learning spaces for all students.

In sum, From a Freirean perspective, administrators wishing to practice leadership for social justice may conclude that the use of the hypothetical teacher-exchange scenario is a meaningful technique school leaders can use to promote dialogical cultural action. Similarly, from a Freirean perspective this may be a good way to unify teachers to realize how much influence they have in the classroom (i.e., a realization of their agency as 
teachers); however, my problem posing may need to go deeper. That is, the content, from a Freirean perspective, is thought provoking, sufficiently complex, and morally and ethically beneficial for students, but it follows—at times-more of a question/answer format ("I speak, you speak") rather than collaborative inquiry.

\section{Dinner Conversation.}

\section{Tentative}

It was one of those weeks again. By Friday, there was a nagging sense I did not do good work. I hate these kinds of weeks because these kinds of weeks represent all the things I do not want to become as an administrator. For the last five days I've found myself doing time-consuming things that don't seem to have anything to do with children. Yes, I know our school levy didn't pass and we need to cut personnel. I know I need to put together a new class schedule. I know I need to make sure the custodians disinfect hard surfaces every night. These are all important things that need to get done, but they are not what move us as a staff in a new direction. This week was one of those weeks that I did not seem to utter one single word about social justice in our school. It was just before the holidays, so everyone was a little on edge as there are a million things to get done in their classrooms and homes.

The week was over and the holidays were close, so there really wasn't any use in bringing up the subject of social justice, but I just felt this nagging sense to do it. The quick and easy way to do this, so I've learned, is to speak directly about the topic of study in my dissertation. Sometimes I can jump right in without making reference to my dissertation, but what I find is the dissertation project is a 
sort of hook to ask more questions, and to start and continue critical dialogue on social justice. So it was when I went out to dinner with some staff members.

We began with the usual small talk of what's good on the menu, what did you get last time you were here, it's nice to get out and relax once in a while, etc. But the question I waited to answer was "What are you doing over the break?" I let the question go around the table. I waited patiently. Each shared what was going on over break. I listened, nodded and commented with, "Wow, that sounds like fun." Then they got to me. "Dave, what are you doing over break?" To say I didn't have a plan on how to answer that question would be untrue. I bowed my head down a little, put both arms flat on the table and made a gesture with my right hand as if to feign writing. I told them I was excited to do some writing on my dissertation. Having done this several times in the past, I knew the protocol of questions that would follow. One strange phenomenon that always happens with issues of social justice is it quickly falls on the priority list if not concertedly kept in the forefront. That is, no one talks about social justice if no one talks about social justice. I've told my entire staff several times that my doctoral work is about social justice, however, the same questions come forth whenever I bring it up, usually in this order: 1. Oh, I didn't know you were writing your dissertation?; 2. How much longer do you have to finish?; 3. How long does it have to be? How many pages have you written so far?; and, 4. What's it on? The last question, "What's it on?" is the one I always wait for. When I say I'm writing on learning about how be a better leader for social justice, the conversation usually dies, unless, that is, someone wants to hear more. 
After getting through all the usual questions-which I don't like to answerSally leaned forward and asked, "Dave, what does leadership for social justice entail?" Not that I feel like I've laid a trap or anything, but it is an effective way to spark dialogue about important issues of social justice education. I stated that basically in public education some students are served well and some are not. Usually, that statement will kill the deal on the spot. I may get a few courtesy nods, but not many folks in schools want to talk about the inequality in public education.

It's interesting that there's really no guessing at what I'm claiming is the inequity in schools. Everyone seems to know that there's some type of "gap" between the mainstream kids (White upper middle class) and "others" (children of color and/or low income, students with an IEP, English language learners). But it's also interesting that we always start the conversation with African Americans. (Sometimes with Latinos if they know I speak Spanish.)

So after telling Sally that I'm trying to learn how to be a better principal so I can try to bring about a more socially just education for all students, she says what we all say. ... "Dave, don't you think it has a lot to do with we way a kid is raised? If he's raised to value education, then he'll be successful, don't you think?" By now, that's really all it took. Everyone at the table is engaged. The conversation isn't riveting (yet) but everyone now has to weigh in and make a comment. Cecilia says, "Some Black people are more racists than White people." Someone else says she grew up in Cleveland and it was bad. Janet, at the end of the table, doesn't say much but seems to be agreeing with my argument that 
regardless of what one thinks the cause is of the gap between groups of students, all children deserve the opportunity to do well. Janet helps me when she said, "But Dave, who creates that opportunity for all kids to succeed?" I said that is a very difficult question to answer, that I don't know how to bring about this type of “overnight” change.

Janet's comments were only a short interlude to the overall discussion as the others weren't having any of the "opportunity discussion." I didn't mind, because I had another move lined up. As I looked around the table, I was the only male; and the youngest. I couldn't very well argue with these women that it's not the fault of Black kids or their parents for not doing well in school, our school. I was clearly outnumbered. I felt it necessary to give familiarity to my fellow colleagues. This is when I linked the Black plight with that of women. Now I could have been way off base, or out of line, but it seemed to work. I explained that if you're Black and born in a particular zip code your life chances at being successful in school could be limited. They waited for me to go on, because this comparison alone wasn't working. I said it's kind of like trying to name all the female CEOs we know. Silence. Dead silence. Or trying to name all the female superintendents we know. More silence. More dead silence. I used my school district as an example.

Because my school district and community could be considered, in a phrase, very traditionally conservative, I needed to make the link to inequality that made sense. I wanted to press for critical consciousness but it had to be comprehensible to the women. They obviously did not seem too sympathetic to people of color and the ravages of racism. And after trying the "in your face tactic of 'if you're the 
wrong color in the wrong zip code", argument, I thought of something else. Having a woman superintendent in my very conservative district would be highly improbable. Of some 550 employees, only a handful, less than five, are people of color. Further, there is only one certificated employee (guidance counselor) currently working in our district. Nonetheless, I asked the question to my friends. "Do think it would be easy for a woman to become superintendent in our school district?" Some more silence.

It seemed to click after I asked this question, though. Everyone around the table knew I was making the glass-ceiling link between people of color and women-both in school and in the work world. Because the colleagues with whom I had dinner were women, it appeared the critical consciousness was personal, and, seemingly, more effective. They could have been yanking my chain, but they truly seemed to get it. It seemed like they were able to internalize the Black struggle with their own struggles as women. Because they must have felt a similar marginalization being a women at some point in their life, there was (at least there appeared to be) some transfer to the understanding of marginalization of students of color, and perhaps others as well (ELLs, students with an IEP, etc.) This was the most recent vignette on a dialogical experience directly related to social justice. Although it is probably naïve to say it was miraculous, it seemed extremely positive and potentially transformative for me and some staff members. In the time leading up to the dinner conversation, I was portraying a previous vignette "The Manager is in the Principal's Office." First, it began with that "nagging feeling" of yet another one of my retreats from social justice work. Yet again, time had gone by and I was not 
engaged in the work of social justice; rather, I was being a manager and "getting things done, marking off items on the to-do checklist." Although I used many of the same techniques to bring about critical dialogue on issues of social justice in the hopes of raising awareness, I seemed to do it in a manner that was less emotionally charged. I relied on evidence, facts, and data. After all, it is difficult to dispute a history of inequality between men and women in this country. There appear to be pivotal learning moments for me in this vignette. One such moment was getting everyone quickly engaged in the dinner conversation, a discussion explicitly dealing with social justice. Thus, although not perfect, it is, evolutionarily speaking, different from some previous attempts to do the same.

Freirean Commentary: From a Freirean perspective, some of the concepts exhibited in this vignette included problem posing, dialogic, conscientização, and praxis. Present in this vignette was not only the Freirean concept of problem posing, but twoway problem posing between the staff and me (e.g., "But Dave, who creates that opportunity for all kids to succeed?"). From a Freirean perspective, this moves all those involved in this critical discussion on a meaningful issue closer to dialogical cultural action.

From a Freirean perspective the staff members did indeed successfully consider the link between women and people of color; that both face oppressive structures in society that prohibit true freedom. This critical consideration, understanding, and reflection of the social, political, and economic contradictions in society may have been the beginning of conscientização and praxis. Moreover, from a Freirean perspective, I, as a leader, used techniques that worked more effectively in stimulating critical dialogue, 
and getting more commitment and agreement from those with whom I was attempting to collaborate. However, there is a word of caution.

On occasion in this vignette, when I revealed to the reader that I "knew what my next move was going to be" or "I was waiting for such a moment as I have a plan" I may need to "proceed with caution" in those instances. From a Freirean perspective, these occasions when I need to proceed with caution could be viewed as flirting with paternalistic behavior. Although it is appropriate as a leader to have a plan when these moments arrive in which opportunities for open, critical dialogue can occur, one must be careful not to be condescending in working with staff members with a "packaged" routine that treats all situations and people the same. This would immediately move to objectify participating members and possibly—in Freirean terms - turn them into "things" to be conquered (Freire, 1970, p. 167). I need to be careful that, as stated in the vignette, I do not behave in a condescending fashion (e.g., "but it had to be comprehensible to the women"). This, too, can turn quickly into paternalistic behavior thereby leading to antidialogical rather than dialogical cultural action.

In sum, from a Freirean perspective, there are many positive steps I have taken to move toward dialogical cultural action with these staff members, as there exists evidence of dialogue surrounding important issues in education, particularly that of social justice (i.e., "no one talks about social justice if no one talks about social justice"). Additionally, from a Freirean perspective, to uncover, explore, understand, and authentically address issues of social justice in schools there needs to be mutual problem posing and a level of critical consciousness through the use and refinement of careful questioning techniques, as evidenced in this vignette. Finally, school leaders who are entrusted to work with 
teachers and staff need to proceed with caution, as the dignity and lived experiences of all involved is important. If leaders are to be authentically in unity with their followersbecause much is at stake for such meaningful issues in education-leaders must try to avoid antidialogical interactions at all times.

\section{The Vignettes as My Ongoing Story of Learning}

These 17 vignettes represent my ongoing story in the process of learning (or trying to learn) to practice leadership for social justice. There was some direction provided in reading them, as they were arranged into adjectival categories. The next chapter, as well as subsequent discussion, will begin to analyze the vignettes as to what these stories mean in my learning process to leading for social justice. 


\section{CHAPTER VI}

\section{MODIFYING THE LEARNING PROCESS}

It is difficult to describe and explain the process of trying to learn how to practice leadership for social justice. I believe an honest pathway into analyzing the learning process depicted in the vignettes is with the use of adjectives. Modifying the learning process through the use of adjectives is valuable for many reasons. First, the adjectives are simple, clear, and accessible for anyone to understand. The work of school leadership is important and needs to be understood in ways that empower school administrators to act. Truly, I believe, the work of better serving all students in schools is—or should bethe topmost priority for all of us (educators and noneducators). Using simple, clear, and accessible adjectives to describe this work can only help further the cause of social justice in schools. Moreover, the adjectives used to tag the vignettes are in plain language, and clearly depict what was going on in a given situation or interaction. I believe the adjectives emotional and euphoric, contentious and inconsistent, and uncertain and tentative do not pose any immediate confusion; rather, they are descriptive words to which anyone can relate. They are neither nebulous nor vague. Second, the adjectives are not finite, fixed, or static. In trying to learn how to lead for social justice, my experiences and learning have been ongoing, never-ending, and diverse. Similarly, my experiences seem to be fairly broad-ranging in many aspects. The use of adjectives helps describe and encompass just how broad-ranging learning experiences can be when trying to lead for 
social justice. For example, the adjectives euphoric and contentious accurately describe just how diverse, and in some cases, diametrically opposite to the work of leadership for social justice in schools. The adjective tentative can bring forth a rich meaning that suggests my momentary understanding of reality, as well as my careful procession of how to lead in the present. Thus, the use of adjectives is helpful in describing and modifying how the learning process manifested in learning how to practice leadership for social justice.

The experiences school leaders may go through seem to be incomplete. In the following discussions, I attempt to align adjectives with the responsive role they played in the vignettes. Although there certainly may be many other interpretations, the following is one interpretation of the ongoing learning process in this study.

\section{An Emotional and Euphoric Response}

My initial reaction to the theoretical literature on leadership for social justice was exhilarating. I was energized by "the call" by scholars in the literature for more just and equitable learning environments for all students in all schools. This initial reaction produced behaviors, actions, and beliefs that could be described as emotional and euphoric. It was emotional to think about the unfairness in schools, that some students are served well whereas others are not. It was emotional to think the lines of equitability were usually drawn on race, class, ability/disability, and native-language proficiency. To think of these injustices in schools, one can easily become emotional, even angry. It was equally euphoric to think and believe I could make a difference in improving inequitable learning arrangements in schools. Emotional and euphoric responses were recorded in the data in such vignettes as "The Hero-A Lance Armstrong Analogy to Leadership for 
Social Justice." and "Stanford Testing, Race, and the Importance of Teachers' Agency." It is clear that when leaders are in these emotional and euphoric spaces, they believe in making a difference, in changing the status quo, and ultimately assisting in creating a more just learning environment in school for all students.

A school leader's emotional connectedness to making a difference does not happen only once, at the beginning of learning or reading theoretical literature on leadership for social justice. When I initially read the theoretical literature on leadership for social justices (Brown, 2004; Furman, 2003a; Larson \& Murtadha, 2002; Marshall, 1995; Murphy, 2002; Shields, 2004), they served as a starting point for me in this study; however, I am still emotional about making a difference and trying to lead for social justice. In many of the 17 vignettes there is evidence of emotional and of euphoric responses. Thus, part of the experience of learning to practice leadership for social justice includes one's emotional connectedness to trying to alleviate unjust and inequitable learning environments in school.

\section{A Contentious and Inconsistent Response}

In addition to emotional and euphoric, it seems possible that leaders learning to practice leadership for social justice would experience the feelings contentious and inconsistent. Once I knew I was emotionally committed to the purpose of leadership for social justice, and I could think of the possibilities of assisting to bring about change in school, I felt I wanted to act on what I believed. This is probably similar to Freire borrowing the Hegelian theory of praxis; a connection between theory and practice, reflection and active attempts to transform the world (Freire, 1970). 
As a school leader, impacting change and leading for social justice inevitably means entering into dialogical relationships with staff. This is where possible contentious interactions can occur. School leaders engaging in contentious interactions with staff and colleagues on issues of social justice seems inevitable. However, the interactions do not necessarily need to be negatively contentious. Many examples in the vignettes point to such strategies as Freire's use of problem posing to ask staff and colleagues to think about potential alternative ways of thinking how to best serve all students. Examples in vignettes such as "What Do You Want Us to Do Dave?" and "The Tracking Debate Goes On." show how debating and arguing issues of social justice can be contentious, but positive and productive:

However, there are contentious interactions with staff and colleagues on the part of school leaders. These interactions may be frustrating for the school administrator. This frustration resulting in contentious interactions can be evidenced in my data in the vignettes "My First Real Attempt at a Team Meeting.” “I Don't Know What I'm Doing. Sarcasm Doesn't Work.” and “Sarcasm Is Not Effective. People Want Me to Make a Decision.” For example, in some of the vignettes, when I seemed most frustrated about not dialoguing on what I thought were important issues of social justice and how to best serve all students, I made sarcastic remarks that were often construed as being contentious.

So far, I have proposed—aligned with the vignettes—-two possible learning experiences for administrators trying to lead for social justice. After becoming initially energized by the theoretical literature on leadership for social justice, there seems to be 
an emotional connection and a commitment to leadership for social justice, as well as a euphoric feeling that one can make a difference and improve education for all students. Then, there seems to be a learning experience that includes moments of contentious and inconsistent engagement, as the school leader tries to put to practice the theories of leadership for social justice. Yet another learning experience occurs that could be described with the adjectives uncertain and tentative.

\section{An Uncertain and Tentative Response}

At first glance, the adjective tentative would appear to be a "way of being" that school administrators would strive to avoid. From the outside looking in, to be tentative in school leadership may appear to others as a weakness, lack of confidence, insecurity, an inability to be bold with various initiatives, and even stern, when dealing with difficult staff members. However, meaningful change in improving the life changes and academic success for all students cannot be accomplished with a singular type of leadership; leaders must recognize the broad spectrum of the ongoing learning process that everyone in education experiences.

To be certain, it is dangerous in education to think of learning in static terms; that is, once something is learned it becomes fixed, finite, and can never be unlearned or amended. Learning is tentative in education. Tentative learning does not mean fleeting, elusive, or timid. By tentative learning I specifically mean learning that is more provisional and existing for the present, always subject to change. Trying to practice leadership for social justice is tentative in many aspects. Knowing that learning is subject to change, any interactions or learning experience is thus open to change. Learning to 
practice leadership for social justice is tentative because the hope is that learning experiences and interactions with staff are not finite and final.

In my learning experiences to try to practice leadership for social justice, there seemed to be times when I questioned my overall commitment to leadership for social justice; a retreat of sorts from practicing leadership for social justice. I have experienced uncertain times in my commitment to leadership for social justice. It is difficult for White male school leaders to reconcile their background with trying to practice leadership for social justice. In my case, this notion is accentuated as believability comes to the fore in purposefully addressing the fact that a White man attempts to practice leadership for social justice in an affluent, mostly racially and socioeconomic homogeneous suburb.

Along the similar lines, leadership for social justice is permeated with uncertainties along the way. It is uncertain when one is learning to practice leadership for social justice. Trying to engage professionals in dialogue that questions their belief system almost inevitably results in uncertainty on may levels. Such questions as whether swapping teachings in the inner city and suburbs means anything can provoke responses that are uncertain. Thus, the adjectives uncertain and tentative could be used to describe another learning experience of trying to practice leadership for social justice. Below, I discuss the difference between the two adjectives.

\section{Difference Between Uncertain and Tentative}

There is a difference between the two adjectives uncertain and tentative. I used the adjective uncertain to describe times in the data when I am uncertain about the usefulness, purpose, and even my own commitment to leadership for social justice. In contrast, I used the adjective tentative to describe times in the data when I am not 
questioning leadership for social justice but my behaviors and actions indicate some hesitancy and reluctance to do what I know to be meaningful and aligned with the orientation of leadership for social justice.

My uncertainty about practicing leadership for social justice can be found in several vignettes including "The Manager Is in the Principal's Office." "Still Struggling With the Who, How, and Why of Leadership for Social Justice." "I Question Myself." and "The Reporter Gets Dave Centered Again on What's Important in School." In these vignettes, evidence seems to indicate a level of doubt, even retreat from the orientation of leadership for social justice. For example, in the vignette, "The Manager Is in the Principal's Office." I seem to be consumed by the notion of efficiency. This leads to the concept of "false veracity" and the "leading in two worlds." One world is that of leadership for social justice. The other is traditional leadership. In this case, according to the data in this vignette, being a manager in a school seems to align more with traditional leadership. The dilemma of leading in two worlds will be described in more depth later in this study.

The adjective tentative, used as a category heading for some of the vignettes, is different from uncertain. By far, this adjective draws the most vignettes under its category heading. It is a pervasive feeling, attitude, behavior, and action in the data. At many times, being tentative seemed to best describe the learning process of trying to practice leadership for social justice as a White man.

Many of the vignettes overlap in categories. This is to say, although there is evidence in the data to support categorizing vignettes under the adjective emotional, for example, the same vignette may fall into more than one category. For example, the 
vignette "What Do You Want Us to Do Dave?" falls under both the adjectival headings of emotional and tentative. Similarly, the vignette "Data Dave is Born." falls under both euphoric and tentative.

It can be difficult to draw conclusions when analyzing oneself. When I analyzed these vignettes, I looked for patterns, recurring themes, or behaviors that seemed to be salient in answering the research question. As expected, I struggled with issues of subjectivity and objectivity. At times, studying oneself takes some of the emotion out of the analysis: studying myself is familiar because I am attempting to analyze my very own actions, beliefs, decisions, and leadership. In contrast, looking directly at a particular core behavior that may or may not coincide with what the literature on leadership for social justice calls for can be emotional, especially if a school leader is doing the opposite of leading for social justice. The struggle of studying oneself, and the challenge I continue to battle with in self-reflection and action, is my narcissistic tendencies. This is why the Freirean theoretical framework helped in structuring my analysis, and was presented after each vignette. Because an autoethnography is a close analysis of oneself, becoming too obsessed with one's own behaviors can be narcissistic. Thus, the hope is the Freirean theoretical framework will serve as a reference lens to assist in avoiding an analysis too narcissistic, but still critical and thorough. I tried to look for an honest story that reflected a deeper sense of what may have been going on with my learning process.

\section{Paternalistic Behavior and Another Retreat from Leadership for Social Justice}

The data indicated some inclination to paternalistic behavior on my part. Because the original vignettes have not been altered, they may authentically capture a "way of being" at the time the vignette was written. This way of being, in some cases, reflected a 
feeling or action of mine. Some of the data indicated arrogance. At other places, there is a presumptuous tone in my writing. This tone, according to the "theory of antidialogical action ... involves a Subject who conquers another person and transforms her or him into a 'thing"” (Freire, 1970, p. 167). In the vignette, "Still Struggling With the Who, How, and Why of Leadership for Social Justice." the data showed I seemingly do not care about the other, but rather am focused on myself. It also indicates that, had I allowed the other to contribute more positively during our interaction, I would likely only have been interested in the teacher agreeing with my struggle to figure out who is poor. Thus, the paternalistic behaviors in the data indicated antidialogical examples, not mutual trust. More succinctly, the data where a paternalistic behavior was noted could represent more of a hierarchical than a horizontal relationship.

Another somewhat salient area in the data is my tentativeness and uncertainty. I really struggled with what to do and how to do it. On one hand, data could be interpreted to show I am not practicing leadership for social justice (i.e., questioning myself, sometimes aloud, rather than engaging dialogically with staff members). On the other hand, data could be interpreted to indicate that trying to practice leadership for social justice is complicated work, full of uncertainties. Present in much of the data is the questioning of myself, my ability to be a leader for social justice, my commitment to social justice, and my false veracity. This is especially important to me as one commonality in the data is getting off track and preoccupying myself with how I should "be" as a leader for social justice. The retreat from leadership for social justice does occur from time to time in my learning experiences. Considering the vignette, "The Manager Is in the Principal's Office.," and my aversions to false veracity and leading for social 
justice, it is clear that the very thing I tried to avoid, a traditional, managerial orientation to leading my school, is what I am practicing. It would seem that false veracity is the antitheses of "how" one should lead for social justice. In the data, there may be many reasons for my false veracity to the practice of leadership for social justice such as internal/external pressure, fear, not bridging theory and practice, and not staying current with leadership for social justice literature. Nonetheless, false veracity to leadership for social justice in my vignettes is an honest portrayal of my learning how to practice leadership for social justice. In the next few paragraphs I delve more deeply into what may be manifest in my learning process of trying to practice leadership for social justice.

\section{A Deeper Look into Teaching, Administration and Inner-city and Suburban Schools}

Asking why I work as an administrator in an affluent, nearly all-White suburb is a regular occurrence for me. Some days I question why I left the seemingly meaningful work of inner-city Chicago and Cleveland to work in the affluent suburbs. Working in the inner city, in schools that were predominately non-White, nonaffluent, seemed more meaningful in addressing issues of social justice. The need and urgency for better schools, teachers, and administrators is undeniable in many inner-city schools. This need was visible and present in my work each day in Chicago and Cleveland. I knew I would continually encounter issues of social justice in inner-city Chicago and Cleveland. The needs of the students, at times, were pervasive. It was difficult to avoid issues of social justice, as the needs of the students were very evident in the everyday work in Chicago and Cleveland. One clear example is that of academic performance.

Hacker (1995) cited many examples of performance data that point to an achievement gap. Darling-Hammond et al. (2001; Darling-Hammond, Holtzman, Gatlin, 
\& Heilig, 2005) closely examined the differences between schools with highly qualified teachers and those that do not have highly qualified teachers. Evidence abounds that schools predominately serving students of color, students receiving free and reducedprice lunches, and students whose native language is not English perform lower academically. In contrast, schools and districts in the suburbs that are predominately White, affluent, and have highly qualified teachers teaching all subject areas perform better academically. This can be seen on many different measures, ranging from a narrow high-stakes state test to graduation rates.

Serving all students well should be the unceasing intent of the teachers, staff, and administrators in all schools. Analyzing my data did not include a comparison of my dramatically different experiences from the inner-city of Chicago to the suburbs of Cleveland. The implicit distinction between my work in Chicago and my current work in a suburban school is evident. As a teacher in Chicago, approximately $80 \%$ of my students spoke Spanish as their native language. All students in the school received free and reduced-price lunches. Gang violence was common and most students were unlikely to graduate from high school. In Chicago, seemingly all students I taught were marginalized, faced less chances of academic success, and were more likely to withdraw from school. Currently, students in my suburban school do not face these challenges. Some students are marginalized in my school, or even by society. In some cases, students with an IEP, the few students who are receiving free and reduced-price lunches, or students who do not speak English as their native language are at greater risk of academic difficulty than their typical suburban peers. Trying to reconcile the obvious social-justice 
work in the inner city with the more discrete work in the suburb can erode the attempt to do social justice work at all.

\section{The "Eroding" Issue: Trying to Avoid the Retreat From Leadership for Social}

\section{Justice}

In some regards, because the sense of urgency in the suburbs for social justice is much less present—but still a need-administrators can remove themselves from the meaningful work of trying to serve all students well. The erosion of commitment to social justice is real in the suburbs. In the inner city, educators and administrators have a sense of urgency, understanding that their work is meaningful. Because students are not served well in the inner city, there is clear "academic ground" to reclaim. The achievement gap is always prevalent, even discussed openly. In the suburbs, there is always a push to improve, but lost in the discussion are the students who may need to reclaim the most academic ground. There is an achievement gap in my suburban school district, but it is not talked about frequently or openly.

It is quite easy to become "professionally distracted" working in the suburbs. Other aspects of schools take precedence, such as fundraisers, schedules, and night events. Data without a social-justice focus consume days, weeks, and months of time. However, I argue that the urgency of social justice is not solely eclipsed by administrators becoming professionally distracted. School administrators are not overtly trying to avoid addressing issues of social justice. It may be that because administrators in suburban schools are not faced with pressing issues of social justice each day, the importance of social justice begins to erode until, eventually, it is not important. This is why, to avoid being professionally distracted from meaningful issues of social justice, 
administrators in the suburbs must essentially "force the issue" and actively engage themselves with others in purposeful dialogue aimed at social justice and serving all students well.

This erosion may be the reason this project and leadership for social justice are so important to me. I have made an effort to avoid the outcome of being professionally distracted from important social justice issues in school. My background working in urban schools has carried over to my present position in the suburbs, and I feel a sense of urgency to force issues of social justice now. However, sometimes I am unable to do this. Why I cannot seem to "shake" or avoid this distraction entirely will be addressed in the last chapter.

In many instances in the vignettes there were purposeful problem-posing examples aimed at sparking dialogue on how to address issues of social justice in school. However, equally evident in the data are examples of me getting off track and not trying to lead for social justice. It appeared that if I did not actively try to force the issue of social justice, important dialogue did not surface. Perhaps this argument can be made about any school administrator anywhere; we seem to do a better job in the suburbs of becoming professionally distracted from social justice, rather than confronting injustices directly in our schools.

In sum, there are two important points here. First, regarding my learning to lead for social justice, it is vitally important that if there is any chance of leading for social justice, it is not "just going to happen" if I do not specifically bring it up, or force the issue of social justice. The second point speaks to my positionality, and the reconciling of my privileged status and commitment to leadership for social justice. 


\section{Continual Learning}

There is no end point for this project. The work is ongoing, and my learning to be a leader for social justice has not concluded. There are some conclusions that could be drawn as a result of looking at the data gathered and the research question initially posed in this project. Gathering data on learning how to be a leader for social justice, it has been clear to me that there is no one way, method, or style on how to lead for social justice in school. It appears that, unlike other traditional-leadership models, leading for social justice is as complex, fluid, and challenging as anything in public schools. In other words, although there may be a more prescribed, formulaic "way" to lead with traditional models such as situational leadership (Hersey, Blanchard, \& Natemeyer, 1979), leadership for social justice does not follow any pattern, matrix, step by step, or checklist. In examining my attempts to practice leadership for social justice in school, I believe that leading for social justice cannot be formulaic because it assumes human relationships are complex and unpredictable. The transactional nature of traditional leadership has, as its goal, obtaining some end (more work from the employee, more efficiency in the organization, etc.), whereas leadership for social justice strives for liberation for all, improving the academic and life chances for all students, and educational equity for all students. In the following paragraphs, I attempt to draw some conclusions as a result of trying to practice leadership for social justice in school.

\section{Researched Question Addressed}

The research question in this project was as follows: How does the ongoing learning process to practice leadership for social justice manifest in a public middle school? 
The only departure from the original research question would be rather than in a public middle school it could ask in school, as I gathered data in an elementary and a middle school. The extent to which the research question was addressed or answered will now be examined.

First, it is clear from the data gathered that I am still learning to be a leader for social justice. There is no end point to my learning. There is no definitive time when data clearly showed some high level of proficiency at being a leader for social justice. Rather, there were many examples of ups and downs, starts and stops, and successes and failures. Researching myself through an autoethnography has enabled me to gain insight into who I am, particularly my position as a White school administrator. It was prevalent many times in the data that paternalistic behaviors and actions surfaced. Similarly, the resistance to (but my acquiescence of) traditional forms of leadership offered a difficult paradox and personal challenge. Further explanation is needed.

I am a White male of privilege in a position of power, attempting to practice leadership for social justice in a school located in an affluent, nearly all-White suburb. Set apart, this statement would definitely minimize the legitimacy of this project. One should ask whether a school leader belonging to these three groups (White, male, privilege) can even practice leadership for social justice. It simply does not seem genuine that, having no history of suffering from systematic oppression such as racism or sexism, I could have the wherewithal, ability, or compelling feeling to somehow understand the plight of those who have been discriminated against and oppressed by institutions such as public education. Not being a minority, I cannot argue to have ever had first-hand knowledge of what students who have been discriminated against go through on a daily 
basis. I can only try to assist in working to bring about change, and hopefully, improve the educational outcomes and life chances of those students who have been traditionally marginalized.

Recently, in the social sciences, autoethnographic studies have given voice to people who have been traditionally marginalized in society. The logical dilemma is that because I hail from the dominant group, I have not been marginalized. My voice has not been shut out. Yet, I am conducting a study on what the learning process looks like in trying to practice leadership for social justice. A more appropriate question may be whether a White man of privilege should even be conducting a study on leadership for social justice. The question of whether I should benefit from a study of learning how to practice leadership for social justice is a legitimate one. In one sense, it seems I am perpetuating the status quo of White male dominance in schools by conducting this study. However, in another sense, assuming White men contribute to perpetuation of social injustices in schools, it would be good to have White men of privilege try to learn to be better leaders for social justice.

The question must be asked whether I should be trying to practice leadership for social justice. Logic would indicated that a person other than me, one with a better understanding of what oppression means, should be leading for social justice in my school. Many times during this study I have questioned if I am doing more harm than good. Although I want to practice leadership for social justice, I am uncertain how others may view this. How can I be believable as a leader for social justice when I am White, privileged, and in a position of authority? According to some examples in the data, I am doing things that are actually the opposite of social justice. Some of my behaviors are not 
democratic, but paternalistic. To address this question, it is appropriate and meaningful to return to the adjectives.

\section{The Adjectives Used and Moving Toward a Meaningful Story}

In the following discussion, each adjective will serve as a springboard into a meaningful story emerging from this study. Following the discussion of each adjective, I will attempt to allow a meaningful story to emerge from the data in this study.

\section{Tentative}

At the beginning of this project, my attitude and approach toward learning how to practice leadership for social justice was not tentative. In the beginning, my attitude and approach could best be described as brash, or even arrogant. This was evidenced in the first vignette. However, on many occasions (as well as the present time) I have exhibited behavior that is best described as tentative. Several times I have questioned myself on why I did not simply say something in a situation that I perceived as unjust. Even when that same situation would arise again, I still failed to say something. Shields (2006) wrote about the pathologies of silence in fighting against injustices in schools. In not speaking up, or by taking insufficient action, my tentativeness could be traced back to not wanting to cause trouble or get in trouble with those in power. I am not shifting responsibility; rather, according to the data, it appeared that my tentativeness was not due to any overt reason to maintain the status quo and my privilege as a White male. Again, there does not appear to be any overt evidence of this; however, there may have been, to some degree, more subtle behaviors that at least subconsciously would indicate that I had a vested interest in remaining tentative in trying to lead for social justice. 
If being tentative could accurately describe what it looks like to lead for social justice, there may be a positive side to being tentative in trying to practice leadership for social justice. Being tentative in my varied leadership functions (e.g., decision making) indicates I am still growing; that I do not know everything there is to know about leading for social justice. In short, the adjective tentativeness may be synonymous with learning how to practice leadership for social justice. There could be an advantage to being tentative in trying to practice leadership for social justice. In some ways, being tentative has helped keep in check some of my paternalistic behaviors. Although my paternalistic behaviors certainly came out while trying to practice leadership for social justice, they could have been more prevalent had I not been tentative at times. In this way, there was an advantage to being tentative, as I could have been more counterproductive to social justice. However, silence is not productive either, and I needed to overcome my propensity to be silent (while maintaining paternalistic behaviors at bay). Digging deeper, however, tentative could have another meaning.

Despite what traditional leaders prescribe to school administrators- that one needs to be decisive, driven, confident, and self-assured-I believe that being tentative when learning to practice leadership for social justice is a virtuous pursuit for all school leaders. First, and particularly in the case of White male school administrators with influence and authority, being tentative in learning to practice leadership for social justice signals an ongoing learning process. To be certain, in many of the vignettes, where I thought I "knew what I was doing," it almost inevitably turned out that I learned something. This is meaningful because it shows that to change existing oppressive structures in school, leaders need to at least begin with an open mind on how to do this. 
Thus, the adjective tentative could take on the meaning of provisional, on-time learning that is always subject to change.

\section{Uncertain}

It is important to note the difference between the two adjectives, tentative and uncertain. The way I understand it, and as it will emerge later into a meaningful story, tentativeness to lead for social justice could be associated with some degree of fear. I may have very well known it was good to speak up when an opportunity arose and be a leader for social justice. I did not, and thus felt guilty for not doing what I knew to be socially just. In contrast, being uncertain to practice leadership for social justice is different. The adjective uncertain, in this study, means not only do I refrain from stepping up and being a leader for social justice, but questioning myself, others, and perhaps the entire theory of leadership for social justice. I may have been uncertain at times as to why I should practice leadership for social justice. It is those times in the data when I retreated from leadership for social justice. It is different from tentativeness because with tentativeness, I seemed to still believe that social justice is important. Perhaps with the adjective uncertain, I question the truthfulness of social justice. Being uncertain in trying to practice leadership for social justice will emerge later in the "Meaningful Story" in the next chapter as a default into traditional leadership that looks more antidialogical cultural action.

There are a few reasons why uncertainty is appropriate in describing my attempts to practice leadership for social justice. First, I do not belong to a group that has been traditionally marginalized in society. This alone can make my work suspect: I do not fully understand what oppressed individuals have experienced. Second, because the 
literature is still emerging on how the theoretical construct of leadership for social justice manifests in practice, I am unable to claim expertise. Last, the data in this study do not support some level of excellence or even proficiency. Particularly, there is no layered description other than that of myself. Data showed how I tried to practice leadership for social justice, but the effect I had interacting with individuals is unclear. Only time and follow up could reveal my impact in trying to practice leadership for social justice. Uncertainty indicated in the data is both not knowing (or understanding) what to do, as well as not knowing my effect on others. I know from the theoretical literature that I should strive to eliminate injustices in school, and that I should lead so that others think likewise, however, actualizing that goal was difficult to obtain. This was the uncertainty I experienced in trying to practice leadership for social justice.

\section{Emotional}

The work of trying to practice leadership for social justice in school is emotional. Looking at the data, on more than one occasion, I had become emotional. Some of this emotion was manifested in sarcastic comments or behavior. This is regrettable because sarcasm, at least in my data, did not seem to lead to a transforming of action in favor of more equitable and just education for all students. Rather, my emotional sarcasm often led to the opposite. I found in the data that when I responded sarcastically to a particular issue I perceived as unjust, most often staff members did not respond, ceased to engage in dialogue with me, and took the opposing view that it is better (or at least easier) to not address social injustices in school.

Perhaps emotional responses are to be expected in trying to practice leadership for social justice. As educators, thinking about the effect of social injustices in school can 
provoke emotion. As evidenced in the data, it provoked an emotional response from me. Sarcasm is certainly not an appropriate response from administrators when trying to practice leadership for social justice; however, in some cases it seemed inevitable.

Emotional behavior accurately describes me trying to lead for social justice. On one hand, being emotional led to anger, which led to sarcasm in my leadership approach. On the other hand, being emotional about social justice signals a level of commitment and passion to alleviate and, if possible, eliminate, unjust learning environments in school. In sum, the work of leadership for social justice is challenging. When I am most committed, I am emotional about affecting change. Trying to undue the status quo that privileges some students over others in school is difficult and emotional work. According to data collected, it would appear that the way I channeled my emotion and passion for changing injustices in school seems to be my ongoing challenge.

\section{Euphoric}

There are two ways of viewing learning to practice leadership for social justice as euphoric. First, as seen in the data, there were times of great exhilaration, times when I felt I was doing good, meaningful work with teachers, staff members, and students. On a few occasions, through dialogue and relationship building, I was able to get people to think and feel more deeply about social justice and how to better serve children in school. These times were small successes that were short lived or did not affect more than one or two people. Nonetheless, it was a euphoric moment when I could see colleagues' attitudes and actions changing to better serve all students. It was euphoric when I played a role in getting teachers to rediscover their agency, helping them believe that what they do in the classroom can be very powerful in helping all students learn. 
However, in staying true to the adjectives that honestly describe what it looks like in practice to try and lead for social justice, the feeling of euphoria at times was somewhat negative. On occasion, there seemed to be a paternalistic side to the euphoric feeling of accomplishing something with teachers and staff. Looking at the data, I had to try to guard against times when popular decisions brought me popularity. It was euphoric to feel this popularity; however, I should have made it clear why certain decisions were made: I was attempting to put students first, not please staff members. Sometimes I failed to make mention of the coincidental nature of popular decisions with doing good for students. Rather than showcasing the goodness of making such decisions with social justice, I accepted all the accolades for myself.

\section{Contentious}

This is an appropriate word to describe some of my dialogical (or antidialogical) interactions with colleagues in trying to practice leadership for social justice. Whereas other adjectives described certain aspects of how it manifests to learn how to practice leadership for social justice, contentious centers mostly on the struggle to bring about change in my school district. Unlike my emotional responses, which were often inappropriate, being contentious and argumentative with my colleagues usually did not push people away or close dialogue all together. If I were able to stay calm, contentious dialogue was productive and beneficial in getting people to consider the injustices in school and what to do about them. However, at least early in my tenure, my contentiousness would lead to some form of personal statement ("My wife is an English language learner"), which ultimately gave way to an emotionally charged interaction on my part. 
Some of the contentious moments in trying to practice leadership for social justice occurred because of the nature of the district. I often battled with others (and myself) regarding who truly is oppressed and marginalized in our White, affluent suburb. I contentiously argued that whereas $95 \%$ of our students are performing well academically, if we dig deeper to find out who comprises the $5 \%$ that is not performing well, we will often uncover the ugly truth that it is those students that have been traditionally marginalized in society and in public education (students of color, students with an IEP, students receiving free and reduced-price lunches, etc.). Conversations became contentious when this was uncovered because the $5 \%$ who were not performing well had been well hidden for so long in my district.

Leading for social justice is contentious. Although I backed out of potential battles because of fear, or leadership weakness, changing the status quo in schools requires contentious battles and arguments. Social justice is about fighting against prejudice like racism and discrimination. Fighting for equality for all students in school is important, meaningful work. Contentious is an accurate word to describe what I believe it takes to lead for social justice in schools; however, to be clear and honest, it does not describe my leadership action at all times. Looking at the data, clearly there were times I was contentious and willing to fight for social justice. Other times, I backed away from a potentially contentious moment. Although it may not be the scope of this project to figure out why I would back down, suffice is to say I did when I should not have.

\section{Inconsistent}

Along with inconsistency in my leadership action in trying to lead for social justice is the notion of starts and stops. The learning process for me has been one of starts 
and stops. Looking at the data, which is spread out over time, they indicate a pattern of starts and stops. Chronologically, the data appear nonlinear. There seems to be no clear progression in the data of becoming a more and more proficient leader for social justice over time. If the first vignette is compared to the last, there does appear to be a progression of improvement; however, I seem to encounter the same pitfalls (i.e., starts and stops) at different points throughout the collection of data. Encountering these pitfalls along the way is what made my learning to lead for social justice inconsistent. Inconsistency is an accurate adjective to describe how it manifests to learn how to lead for social justice. I noticed that my leadership behavior changed daily, weekly, or even monthly depending on the situation and people involved. According to the data, I used some of the same strategies to try to get colleagues to consider injustices in our district, but the strategies were not used systematically. I maintained a plan of what I wanted to do or say with particular staff members, but it was often a short-term plan; a plan just for a team meeting or presentation for the staff. This lack of a long-term plan may have contributed to some of the inconsistency in trying to practice leadership for social justice; however, there is one other factor to consider in my inconsistency in leadership, which I describe next.

\section{Retreating from Leadership for Social Justice}

In considering the data and asking why trying to learn to be a better leader for social justice was inconsistent, one pattern seemed to emerge. I seemed most engaged and focused on bringing about a more just learning environment for all children when I was reading literature on leadership for social justice. This included theoretical works on leadership for social justice by such authors as Furman (2003, 2004, 2012), Grogan 
(2004), Foster (2002), Murphy (2002, 2004), Larson (2010), Murtadha (2002), Theoharis (2007), and many others. In fact, in may be easier than ever for school administrators to stay connected with emerging literature on leadership for social justice, as there seems to be great emphasis on social justice in mainstream literature on educational leadership. When I stayed connected to the literature, I seemed to be more consistent in trying to practice leadership for social justice. In contrast, when I did not stay connected to the literature on leadership for social justice, I seemed far less consistent; that is, my actions did not indicate that I was even trying to lead for social justice in my school. This is when I retreated from leadership for social justice. Originally, the literature on leadership for social justice energized me to take on this project, to do an autoethnography on this very important topic. In summary, I do not know why or how I got away from the literature on leadership for social justice at times. Answering that question may be beyond the scope of this project. I do know that there was a profound effect on me and my learning how to be a leader for social justice when I did not stay connected to the literature.

The literature on leadership for social justice is clear on the end goal in education. The theoretical literature on leadership for social justice calls for a change in the way schools are led by school leaders (Furman, 2003a; Greenfield, 2004; Murphy, 2004). Rapp called for leaders for social justice to "resist, dissent, rebel, subvert, possess oppositional imaginations ... committed to transforming oppressive and exploitive social relations in and out of schools" (p. 226). The premise in the theoretical literature is that some students are served well in schools whereas others are not. The students not served well in schools are those who have traditionally been marginalized in society, that is, students of color, students whose native language is not English, and students with an 
IEP. As a person of privilege, I found it difficult to be absolutely certain about what I was doing. As the data indicate on several occasions, I questioned myself, my ability, my potential to affect change, and even my commitment to social justice. Using the adjective uncertain to describe my leadership is truly humbling, if not depressing. Uncertainty's opposite, confidence, is usually what constituents want in their leaders. Again, to be honest with myself in assessing my ability to try to practice leadership for social justice, uncertainty is an accurate depiction of my leadership, both then and now.

These adjectives could be helpful to other school administrators involved in trying to practice leadership for social justice. They may be appropriate to the practice of leadership for social justice for a few reasons. First, these adjectives do not offer an immediate solution to social injustice in schools. Because social injustices in schools have been pervasive from the beginning of public education, eliminating them immediately is impossible. It is, however, important to strive toward eliminating inequality in education. Sustainable change that maintains social justice probably occurs gradually. One should be leery of immediate solutions to social injustice in schools. One example of an immediate solution to closing the achievement gap has been seen with high-stakes testing in schools and districts across the United States. Many schools have dramatically increased test-preparation time in lieu of quality classroom instruction. Thus the adage, "It didn't just happen over night, so it won't cease to exist overnight" could be a useful way to assess how these adjectives apply to the practice of leadership for social justice in schools.

Similarly, these adjectives could be useful for administrators like me, White privileged men in a position of power, influence, and leadership. The hope is that these 
adjectives, used to describe the learning process in trying to lead for social justice, places one in a role of more awareness to a lasting effect. That is, I hope to have uncovered some part of the problem perpetuating the status quo of social injustices in schools, possibly paternalistic leadership, often used by White men in power. Perhaps these adjectives, showing the learning process, reveal something authentic and meaningfulnot an immediate solution—-to trying to lead for social justice.

The final adjective comes from Freire's (1970) Pedagogy of the Oppressed. It was not a new concept to Freire; rather one Freire borrowed from such philosophers as Hegel. To sum up the six adjectives and the way they addressed the research questiontentative, uncertain, emotional, euphoric, contentious, and inconsistent-all seem to fall under Freire's concept of incompleteness. According to Freire, incompleteness is inevitable when people maintain an open mind to learning. Freire (1970) believed learning is incomplete and unfinished, that human beings must continue to search for meaning. All six adjectives seem to describe incompleteness in my work in learning how to be a leader for social justice. Incompleteness is evident in the data. Throughout this project I have questioned myself, my ability to lead, and even my commitment to social justice. I have experienced great self-doubt along with seemingly small but euphoric successes. There is no end point to my learning to be a better leader for social justice. There are some limitations to this work that have been included in much of what has been stated in this conclusion, however, a few will be discussed in the final chapter. 


\section{CHAPTER VII}

\section{A MEANINGFUL STORY}

In this study, I wanted to try to show, through the use of first-person narratives, how learning to practice leadership for social justice manifested by a White, male administrator of privilege working in a nearly all-White, affluent suburb. It would appear that these characteristics—White, male, administrator, suburbs, and social justice-do not seem to go together. I initially wanted to study schools and administrators where students with an IEP were doing well academically. This original intent did not fully materialize, as I was unable to find a single school or district that had successfully eliminated the achievement gap between students with an IEP and typical peers. As I became energized by the theoretical literature on leadership for social justice, my focus shifted to wanting to investigate how it manifested to learn to practice leadership for social justice. Although I still struggle with determining the who, what, and most certainly the how of practicing leadership for social justice, the conclusions from this study seem to point to the meaning of social justice in schools as decisively being about serving all students well, not only those traditionally marginalized. It seems ironic that the person least likely in need of social justice, a White man of privilege, could actually start down the path of leadership for social justice and wind up learning many new things.

There is irony in this story because I should not be reporting how learning to practice leadership for social justice manifests. Because of who I am and what I represent 
(White man in a position of power), I have questioned if there is any relevance to this story. Specifically, a White man of privilege in a position of power has little connection to the suffering and plight of the oppressed. For this reason I have questioned the relevance of the story as to who may benefit from knowing my story. Thus, a legitimate concern could be the following: Would this story, a story about trying to practice leadership for social justice, be better told by someone with a real connection to personally experienced social injustices; someone with first-hand knowledge and experience of being oppressed and the target of discrimination? To be certain, conventional thinking would point to someone else telling this story.

I also question whether I should be benefiting from a study on social justice. It is undeniable that White men in positions of power have created decades of injustices in public education. However, given that many public schools in the United States have White male administrators, this study can offer something to readers regarding how school leaders can work to better serve all students. Perhaps the data and some conclusions from this study can serve as somewhat of a conscientização for White male school administrators. It could be meaningful if a critical awareness were achieved from considering the adjectives used in the study to describe how the learning process manifests in trying to practice leadership for social justice. A hopeful conclusion could be that White men of privilege, like me, could work to avoid heroic leadership and move toward more equitable forms of leadership that serve to empower staff to take on socialjustice belief systems. To be certain, however, the coming paragraphs will point out the difficulty I have experienced in trying to leave behind traditional modes of leadership. 


\section{Beyond the Adjectives}

The seven adjectives, tentative, uncertain, emotional, euphoric, contentious, inconsistent, and incompleteness, described how a White male administrator, trying to learn how to practice leadership for social justice, attempted to address the research question presented in this study. These seven adjectives seem to only partially address or describe the learning process. Admittedly, these adjectives alone do not tell a complete story of how it manifested to learn to practice leadership for social justice; rather, they discretely describe the experiences in trying to do so. A more meaningful story could emerge. Through the various narratives I presented, I believe a naturally occurring story has emerged; a story that goes beyond the adjectives alone. The meaningful story surfacing from this study is one that reflects the collective data narratives presented in this project over the years. In short, the meaningful emerging story could be that while trying to practice leadership for social justice there seems to be a resistance on my part at some level—but equal capitulation to—-traditional forms of leadership. Sometimes I practice leadership for social justice and sometimes I am a traditional leader. Specifically, sometimes these roles are acceptable and fit the task at hand, and sometimes I know I should not be using traditional leadership, but still do.

An example of this is that traditional leadership, at times, is necessary. Making schedules that call for the algorithmic organization of people in very logical fashion is important in establishing consistent, predictable routines for staff and students. However, it is only out of necessity that administrators do this. Traditional thinking is required, at best, a few times a year, not daily. However, school administrators can easily fall into the rigid thinking of algorithmic organization and apply it not only to scheduling but also to 
other aspects of leadership such as identification of children for special-education services, the Response to Intervention process, and even instructional leadership.

\section{Having Two Leadership Belief Systems}

Although I continually grapple with trying to understand the data presented in this project, and why I have done some of the things I have done as a school leader, I have developed a possible explanation. This explanation seemed to have surfaced from rereading and thinking more deeply about my data. Mostly, it appears, I am performing under two leadership belief systems: one, trying to practice this orientation of leadership called leadership for social justice, and one, of traditional leadership. I do not experience moment-to-moment shifts in leadership styles, but some of the data would indicate that indeed my leadership does seem to shift quickly from leadership for social justice to traditional leadership. Thus, although shifts in my leadership may appear moment-tomoment, I do not believe this is the case. Here, I discuss some of the possible reasons for the shifting back and forth between leadership for social justice and traditional leadership. As this study indicated, I was, and still am, learning how to practice leadership for social justice. Because it is impossible for me to claim expertise as a leader for social justice in my school, I can only surmise why I literally "live in two worlds," or under two leadership belief systems, those of leadership for social justice and traditional leadership.

\section{"I Can't Shake It"}

While performing leadership in my daily practice as a school administrator, a tension arises. The dialectic of "two worlds" could explain the story that seems to be emerging from my practice. It is this tension from being in both these worlds that leads to 
the nonacademic term, "I can't shake it." The meaningful story could be that I cannot escape from the practice of traditional leadership. That is, I cannot diminish the way of leading that includes such attributes as charismatic, dynamic, innovative, decisive, problem solver, and motivator. These are the attributes contained in Chapter I that are part of Furman's (2004) delineation between what is leadership and what leadership is for. As I explore this emerging meaningful story in the coming paragraphs, the continual tension between trying to lead for social justice and being pulled toward traditional leadership is the crux of this study. I will use some examples that relate to the data, and some examples are nearer to the present, such as the climate of fear and economic/political uncertainty on school finances. This fear and uncertainty is, I believe, having an enormous impact on school leaders. I will attempt to show how this relates to traditional leadership, but more specifically to trying to learn to practice leadership for social justice. This is the meaningful story.

Because of my acquiescence to traditional leadership, which creates tension for trying to practice leadership for social justice, the story presenting itself, I believe, is "I can't shake it." I need to explore the unfolding story, and what exactly it is that I cannot escape. There are certain aspects of traditional leadership that are not bad, but rather, quite necessary. Because administrators need to run buildings, certain things need to occur that would seem to fit under the classification of traditional leadership. For example, if the security monitor stops working in the office and there is no way the office staff can see the people who are entering at the front door, it is my job to quickly and efficiently solve the problem so as to not have a gap in the security of the school. Similar to the previous example of school administrators algorithmically organizing people with 
schedules, we need to exercise caution that we do not use traditional leadership methods with other, very important, aspects of education.

\section{Two Sides of Being Impatient}

In attempting to allow the story to emerge from the data in this study so as to interpret more clearly what may be happening, a few behaviors that occurred in the data could point to a more meaningful, but complex story. One recurring behavior of mine while trying to "be" a leader for social justice seemed to be impatience. I will explore some possible reasons for my impatience. Most of my impatience seemed to have come when engaging in, or trying to engage in dialogical action with individuals or groups of staff members. I seemed to get upset when staff did not quickly come around to my way of thinking. I have to believe that my way of thinking, that trying to get staff to address issues of social justice in school, is a meaningful way of thinking. Perhaps because in my mind I have "drawn the line in the sand," I have made the decision that issues of social justice are important in my school. This may sound paternalistic, that my way of thinking is the right way of thinking; I am trying to follow a particular school-leadership orientation that I believe is what should be happening in schools. Taking a stand and attempting to be bold and assertive regarding pushing forth issues of social justice in my school opens up the possibility of heated, passionate arguments that often become emotional, even personal. Sometimes I was patient and sometimes I was impatient in pushing forth these issues of social justice.

I became impatient when staff would not think like me, that is, they did not readily see or understand social injustices in our school, or on a larger scale of public education in the United States. I should be more patient, but for some reason, it appears I 
have a sense of urgency to get staff to understand (in my time frame) that social justice in school is meaningful and important. This is antidialogical as I was not allowing for dialogue to run its course per se. Because of my impatience, some unsavory behaviors of mine sometimes emerge. Sometimes when I am impatient about pushing forth my beliefs about social justice, I can become sarcastic, even condescending. Although these behaviors are ugly enough, the question becomes why do I default to these behaviors sometimes?

If my impatience is linked to some sense of urgency, there could be two possible explanations. First, creating and sustaining socially just learning environments for all students is a meaningful pursuit for school leaders. This study began as I was energized by the theoretical literature on leadership for social justice. Schools, including the one where I work, do not serve all students well and there is no time to lose as the education of children is of the utmost importance (or should be) to us. However, if my sense of urgency is beckoning notions of efficiency and management, this is where I can potentially slide into the role of a traditional leader.

There is the possible interpretation that I am portraying more of the qualities of a traditional leader when I become impatient because a colleague will not, or is slow to, change a way of thinking. I struggle trying to determine whether I am impatient because I may feel my colleague is morally at a different place from me in serving all students well. Sometimes I have patience to interact with my colleague and we dialogue and perhaps we both learn. This would be dialogical cultural action and leadership for social justice. In contrast, if I am impatient because I feel I may be wasting my time with my colleague, as there are many pressing issues to which I need to attend, then my impatience is firmly 
planted in traditional leadership, as I know I could be doing something else more productive (most likely, more managerial).

To honestly interpret and explain the story emerging from this study, I admit that having things pile up on my desk, and leaving in limbo rich and meaningful dialogical interactions on social justice with colleagues can, at times, wear me down. These may also be times I am impatient. Rather than intuitively knowing that if I could just be patient enough to wait for the window of opportunity to enter again into dialogue with my colleague, I will sometimes get nervous, cut the dialogue short, and get back to my office to complete a pressing task, answer long overdue e-mails, or review lesson plans. That is, I feel the need to get back to being a manager.

This is one possible explanation of how I may be leading in two worlds. On one hand, I am not able to escape traditional leadership, being antidialogical, and worrying about completing my work apace and managing. On the other hand, my sense of urgency, manifested in impatience, could be viewed as being well intended and meaningful in trying to bring about more social justice in my school.

\section{Why Be Fearful?}

Employing, or trying to employ democratic processes in my school is messy and complicated. It takes patience to use, with some fidelity, democratic processes and genuine dialogue. This can make people, including me, feel uncomfortable, or even angry. Efficiency and decisiveness is far cleaner. As a traditional but antidialogical leader, I can walk away from difficult conversations. I can easily stop a potentially dialogical interaction moving down a democratic but messy path, and make a decision to move on. Not only do I feel the urge to lead decisively sometimes, I am asked, even 
demanded, to do so. This must be inherent to the process of learning to lead for social justice. It is easier, quicker, and less painful to lead in a traditional manner, especially with complicated issues like social justice. However, it is antidialogical cultural action to lead in traditional ways and not—in the long run-meaningful to achieve social justice and ultimately working toward better serving all students in schools.

Sometimes I am fearful. This is not to say that I am frightened to go to work, but considering where I am actually attempting to lead for social justice-a nearly all-White, affluent suburb—it may go without saying that concepts and ideas about leadership for social justice are not widely known, accepted, or embraced by staff and community members. Some of the language I have used in dialogue has caused much discomfort. However, this is the work I try to do: discuss issues of social justice and bring these issues to bear on the lives of our students. Occasionally, in the back of my mind, I ask myself whether I would be approached by the superintendent some day and told I am not "fitting in with the mission and vision." I'm fearful that if I sound or act too radical as a school administrator, I could run the risk of not having my contract renewed. My relative fear can be put into perspective when reading about individuals with true convictions, such as exemplar Picott, an African American school administrator who, in the prevailing atmosphere of traditional leadership used by contemporaries, lost a position as a building principal because of a stance and outspoken commitment to social justice (Karpinski \& Lugg, 2006).

\section{Leading for Social Justice in Difficult Times}

It is embarrassing to admit that at times I am fearful of leading for social justice. Adding to my sporadic fear of leading for social justice is another type of uneasiness, not 
specifically mentioned in the vignettes. The pressure of trying to learn to practice leadership for social justice has recently been confounded by difficult economic times. Because of economic difficulties, the public has turned to teachers and administrators as possible culprits, making school unstable and underlying all problems in public education. Thus, public education is under attack everywhere, and much of the attack directed at public education is related to finances, specifically the salaries of those working in schools. Although difficult economic times can serve as distractions from the meaningful work of leadership for social justice, budgetary cuts, staff reductions, school levies, teacher and administrator pay, medical benefits, and retirement packages constantly dominate conversations in and out of school, adding a level of anxiety that can quickly morph into fear and uncertainty. How does one answer the question, "Who cares about social justice when we' re deficit spending \$3.1 million?”

This is a debate that I dislike immensely, but one that continually surfaces in school districts across the United States that are either close to operating at a deficit or already doing so. I have heard several variations of the same question, but in the end, debating money and social justice in schools can only serve as a distraction to the real work of figuring out how to best serve all students. I can often default into traditional leadership when these two subjects are discussed. There are a few possible, albeit cowardly, explanations for why I may tend to be more of a traditional leader when social justice and the economy are discussed. First, and overwhelmingly, I am fearful of saying something when I am the only person in the room who believes it appropriate to discuss issues of race, class, native language, and ability/disability. That is, in a discussion with administrators, teachers, or staff members regarding the prioritization of budget cuts, I 
sometimes lack the gumption to bring up the topic of social justice. The times I have, I run the risk of the question being asked, "Who cares about social justice when we' re deficit spending \$3.1 million?” At times I fear that if I speak up too frequently, I could jeopardize my livelihood. Therefore, I am compliant to the agenda and do not speak up. Meeting agendas do not include social-justice issues.

\section{Can't Operate Exclusively Out of Fear}

I am not certain whether compliance is a trait that fits with traditional leadership, especially in school finances and social justice, but efficiency is one such trait. Being a traditional leader means being efficient in certain aspects of daily administrative duties. I assert that under a traditional model of leadership, planning and executing efficient, disruption/distraction-free meetings that do not deviate from the agenda is viewed (or welcomed or demanded) by constituents and stakeholders as good, strong leadership. I also assert that it is far more messy, complicated, and uncomfortable to ask, sort out, argue, and dialogue about issues of social justice during meetings on budgetary reductions. I am fearful to attempt to do this because the few times I have done so, it has not been embraced. But in contrast, operating out of fear could mean stagnation for school leaders. Thus, aiming toward school leadership that incorporates communal learning and critical dialogue among teachers and administrators, toward deep democracy and relationships focused on renewing teachers' commitment to agency in their own profession, and ultimately toward a genuine expression of reality, that is risky and not silent.

Perhaps the real issue at hand may be my timidity to stand up and be a voice for social justice in school. Practically speaking, if I were to say something about better 
serving students of color or students receiving free and reduced-price lunches during a meeting to determine certain budget cuts and fiscal measures in the district, I would certainly be met with one or both of the following comments: (a) What does race and class have anything to do with the current financial crisis; or (b) Although better serving all children is a priority in the district, employees will not lose their jobs over it; they will over this financial crisis, though. Therefore, I have a decision to make. Do I press the issue of social justice or acquiesce to the will of the majority? It may not even be the will of the majority, but money is powerful and does take precedence in most discussions, especially when economic times are difficult. The falling back into traditional leadership because of timidity to stand up to driving forces in public education like money is an issue with which I struggle. This is only one example of the real story of living in two worlds of leadership and the tension between the two.

\section{What do We Want to Look Like?}

How do we want to manifest as leaders for social justice? How do we want to be perceived? If we knew this information, would it change anything about our leadership? Specifically, how do we want to appear in public? As school leaders, our actions and words influence those around us, positively and negatively. What we say and do in our interactions matters a great deal. At times, perhaps we are self-serving as leaders, meaning we pull away from more altruistic motives and toward more selfish ones. One such example in the data is my ability to make an abstract argument for social justice without any visible action of leadership for social justice. Trying to find an explanation for why I did this has been challenging. It is possible that my public embrace of leading for social justice, and the dialogue with colleagues, leads me to do something for me. For 
example, it is probably correct to engage in an abstract discussion with a colleague regarding social justice, such as suburban educational privilege, however if this is the only reason for doing so, to simply debate for a self-serving purpose, then I question my real motive behind such an action. This happened frequently enough that it warrants some discussion here.

One possible explanation that may fit in the dialectic of leading in two worlds is that there is much merit and praise given to leaders appearing to have traditional leadership qualities such as decisiveness, confidence, and intelligence. Given some of my experiences and background that many suburban school employees do not share, I could have been taking advantage of conversations and situations to be viewed as a "good" leader, albeit in a very traditional sense. For example, I can probably articulate well the changing demographics in public schools, due to my varied experiences. Dialogue and debate in this area, particularly as it pertains to the achievement gap, is a worthy pursuit that can work for social-justice causes. However, I am not convinced that while dialoguing about issues of social justice, I am trying to get someone to understand the importance of race, class, and ability/disability, at least all the time. I question whether I want to be accepted in order to be viewed as knowledgeable, well informed, worldly, or maybe even sensitive. I wonder if, at these critical points, I am not more worried about how I am viewed as a leader rather than the cause of equality and fairness for all students in schools.

Indeed, a school leader appearing to give his constituents what they wantpresumably, traditional leadership—is probably equated with effectiveness. Perhaps the "appearance" of a school leader exhibiting traditional leadership traits may have 
something to do with power and control. It could be that school leaders exhibiting traditional leadership traits can easily maintain followers. This is precisely what I question in my attempts to practice leadership for social justice, at times. I acquiesce to traditional forms of leadership; I buckle under the demand to run my school smoothly and efficiently because this can be powerful and popular, thus self-serving.

Traditional leadership is antidialogical. Reason would purport that if any dialogically cultural action is one-sided, in this case in favor of the administrator, that interaction is not dialogical but antidialogical. Freire (1970) stated that in these types of interactions, both/all parties should be trying to teach/learn from one another. If not, it is simply manipulation by the oppressor. To rephrase, in my practice, when discussions of social justice occur, I cannot be certain whether I want to appear effective, popular, or "giving the people what they want" to be viewed as effective (traditional leadership) or genuinely I want to try to educate, and learn from those with whom I am conversing (leadership for social justice).

\section{Toward a Delicate Balance}

What teachers and staff think of my administrative performance can pull me back to traditional leadership styles. However, this notion is dichotomous. Some want and expect efficiency, strong management skills, and decisiveness in a principal. Some want and like to be led or told what to do. These desires may work well with managerial types of tasks in a school building, but not with meaningful social-justice endeavors. For example, if the pressing issue of the day is whether the district will offer paid professional development, I can tell everyone that no professional development can be paid for out of the general fund, that it must be grant funded, but that should not be our 
pressing issue. I know that if I do not answer questions in a timely fashion, I run the risk of being viewed by some as an ineffective administrator. This creates a tension toward antidialogical ways of leading, because some staff want me to lead. Managerial tasks are time consuming and can multiple quickly, even completely take over what an administrator does on a daily basis. This is where I need to make a choice about what to do.

Making a choice to enter into a dialogical relationship on issues that do not seem to have relevance, that is, entering into a dialogical relationship regarding managerial tasks presents a potential opportunity. This sounds hypocritical. However, the swift, clean execution of managerial tasks is a high priority for some staff members. If I fail to validate what is important to others but not necessarily me in some way, I could be failing at an opportunity to enter into a dialogical relationship and possibly help colleagues think about and value more pressing issues of social justice. Therefore, it appears that there is a very delicate balance at work. On one hand, it is not meaningful to be "too much" of a traditional leader, occupied inordinately with managerial tasks. On the other hand, it may be the only "in" a school leader is afforded to attempt to lead for social justice. Succinctly, if I have to gain respect by being a manager for staff to seriously consider social justice and how we can best serve all students, I will. This may entail a different sort of "pull” between traditional leadership and leadership for social justice, but it would appear to be the same dialectic at work. I should not liken the work of leadership for social justice to a hierarchy of needs; I have thought about this concept. Briefly, some staff members may need more basic personal needs cared for in their daily work at school (what is the schedule on picture day) before they can think about bigger 
needs (how can we ensure all students are served well). If satisfying these basic personal needs can lead to dialogical cultural action and through to leadership for social justice, I will do it.

\section{The Constant Pull and the Constant Tension}

I know I need to complete the minutia of managerial tasks each day. I also know that colleagues need to know where I stand and what I think is important for the school. Most importantly for me and the staff is assisting each other in understanding issues of social justice, and acting on behalf of all students in our school. Perhaps this is the "pull" with which I struggle; not allowing managerial tasks to consume my leadership, but accomplishing those tasks that need to be accomplished and being assertive enough to stand up/speak up and lead for social justice.

The pull toward antidialogical, traditional forms of leadership is, in many cases, an easier, cleaner way to lead schools. To some extent, perhaps all school leaders at any level look for easier ways to do things. If antidialogical, traditional leadership is easier, then there may be more of a natural tendency to take on such attributes as confidence, integrity, and energy. Another possible explanation is that it is easier to quantify the degree to which administrators are performing such attributes of traditional leadership. Quantifying leadership actions in traditional leadership is attractive for many reasons. Because efficiency is quantifiable, simply checking off on a spreadsheet and providing evidence of whether a managerial task was completed is very attractive. Because efficiency is completing tasks quickly, it is a very appealing leadership trait, as it gives the appearance that a building is running smoothly. A smooth-running school building is 
important but should not be an end goal. Nonetheless, most everyone working in schools feels better when things get done quickly, and everything runs smoothly.

Conversely, leadership for social justice is anything but easy. It is messy work that is new, unfamiliar, and uncomfortable for school administrators. Dialogical relationships are democratic, as there is (or should be) a genuine interest and concern on the part of those engaged to come to some form of agreement about how to best serve all children. The constant tension will always exist between taking the straightforward route of traditional leadership or the more difficult, messy path of leadership for social justice. I believe the latter can move schools forward in meaningful directions. But there is a tendency to take the easier path of traditional leadership sometimes. It is easier to complete tasks efficiently, try to run a quiet, smooth building, and most importantly, be perceived by all as a good principal.

The constant pull and tension of trying to effectively manage a school building and lead for a higher moral purpose, such as social justice, is not new. Philip Selznick (1957) detailed the complex roles of both management and leadership in Leadership in Administration: A Sociological Interpretation. Selznick (1957) addressed the dangers of exclusively focusing on managing without the greater good in mind:

The cult of efficiency in administrative theory and practice is a modern way of overstressing means and neglecting ends. This it does in two ways. First, by fixing attention on maintaining a smooth-running machine, it slights the more basic and more difficult problem of defining and safeguarding the ends of an enterprise. Second, the cult of efficiency tends to stress techniques of organization that are essentially neutral, and therefore available for any goals, rather than methods 
peculiarly adapted to a distinctive type of organization or stage of development (p. 135).

Selznick sheds light on many important points. Safeguarding the ends of the enterprise, or ensuring that all teachers and staff have in mind and practice to meet the learning needs of all students in a safe and nurturing environment must be near-sacred in schools and never compromised. Understandably, this is very difficult to accomplish in schools. Another important point Selznick makes is the neutrality of managerial tasks. There does not seem to be any moral calling in developing a smooth running master schedule, conducting efficient fire drills, or ensuring students line up correctly after recess.

To try and reconcile these important points Selznick raises between administration and leadership, school leaders may need to look for opportunities to act socially just, fair, and equitable in all aspects of carrying out managerial tasks. For example, creating a favorable schedule in which students with an IEP have access to key resources throughout the day could be one important way to reconcile administrative managerial tasks and leadership for social justice. Preparing students to line up correctly after recess could include using the buddy system. Each child could "turn and talk" in a cooperative fashion to remind friends of the rules of walking respectfully and responsibility to their classrooms. Students would internalize that they not only need to care for themselves but others as well, thus creating a community of care. However, can this be maintained each and every moment of the school day? Can school leaders literally view all aspects of school administration through the lens of social justice? In reality, this would be dogged, tiring, laborious work. One would ask, "Why do this work?" 


\section{You Have to Ask Yourself "Why?"}

Whenever there is the overwhelming feeling that I am not doing what I am supposed to be doing as a principal, I ask myself the same question repeatedly: Why am I not trying to be a leader for social justice? I find this question easy to ask but difficult to answer. Sometimes I do not even try to answer this question in my daily practice as a school principal. Why am I not trying to be a leader for social justice is an important question school leaders must ask themselves from time to time, or even each day.

It is an important question for many reasons. First, when I ask myself this question, it signals something is wrong. Something is wrong when I am not even trying to practice leadership for social justice. Ideally, I would imagine, if I were practicing leadership for social justice to a high degree each day as a school principal (although it would be difficult to determine what "a high degree" is), and I knew it, and everyone around me knew it, this question would be less likely to cross my mind. Second, asking this question is self-reflective and, hopefully, a springboard to reorient myself back to the meaningful practice of trying to be a leader for social justice. Thus, it is probably good that I question whether I am trying to be a leader for social justice each day.

Why do I ask myself this question each day? It is because I believe I fail to practice leadership for social justice on a consistent basis. I know I do not lead for social justice each day. The selfish result, sometimes, is that I feel badly or guilty for not doing what I want or should do. The grim reality is that I perpetuate inequality; that some students are not being served well in my school. In other words, my lack of action for social justice as a leader is a replication of the status quo. Sometimes I do not do what I should do for long periods of time. There have been times in which weeks go by and I do 
not so much as think as a leader for social justice. Thus, there are times when there is no back and forth shift in my leadership because I seem temporarily stuck in a vacuum of traditional leadership.

The autoethnographic methodology employed in this study has forced me to gaze inward at my practice as a school administrator. This gazing inward has produced a story that seems to be saying I am practicing leadership in two worlds, one of leadership for social justice and one of traditional leadership. Gazing inward can expose a vulnerable self. This can be very painful. As discussed, asking myself painful questions like Why am I not trying to be a leader for social justice? can expose a side or story in me that is not appealing.

\section{Don't Retreat from Leadership for Social Justice}

During these times of seemingly prolonged traditional leadership, the question persists, Why am I not trying to be a leader for social justice? One possible explanation for my reluctance to act on my own question is that there is no accountability to social justice in the suburbs. No one will audit the degree to which I am using leadership for social justice each day in school. The inverse is perhaps more true. That is, a higher degree of concern could arise if I were trying to practice leadership for social justice on a consistent basis. As a White man of privilege, knowing no one will ask me the question Why am I not trying to be a leader for social justice, complacency can easily dominate my leadership.

School happenings serve to distract from more meaningful work and appear to take away from the work of social justice in school. This is where the school leader must work. If I fail to address someone's hurt feelings, that is, if I do not listen to what seems 
to be important to staff members, I may not be meeting colleagues where they are in building relationships. If I hammer away with "What does this have to do with children of color not reading at grade level!" I may push staff further from entering into a dialogical relationship. From time to time, when these types of interpersonal issues arise, I have asked myself whether a colleague is "ready" to have the sort of conversation that focuses on what I believe are the "real" problems our school faces. I must balance to find the right moment to interject meaningful dialogue about social justice and serving all students well.

In some way, I sense that sometimes people want me to just "bring the hammer down" in some traditional leadership way. Perhaps my lack of "strong" leadership could be viewed as a weakness, that I should indeed get angry with and discipline pettiness. I do feel the tug to be more of a traditional leader when pettiness seems to become more acute. Sometimes I get angry about the pettiness and simply impose a decision. Rather than argue the merit of being petty versus focusing on important issues of social justice and how to best serve all children, I get lazy, tired, frustrated, and discouraged, and try to let it go. This could, however, be a reflection of my inability to get a critical majority to rally around the "cause" of social-justice issues in my school and district. If this is the case, there is an opportunity to salvage what I have construed as worthless conversations about petty issues.

A perspective I have not addressed yet is one of guilt. First, I attempt to show that living in both the traditional leadership world and leadership-for-social-justice world can be, to some degree, attributed to my guilty feelings or to not wanting to be classified as a racist or anything else unpleasant in contemporary society. That is, I ask myself the 
question, Am I leading this way because it is what is meaningful, moral, and just, or because I want to be viewed as being an ethical, compassionate administrator?

Evident in many areas in the data are several examples of passionate, emotional, sarcastic, angry portrayals of interactions I have had with people in an attempt to lead for social justice. I use all the adjectives—-passionate, emotional, sarcastic, angry—in a holistic attempt to possibly answer the question of why I may be leading in this way. It would be quite simple to dismiss the "why" in the actions and motives of my leadership. However, if I did this, it could lead to a disingenuous and short-lived leadership orientation. I must be honest and state that, on occasion, in this study, I was uncertain of my motive for doing what I did as a leader.

On occasion, it felt good to be viewed as a progressive, compassionate administrator that "has his priorities and heart in the right place." To clarify, I am not saying that I do not truly believe in the meaningfulness of the leadership orientation of leadership for social justice. I do, and I am committed to trying to lead for social justice. However, I can honestly say that when given a compliment of "Dave sure has his priorities and heart in the right place," it can often go to my head. This, to me, can lead to some form of moral corruption. What would students think if they knew that I spoke up on their behalf on a particular occasion to be viewed more favorably by the masses? Staff members and colleagues of mine surely would feel betrayed knowing their leader did certain things and made decisions only to gain praise and favor from superiors. Parents would feel incensed as well.

A slightly different interpretation to the answer of my question Am I leading this way because it is what is meaningful, moral, and just, or because I want to be viewed as 
being an ethical, compassionate administrator? could be that I start with all the right intentions to be a leader for social justice but end up with a quasi-outcome that is neither morally sound nor true to the ideal of social justice. By morally sound I mean that although my leadership actions may appear compassionate and committed to bettering the academic futures and life chance of those students traditionally marginalized in schools, the real reason is not moral in nature but self-centered. By true to the ideal of social justice, I mean I am committed to assisting in the transformation of my school/district to more equitable learning places for all students. Perhaps because White men in positions of power do not want to be classified as racists, bigots, English-only zealots, intolerant, or lacking compassion toward students, we start out wanting to be leaders for social justice, but sometimes, because of our actions, end up being viewed differently.

There is, I believe, a constant tension or dialect occurring in my practice. The two opposing forces are leadership for social justice and traditional leadership. I am literally, intellectually, and practically working in these two worlds. It appears that this is what the data in my practice have revealed as the emerging story.

\section{The Window}

There is a term I use to try to keep myself moving forward in trying to practice leadership for social justice. I call it "The Window." I have presented many reasons not to lead for social justice in an affluent, nearly all-White suburb. I have shown how my reluctance to lead for social justice out of impatience, fear, guilt, and pressure to be viewed as a strong leader is reflected in my practice as a school principal. I have presented examples that show the tension between trying to practice leadership for social 
justice and that of traditional leadership. Indeed, there appears to be a dialectic of two forms of leadership that pull, at times, in opposite directions. Traditional leadership tends to be more antidialogical. Leadership for social justice tends to be more dialogical. "The Window" is a term I tell myself when I need to try to take advantage-when the situation arises - to lead for social justice. In short, while it is fairly clear that I can and do fail on a regular basis to lead for social justice, I keep looking for opportunities, or windows of opportunities, to try to enter into a dialogical situation whereby I can influence colleagues in favor of educational equity for all students.

Before this study began, I held the belief that I could become a better leader for social justice in my school. Throughout this study, I anticipated a moment in time when I would encounter a turning point or crossroads at which point I could simply choose to be a leader for social justice and leave behind any trace of behaviors associated with traditional leadership. As I have shown through various examples in the data and my current practice, I neither practice solely leadership for social justice nor traditional leadership. This seems to be a meaningful interpretation of my leadership.

Considering Rapp's (2002) definition of leadership for social justice, it becomes clear that, at times, my leadership was the direct opposite: "Leaders for social justice ... resist, dissent, rebel, subvert, possess oppositional imaginations, and are committed to transforming oppressive and exploitative social relations in and out of schools" (p. 226). At times during my practice as a school administrator, I was not "committed to transforming oppressive and exploitative social relations." For the reasons mentioned in this discussion, impatience, fear, distractibility, pettiness, lack of accountability, and guilt, I did not accomplish what I initially thought I could; that is, to fully practice 
leadership for social justice. In contrast, there are examples in the data (problem posing questions, dialogue on teacher agency, etc.) that show my attempt to "resist, dissent, rebel, and subvert" situations both in and out of my school.

Admittedly, there is a dichotomy between traditional and leadership for social justice. Many times in my practice as a school leader, there is an either-or dichotomy at work. Either I am trying to practice leadership for social justice or falling back into traditional leadership. I am trying to somehow reconcile, where possible, the two distinct orientations of leadership. I would very much like to do a better job as a leader for social justice. I do not like falling into the snares of traditional leadership, wearing blinders to inequalities that exist in and out of my school building. However, some aspects of traditional leadership are important and meaningful, and could, quite possibly, mesh well with leadership for social justice. As I have hoped to shed some light on the emerging story of "living in both worlds of traditional leadership and leadership for social justice," meshing the particularly useful components of traditional leadership with leadership for social justice is an area I hope to intensify in the future.

\section{Autoethnographic Work}

To conclude, and returning to what autoethnographies should include, are the following criteria: substantive contribution, aesthetic merit, reflexivity, impact, and expression of a reality (Richardson, 2000b). Framing these five criteria in the form of questions, I have tried to ask the following of myself during each process and experience in the writing of this autoethnography:

1. Does this autoethnography make a substantive contribution to understanding social life? 
2. Does this autoethnography have aesthetic merit?

3. Does this autoethnography demonstrate reflexivity?

4. Does this autoethnography have an impact on the reader?

5. Does this autoethnography express a reflection of reality?

To answer Question 1, this autoethnography does make a substantive contribution to understanding social life. My study deals explicitly with social justice and the role I play as a school administrator trying to lead for social justice. I believe I made it clear in this study that the particular contribution to understanding an aspect of social life was that of equality, fairness, and how to better serve all students in school. I showed how this could be accomplished through deep democratic practices, open and critical dialogue explicitly exploring ways in which all school staff members can better serve all students, and remaining committed to the ethical practices of leadership for social justice. From the outset, I stated that society and schools are unjust, that some children are served well and others are not. My contribution in this autoethnography was trying to lessen inequality by trying to learn to practice leadership for social justice.

To answer Question 2, this autoethnography has aesthetic merit. I believe my autoethnography is sufficiently artistic in a literary sense. It possess artistic appeal as it "looks" different; particularly the vignettes. I use language in my autoethnography that is, at times, colorful and descriptive. I also use language that my be considered aesthetically abrasive and unsettling. Additionally, in the vignettes I believe my writings accomplished a level of emotional transparency for the reader. I wrote honestly-unconventionally at times - and portrayed what was happening in my thoughts, ideas, and attempts to change unjust arrangements in school. 
To answer Question 3, this autoethnography demonstrates reflexivity. I attempted to make a substantive contribution with the "reflexivity to refute traditional models of school leadership" in this study. The way I accomplished this was to use autoethnographic techniques that required me to constantly analyze what I was doing as a school leader and consider how my leadership fit into the broader culture. I had to continually reflect on what I was attempting to do as a leader while knowing that what I was trying to enact went against traditional models of school leadership; went against, in some cases societal norms and expectations.

To answer Question 4, although I cannot know for certain the level of impact my autoethnography may have on the reader, I believe this autoethnography has the potential to impact the reader. As with all meaningful writing, a certain level of connectedness must occur between the writer and reader. In some regards, I believe my autoethnography can be provocative and possibly move readers to consider (and hopefully act on) injustices in schools that contribute to the marginalization of some groups of students. Given what I am trying to accomplish in this study, that is, to improve the lives, learning, and overall well-being of children, I believe this study must compel any readerespecially a reader currently working in the field of education - to act justly and ethically in favor of equality for all children. For these reasons, I believe this study to be impactful.

To answer Question 5, I believe this autoethnography reflects reality. First, it is well documented — not only in this autoethnography—that there exists an achievement gap in schools and society. The achievement gap, based on race, class, native language, and ability/disability, is persistent and complex. Not only is the achievement gap undeniable, but perhaps our greatest social injustice is that it includes deep-rooted belief 
systems such as racism, bias, and systematic discrimination. The reality of these social ills continue to plague all of us today.

\section{Some Limitations and Promises}

One limitation to this project, according to my data, was the somewhat episodic nature of my interactions and dialogue with staff. Much of my data indicated a one-time interaction with a particular staff member or group of staff members. On one occasion, however, my data indicated a short-lived, but ongoing relationship with a group of teachers using common assessments. We used student-performance data as a centerpiece for dialogue on how to best serve all students. We explicitly discussed students who were struggling. Some of those conversations included dialogue on root causes for particular students to be marginalized (i.e., teacher expectations, classroom biases, instructional methodology, etc.). However, these types of ongoing dialogical relationships were not the norm. It may have had something to do with me changing schools, going from assistant principal at the middle school to principal at the elementary school.

Along the same lines, in episodic interaction with staff members, one thing I seemed to have overlooked was the use of group dynamics. Although I did work with teams of teachers, more at the middle school level, working in teams appears to have waned in more recent vignettes at the elementary school. It is difficult to determine whether this change made a difference in assisting staff members to understand the contradictions and injustices in school. Another limitation of mine in this project was not engaging fellow administrators in dialogue on social justice in schools. I believe there were opportunities to do so; however, perhaps due to a lack of daily contact with 
administrators, I was unable to successfully dialogue with other administrators regarding social justice.

The promise of this study is the honest contribution it can make in a growing body of literature on how learning to practice leadership for social justice manifests by administrators in public schools. I believe the autoethnographic data in this study have answered the research question and provided an honest description of how a White man of privilege tries to learn to be a leader for social justice. Also, perhaps the methodology of autoethnography can help serve as a legitimate form of research for those interested in learning to be better leaders for social justice, but currently do not have space or voice to do so. 


\section{REFERENCES}

Alexander, B. K. (2003). (Re)Visioning the ethnographic site: Interpretive ethnography as a method of pedagogical reflexivity and scholarly production, Qualitative Inquiry, 9, 416-441. doi:10.1177/1077800403009003006

Anderson, L. (2006). Analytic autoethnography. Journal of Contemporary Ethnography, 34, 373-395. doi:10.1177/0891241605280449

Apple, M. W., \& Beane, J. A. (Eds.). (1995). Democratic schools. Alexandria, VA: Association for Supervision and Curriculum.

Armstrong, L. (2001). It's not about the bike: My journey back to life. New York, NY: Berkeley.

Autoethnography. (1994). The American heritage dictionary of the English language. Boston, MA: Houghton Mifflin.

Bass, B. M. (1985). Leadership and performance beyond expectations. New York: The Free Press.

Bass, B. M. (1990). From transactional to transformational leadership: Learning to share the vision. Organizational Dynamics, 8, 19-31.

Bass, B. M., \& Avolio, B. J. (1994). Improving organizational effectiveness through transformational leadership. Thousand Oaks, CA: Sage.

Barker, R. L. (1999). Social work dictionary (4th ed.). Washington, DC: National Association of Social Workers.

Bates, R. (2006). Educational administration and social justice. Education, Citizenship and Social Justice, 1, 141-156. doi:10.1177/1746197906064676

Beck, L., \& Murphy, J. (1994). Ethics in educational leadership programs: An expanding role. Thousand Oaks, CA: Corwin Press.

Beecher, M., \& Sweeny, S. (2008). Closing the achievement gap with curriculum enrichment and differentiation: One school's story. Journal of Advanced Academics, 19, 502-530. doi:10.4219/jaa-2008-815 
Berlak, H. (2001). Academic achievement, race, and reform: Six essays on understanding assessment policy, standardized achievement tests, and anti-racist alternatives. ERIC Number ED464973. Retrieved from http://files.eric.ed.gov/fulltext /ED464973.pdf

Berger, L. (2001). Inside out: Narrative autoethnography as a path toward rapport. Qualitative Inquiry, 7, 504-518. doi:10.1177/107780040100700407

Blackburn, J. (2000). Understanding Paulo Freire: Reflections on the origins, concepts, and possible pitfalls of his educational approach. Community Development Journal, 35, 3-15. doi:10.1093/cdj/35.1.3

Blackmore, J. (1999). Troubling women. Buckingham, England: Open University Press.

Blackmore, J. (2002). Leadership for socially just schooling: More substance and less style in high-risk low-trust times? Journal of School Leadership, 12, 198-219.

Blum, J. (1978). Pseudoscience and mental ability: The origins and fallacies of the IQ controversy. New York: Monthly Review Press.

Bochner, A., \& Ellis, C. (1999). "Which way to turn?" Journal of Contemporary Ethnography, 28, 485-499. doi:10.1177/089124199129023613

Bochner, A., \& Ellis, C. (2003). An introduction to the arts and narrative research: Art as inquiry. Qualitative Inquiry, 9, 506-514. doi:10.1177/1077800403254394

Bogotch, I. E. (2002). Educational leadership and social justice: Practice into theory. Journal of School Leadership, 12, 138-156.

Brown, K. M. (2004). Leadership for social justice and equity: Weaving a transformative framework and pedagogy. Educational Administration Quarterly, 40, 77-108. doi:10.1177/0013161X03259147

Bruckheimer, J. (Producer), Simpson, D. (Producer), \& Smith, J. N. (Director). (1995). Dangerous minds [Motion picture]. USA: Hollywood Pictures.

Burns, J. M. (1978). Leadership. New York, NY: Harper \& Row.

Callahan, R. (1962). Education and the cult of efficiency. Chicago, IL: University of Chicago Press.

Cambron-McCabe, N., \& McCarthy, M. M. (2005). Educating school leaders for social justice. Educational Policy, 19, 201-222. doi:10.1177/0895904804271609 
Capper, C. A., Theoharis, G., \& Sebastian, J. (2006). Toward a framework for preparing leaders for social justice. Journal of Educational Administration, 44, 209-224. doi:10.1108/09578230610664814

Carlyle, T. (1993). On heroes, hero-worship, and the heroic in history (Vol. 1). Berkeley: University of California Press. (Original work published 1840)

Chiu, J. (2004). I salute the spirit of my communities: Autoethnographic innovations in Hmong American literature. College Literature, 31(3), 43-69. doi:10.1353/lit .2004 .0030

Clifford, J. (1988). The predicament of culture: Twentieth-century ethnography, literature, and art. Cambridge, MA: Harvard University Press.

Coleman, J. S., Campbell, E. Q., Hobson, C. J., McPartland, J., Mood, A. M., Weinfeld, F. D., \& York, R. L. (1966). Equality of educational opportunity. Washington, DC: U.S. Government Printing Office.

Coffey, A., \& Atkinson, P. (1996). Making sense of qualitative data: Complementary research strategies. Sage.

Cotton, K. (2003). Principals and student achievement: What the research says. Alexandria, VA: Association for Supervision and Curriculum Development

Counts, G. S. (1978). Dare the school build a new social order? Carbondale, IL: Southern Illinois University Press. (Original work published 1932)

Darling-Hammond, L., Holtzman, D. J., Gatlin, S. J., Heilig, J. V. (2005). Does teacher preparation matter? Evidence about teacher certification, Teach for America, and teacher effectiveness. Education Policy Analysis Archives, 13(42). doi:10.14507 /epaa.v13n42.2005

Darling-Hammond, L., Berry, B., \& Thoreson, A. (2001). Does teacher certification matter? Evaluation of the evidence. Educational Evaluation and Policy Analysis, 23, 57-77. doi:10.3102/01623737023001057

Davis, B. M., Skrla, L., Lindsey, R. B., \& Scheurich, J. J. (2011). Becoming an equityoriented change agent. In A. M. Blankstein \& P. D. Houston (Eds.), Leadership for social justice and democracy in our schools (pp. 45-58). Thousand Oaks, CA: Corwin.

Deal. T. E., \& Peterson, K. D. (2009). Shaping school culture: Pitfalls, paradoxes, and promises (2nd ed.). San Francisco, CA: Jossey-Bass.

Delpit, L. D. (2006). Other people's children: Cultural conflict in the classroom. New York, NY: The New Press. 
Denzin, N. K., \& Lincoln, Y. S. (2000). Introduction: The discipline and practice of qualitative research. In N. K. Denzin \& Y. S. Lincoln (Eds.), Handbook of qualitative research (2nd ed., pp. 1-28). Thousand Oaks, CA: Sage.

Denzin, N. K., \& Lincoln, Y. S. (Eds.). (2005). The Sage handbook of qualitative research (3rd ed.). Thousand Oaks, CA: Sage.

Desimone, L. (1999). Linking parent involvement with student achievement: Do race and income matter? The Journal of Educational Research, 93, 11-30. doi:10.1080 /00220679909597625

Dewey, J. (1916). Democracy and education: An introduction to the philosophy of education. New York, NY: Macmillan.

Dwyer, J. (2005). Global health and justice. Bioethics, 19, 460-475. doi:10.1111/j.1467 $-8519.2005 .00458 . x$

Education Trust. (2012). Closing the achievement gap: 2005 NAEP reading and math results show some gains, but slowing progress. Retrieved from http://www.edtrust .org/dc/press-room/press-release/closing-the-achievement-gap-2005-naepreading-and-math-results-show-some

Ellis, C. (1999). Heartful autoethnography. Qualitative Health Research, 9, 669-683. doi: $10.1177 / 104973299129122153$

Ellis, C. (2004). The ethnographic I: A methodological novel about autoethnography. Walnut Creek, CA: AltaMira Press.

Ellis, C., \& Bochner, A. P. (2000). Autoethnography, personal narrative, reflexivity: Research as subject. In N. K. Denzin, \& Y. S. Lincoln (Eds.), Handbook of qualitative research (2nd ed., pp. 733-768). Thousand Oaks, CA: Sage.

Fasching, D. J. (1992). Narrative theology after Auschwitz: From alienation to ethics. Minneapolis, MN: Fortress.

Ferguson, R. F. (2003). Teachers' perceptions and expectations and the Black-White test score gap. Urban Education, 38, 460-507.

Foss, S. K., \& Foss, K. A. (2012). Inviting transformation: Presentational speaking for a changing world ( ${ }^{\text {rd }}$ ed.). Long Grove, IL: Waveland Press.

Foster, W. (2002, October). The decline of the local: A challenge to educational leadership. Paper presented at the UCEA Conference on Values and Educational Leadership, Toronto, ON. 
Frattura, E., \& Capper, C. A. (2007). Leading for social justice: Transforming schools for all learners. Newbury Park, CA: Corwin.

Freeman, M. (1998). Experience, narrative and the relation between them. Narrative Inquiry, 8, 455-466.

Freire, P. (1970). Pedagogy of the oppressed. New York, NY: Herder and Herder.

Freire, P. (1998). Critical Perspectives Series: Pedagogy of freedom: Ethics, democracy, and civic courage. Lanham, MD: Rowman \& Littlefield.

Furman, G. C. (2003a). The 2002 UCEA presidential address: Toward a 'new' scholarship of educational leadership? UCEA Review, 45(1), 1-6.

Furman, G. C. (2003b). Moral leadership and the ethic of community. Values and Ethics in Educational Administration, 2(1), 1-7.

Furman, G. C. (2004). The ethic of community. Journal of Educational Administration, 42, 215-235. doi:10.1108/09578230410525612

Furman, G. C. (2012). Social justice leadership as praxis: Developing capacities through preparation programs. Educational Administration Quarterly, 48, 191-229. doi:10.1177/0013161X11427394

Furman, G. C., \& Gruenewald, D. (2004). Expanding the landscape of social justice: A critical ecological analysis. Educational Administration Quarterly, 40, 49-78. doi:10.1177/0013161X03259142

Furman, G. C., \& Starratt, R. J. (2002). Leadership for democratic community in schools. In J. Murphy (Ed.), The educational leadership challenge: Redefining leadership for the 21st century (Part 1, pp. 105-133). Chicago, IL: University of Chicago Press.

Garza, E. (2008). Autoethnography of a first-time superintendent: Challenges to leadership for social justice. Journal of Latinos and Education, 7, 163-176. doi: $10.1080 / 15348430701828749$

Gerstl-Pepin, C. I., Killeen, K. M., \& Hasazi, S. B. (2006). Utilizing an 'ethic of care' in leadership preparation: Uncovering the complexity of colorblind social justice. Journal of Educational Administration, 44, 250-263.

Glaser, B. G., \& Strauss, A. L. (1967). The discovery of grounded theory: Strategies for qualitative research. London, England: Wiedenfeld and Nicholson. 
Gostin, L., \& Powers, M. (2006). What does social justice require for the public's health? Public health ethics and policy imperatives. Health Affairs, 25, 1053-1060. doi:10 $.1377 /$ hlthaff.25.4.1053

Green, J. M., (1999). Deep democracy: Community, diversity, and transformation. Lanham, MD: Roman \& Littlefield.

Greenfield, T. (2004). Moral leadership in schools. Journal of Educational Administration, 42, 174-196. doi:10.1108/09578230410525595

Grogan, M. (2004). Keeping a critical, postmodern eye on educational leadership in the United States: In appreciation of Bill Foster. Educational Administration Quarterly, 40, 222-239. doi:10.1177/0013161X03261237

Gutmann, A. (1987). Democratic education. Princeton, NJ: Princeton University Press.

Hacker, A. (1995). Two nations: Black and white, separate, unequal, and hostile. New York, NY: Ballantine.

Hatch, J. A. (2002). Doing qualitative research in education settings. Albany: State University of New York Press.

Hersey, P., Blanchard, K. H., \& Natemeyer, W. E. (1979). Situational leadership, perception, and the impact of power. Group \& Organization Management, 4, 418-428. doi:10.1177/105960117900400404

Hill, T. D. (2011). Every closed eye ain't sleep: African American perspectives on the achievement gap. Lanham, MD: Rowman \& Littlefield.

Hytten, K. (2006). Education for social justice: Provocations and challenges. Educational Theory, 56, 221-236. doi:10.1111/j.1741-5446.2006.00013.x

Jackson, B. (2005). The conceptual history of social justice. Political Studies Review, 3, 356-373. doi:10.1111/j.1478-9299.2005.00028.x

Jean-Marie, G., Normore, A. H., \& Brooks, J. S. (2009). Leadership for social justice: Preparing 21st century school leaders for a new social order. Journal of Research on Leadership Education, 4, Article 6. doi:10.1177/194277510900400102

Jencks, C. \& Meredith P. (Eds.). (1998). The Black-White test score gap. Washington, DC: Brookings Institution Press.

Karpinski, C. F., \& Lugg, C. A. (2006). Social justice and educational administration: Mutually exclusive? Journal of Educational Administration, 44, 278-292. doi:10 $.1108 / 09578230610664869$ 
Kennedy, M. (2012). Occupy money: Creating an economy where everybody wins. Gabriola Island, BC, Canada: New Society.

Kozol, J. (1991). The savage inequalities of public education in New York. New York, NY: Crown.

Kozol, J. (2005). Still separate, still unequal. Harper's Magazine, 9, 41-55.

Larson, C. L. (2010). Responsibility and accountability in educational leadership: Keeping democracy and social justice central to reform. Scholar-Practitioner Quarterly, 4, 323-327.

Larson, C. L., \& Murtadha, K. (2002). Leadership for social justice. In J. Murphy (Ed.), The educational leadership challenge. Redefining leadership for the 21st century (Part 1, pp. 134-161). Chicago, IL: University of Chicago Press.

Lau, K. J. (2002). This text which is not one: Dialectics of self and culture in experimental autoethnography. Journal of Folklore Research, 39, 243-259.

Lee, J. (2002). Racial and ethnic achievement gap trends: Reversing the progress toward equity? Educational Researcher, 31(1), 3-12.

Lewin, K. (1939). Field theory and experiment in social psychology: Concepts and methods. American Journal of Sociology, 44, 868-896. doi:10.1086/218177

Lewin, K. (1951). Field theory in social science. New York, NY: Harper.

Lincoln, Y. S., \& Guba, E. G. (1985). Naturalistic inquiry. Newbury, CA: Sage.

Lugg, C. A., \& Shoho, A. R. (2006). Dare public school administrators build a new social order?: Social justice and the possibly perilous politics of educational leadership. Journal of Educational Administration, 44, 196-208. doi:10.1108 /09578230610664805

Lunenburg, F. (2003, August). Leadership for learning: State and national accountability policy can leverage social justice. Paper presented at the Annual Meeting of the National Council of Professors of Educational Administration, Sedona, AZ.

Martenson, C. (2011). The crash course: The unsustainable future of our economy, energy, and environment. New York, NY: John Wiley \& Sons.

Marshall, C. (1995). Imagining leadership. Educational Administration Quarterly, 31, 484-492. doi:10.1177/0013161X95031003009 
Marshall, C. (2004). Social justice challenges to educational administration: Introduction to a special issue. Educational Administration Quarterly, 40, 3-13. doi:10.1177 /0013161X03258139

Marshall, C., \& Gerstl-Pepin, C. I. (2005). Re-framing educational politics for social justice. Boston, MA: Allyn \& Bacon.

Marshall, C., \& Oliva, M. (2010). Leadership for social justice: Making revolutions in education (2nd ed.). Boston, MA: Allyn \& Bacon.

Marshall, C., \& Ward, M. (2004). Strategic policy for social justice training for leadership. Journal of School Leadership, 14, 530-563.

Marzano, R. J., Waters, T., \& McNulty, B. A. (2005). School leadership that works: From research to results. Alexandria, VA: Association for Supervision and Curriculum Development.

McGregor, D. (1990a). Theory X: The integration of individual and organizational goals. In J. Hall (Ed.), Models of management: The structure of competence (2nd ed., pp. 11-18). Woodlands, TX: Woodstead Press.

McGregor, D. (1990b). Theory Y: The integration of individual and organizational goals. In J. Hall (Ed.), Models of management: The structure of competence (2nd ed., pp. 19-27). Woodlands, TX: Woodstead Press.

McIntosh, P. (1988). White privilege: Unpacking the invisible knapsack. Race, class, and gender in the United States: An integrated study, 4, 165-169.

McLaren, P. (1999). A pedagogy of possibility: Reflecting upon Paulo Freire's Politics of education: In memory of Paulo Freire. Educational Researcher, 28(2), 49-56. doi:10.3102/0013189X028002049

Miles, M. B., \& Huberman, A. M. (1994). Qualitative data analysis: An expanded sourcebook. Thousand Oaks, CA: Sage.

Mullen, C. (2010). 21st-century priorities for leadership education and prospective school leaders. Scholar-Practitioner Quarterly, 4, 331-333.

Murphy, J. (2002). Reculturing the profession of educational leadership: New blueprints. Yearbook of the National Society for the Study of Education, 101(1), 65-82.

Murphy, J. (2004). Reculturing the profession of educational leadership: New blueprints. Educational Administration Quarterly, 38, 176-191.

Murphy, J. (2009). Closing achievement gaps: Lessons from the last 15 years. Phi Delta Kappan, 91, 8-12. 
Murphy, J. (Ed.). (2009). The educator's handbook for understanding and closing achievement gaps. Thousand Oaks, CA: Sage.

Musca, T. (Producer), \& Menéndez, R. (Director). (1988). Stand and deliver [Motion picture]. USA: Warner Bros.

National Center for Educational Statistics. (2014). Home Page. http://nces.ed.gov /nationsreportcard/studies/gaps/

Neumann, M. (1996). Collecting ourselves at the end of the century. In C. Ellis \& A. P. Bochner (Eds.), Composing ethnography: Alternative forms of qualitative writing (pp. 172-198). Walnut Creek, CA: AltaMira.

Neville-Jan, A. (2004). Selling your soul to the devil: An autoethnography of pain, pleasure and the quest for a child. Disability \& Society, 19, 113-127. doi:10.1080 /0968759042000181758

No Child Left Behind Act, 20 U.S.C. §§ 6301 et seq (2001).

Noguera, P., \& Boykin, A. W. (2011). Creating the opportunity to learn: Moving from research to practice to close the achievement gap. Alexandria, VA: ASCD.

Novak, M. (2000). Defining social justice. First Things, 108, 11-13.

Ohio State Board of Education. (2013). Standards for Ohio educators. Retrieved November 30, 2013, from http://esb.ode.state.oh.us/PDF/Standards _OhioEducators.pdf

Oplatka, I. (2009). Shall our leadership preparation programs be focused on proactive leadership for social justice? A rejoinder to Jean-Marie, Normore, and Brooks. Journal of Research on Leadership Education, 4, 1-5. doi:10.1177 /194277510900400103

Oram-Sterling, J. (2009). Biography of Joan Wint: A principal whose leadership for social justice transformed a rural Jamaican high school. Journal of Women in Educational Leadership, 7, 195-217.

Orfield, G. (2009). Reviving the goal of an integrated society: 21st century challenge. Los Angeles, CA: Civil Rights Project/Proyecto Derechos Civiles.

Ottmann, J. (2009). Leadership for social justice: A Canadian perspective. Journal of Research on Leadership Education, 4, Article 4. doi:10.1177 /194277510900400105

Patton, M. (2002). Qualitative research and evaluation methods (3rd ed.). Thousand Oaks, CA: Sage. 
Peters, T. J., \& Waterman, R. H. (1982). In search of excellence: Lessons from America's best-run companies. New York, NY: Harper \& Row.

Picott, J. R. (1947). Editorial: Our goal is \$2,400 minimum salary per teacher. Virginia Education Bulletinn, May, p. 2.

Picott, J. R. (1960). Editorial: These are our children. Virginia Teachers Association Bulletin, April, p. 125.

Plato (1993). The republic (R. Waterfield, Trans.). Oxford: Oxford University Press. (Original work published 380BC)

Plessy v. Ferguson, 163 U.S. 537 (1896).

Ponterotto, J. G. (2005). Qualitative research in counseling psychology: A primer on research paradigms and philosophy of science. Journal of Counseling Psychology, 52, 126-136. doi:10.1037/0022-0167.52.2.126

Ramirez, A., \& Carpenter, D. (2005). Challenging assumptions about the achievement gap. Phi Delta Kappan, 86, 599-603.

Rapp, D. (2002). Social justice and the importance of rebellious, oppositional imaginations. Journal of School Leadership, 12, 226-245.

Rawls, J. (1971). A theory of justice. Cambridge, MA: Harvard University Press.

Rawls, J., \& Kelly, E. (2001). Justice as fairness: A restatement. Cambridge, MA: Harvard University Press.

Reed-Danahay, D. (1997). Auto/ethnography: Rewriting the self and the social. Oxford, England: Berg.

Richardson, L. (2000a). Evaluating ethnography. Qualitative Inquiry, 6, 253-255. doi: $10.1177 / 107780040000600207$

Richardson, L. (2000b). Writing: A method of inquiry. In N. K. Denzin, \& Y. S. Lincoln (Eds.), Handbook of qualitative research (2nd ed., pp. 923-948). Thousand Oaks, CA: Sage.

Rodriguez, M. A., Chambers, T. V., Gonzalez, M. L., \& Scheurich, J. J. (2010). A crosscase analysis of three social justice-oriented education programs. Journal of Research on Leadership Education, 5, 138-153. doi:10.1177 /194277511000500305

Rothstein, R. (2008). Whose problem is poverty? Educational Leadership, 65(7), 8-13. 
Rubinowitz, L. S., \& Perry, I. (2002). Crimes without punishment: White neighbors' resistance to Black entry. Journal of Criminal Law and Criminology, 92, 335428.

Ryan, J. (1988). Conservative science in educational administration. Journal of Educational Administration and Foundations, 3(2), 5-22.

Ryan, J. (1991). Observing and normalizing: Foucault, discipline, and inequality in schooling. Journal of Educational Thought, 25(2), 104-119.

Ryan, W. (1971). Blaming the victim. New York: Pantheon.

Sarason, S. (1996). Revisiting the culture of the school and the problem of change. New York, NY: Teachers College Press.

Scanlan, M., \& López, F. (2012). ¡Vamos! How school leaders promote equity and excellence for bilingual students. Educational Administration Quarterly 20, 1-43.

Schultz, J. R. (2010). The scholar-practitioner: A philosophy of leadership. ScholarPractitioner Quarterly, 4, 52-64.

Schwandt, T. A. (1994). Constructivist, interpretivist approaches to human inquiry. In N. K. Denzin \& Y. S. Lincoln (Eds.), Handbook of qualitative research (pp. 118137). Thousand Oaks, CA: Sage.

Schwandt, T. A. (2000). Three epistemological stances for qualitative inquiry: Interpretivism, hermeneutics, and social constructionism. In N. K. Denzin \& Y. S. Lincoln (Eds.), Handbook of qualitative research (2nd ed., pp. 189-213). Thousand Oaks, CA: Sage.

Schwandt, T. A. (2001). Dictionary of qualitative inquiry (2nd ed.). Thousand Oaks, CA: Sage.

Selznick, P. (1957). Leadership in administration: A sociological interpretation. New York, NY: Harper and Row.

Sergiovanni, T. A. (1992). Moral leadership: Getting to the heart of school improvement. San Francisco, CA: Jossey-Bass.

Sergiovanni, T. J. (2000). The lifeworld of leadership: Creating culture, community, and personal meaning in our schools. San Francisco, CA: Jossey-Bass.

Shaull, R. (1970). Forward. In P. Freire, Pedagogy of the Oppressed, New York, NY: Herder and Herder. 
Shields, C. M. (2004). Dialogic leadership for social justice: Overcoming pathologies of silence. Educational Administration Quarterly, 40, 109-132. doi:10.1177 /0013161X03258963

Shields. C. M. (2006). Creating spaces for values-based conversations: The role of school leaders in the 21 st century. International Journal of Educational Administration, $34,62-81$.

Shor, I. (1992). Empowering education: Critical teaching for social change. Chicago, IL: University of Chicago Press.

Sizer, T. (1996). Horace's hope: What works for the American high school. Boston, MA: Houghton Mifflin.

Skinner, B. F. (1953). Science and human behavior. New York, NY: Macmillan.

Skrla, L., \& Scheurich, J. (2004). Equity audits: A practical leadership tool for developing equitable and excellent schools. Educational Administration Quarterly, 40, 133-161. doi:10.1177/0013161X03259148

Skrla, L., McKenzie, K., \& Scheurich, J. (2009). Using equity audits to create equitable and excellent schools. Thousand Oaks, CA: Corwin Press.

Starratt, R. J. (1994). Building an ethical school: A practical response to the moral crisis in schools, Washington, DC: Falmer Press.

Starratt, R. J. (1999). Moral dimensions of leadership. In P. Begley \& P. Leonard (Eds.), The Values of educational administration: A book of readings (pp. 22-35). New York, NY: Garland.

Starratt, R. J. (2003). Centering educational administration. Mahwah, NJ: Lawrence Erlbaum.

Stevenson, H. P. (2007). A case study in leading schools for social justice: When morals and markets collide. Journal of Educational Administration, 45, 769-781. doi:10.1108/09578230710829937

Stigler, J. W., \& Hiebert, J. (1999). The teaching gap: Best ideas from the world's teachers for improving education in the classroom. New York, NY: Free Press.

Taylor, F. W. (1947). Principles of scientific management. New York, NY: Pitman. (Original work published 1911)

Taylor, Q. (1994). The forging of a Black community: Seattle's central district from 1870 through the civil rights era. Seattle: University of Washington Press. 
Theoharis, G. (2007). Social justice educational leaders and resistance: Toward a theory of social justice leadership. Educational Administration Quarterly, 43, 221-258. doi:10.1177/0013161X06293717

Tomlinson, C. A. (2001). How to differentiate instruction in mixed-ability classrooms (2nd ed.). Alexandria, VA: Association for Supervision and Curriculum Development.

Turhan, M. (2010). Social justice leadership: Implications for roles and responsibilities of school administrators. Procedia-Social and Behavioral Sciences, 9, 1357-1361. doi:10.1016/j.sbspro.2010.12.334

Twain, N. (Producer), \& Avildsen, J. G. (Director). (1989). Lean on me [Motion picture]. USA: Warner Bros.

United Nations. (2007). Universal declaration of human rights. New York, NY: Author.

Valencia, R. (1997). The evolution of deficit thinking. London, UK: Falmer.

Valencia, R. (2010). Dismantling contemporary deficit thinking: Educational thought and practice. New York, NY: Routledge.

Valencia, R., Valenzuela, A., Sloan, K., \& Foley, D. E. (2001). Let's treat the cause, not the symptoms: Equity and accountability in Texas revisited. Phi Delta Kappan, $83,321-326$.

Valenzuela, A. (1999). Subtractive schooling: U.S.-Mexican youth and the politics of caring. Albany: State University of New York Press.

Vanneman, A., Hamilton, L., Anderson, J. B., \& Rahman, T. (2009). Achievement gaps: How Black and White students in public schools perform in mathematics and reading on the National Assessment of Educational Progress. Statistical Analysis Report (NCES 2009-455). Washington, DC: U.S. Department of Education, Institute of Education Sciences, National Center for Education Statistics.

Vidal-Ortiz, S. (2004). On being a White person of color: Using autoethnography to understand Puerto Ricans' racialization. Qualitative Sociology, 27, 179-203.

Wall, S. (2008). Easier said than done: Writing an autoethnography. International Journal of Qualitative Methods, 7(1), 38-53.

Weber, M. (1947). The theory of social and economic organization. New York, NY: Free Press.

Weiler, K. (1991). Freire and a feminist pedagogy of difference. Harvard Educational Review, 61, 449-475. 
Williamson, J. A., Rhodes, L., \& Dunson, M. (2007). A selected history of social justice in education. Review of Research in Education, 31, 195-224. doi:10.3102 /0091732X07300046195

Williamson, K. (2002). Research methods for students, academics and professionals: Information management and systems (2nd ed.). Wagga Wagga, Australia: Centre for Information Studies, Charles Sturt University.

Wolcott, H. F. (2001). Writing up qualitative research (2nd ed.). Thousand Oaks, CA: Sage.

Zembylas, M. (2010). The emotional aspects of leadership for social justice: Implications for leadership preparation programs. Journal of Educational Administration, 48, 611-625. doi:10.1108/09578231011067767 